Evandro Paulo Folletto

\title{
Detecção de dano utilizando otimização topológica
}

Florianópolis/SC-Brasil

2016 



\title{
Evandro Paulo Folletto
}

\section{Detecção de dano utilizando otimização topológica}

\author{
Dissertação apresentada como requi- \\ sito para a obtenção do título de Mes- \\ tre em Engenharia Civil pela Uni- \\ versidade Federal de Santa Catarina. \\ Área de concentração: estruturas.
}

Universidade Federal de Santa Catarina - UFSC

Departamento de Engenharia Civil

Programa de Pós-Graduação em Engenharia Civil

Orientador: Otávio Augusto Alves da Silveira

Florianópolis/SC-Brasil

2016 
Ficha de identificação da obra elaborada pelo autor, através do Programa de Geração Automática da Biblioteca Universitária da UFSC.

Folletto, Evandro Paulo

Detecção de dano utilizando otimização topológica /

Evandro Paulo Folletto; orientador, Otávio Augusto Alves

da Silveira - Florianópolis, SC, 2016.

$108 \mathrm{p}$.

Dissertação (mestrado) - Universidade Federal de Santa

Catarina, . Programa de Pós-Graduação em Engenharia Civil.

Inclui referências

1. Engenharia Civil. 2. Detecção de dano. 3. Otimização topológica. 4. Função de resposta em frequência. I. Silveira, otávio Augusto Alves da. II. Universidade Federal de Santa Catarina. Programa de Pós-Graduação em Engenharia Civil. III. Título. 


\section{Evandro Paulo Folletto}

\section{Detecção de dano utilizando otimização topológica}

Esta dissertação foi julgada adequada para a obtenção do Título de mestre em Engenharia Civil, e aprovada em sua forma final pelo Programa de Pós-Graduação em Engenharia Civil.

Florianópolis, 06 de dezembro de 2016.

\section{Prof. Dr. Glicério Trichês}

Coordenador do Curso

\section{Banca Examinadora:}

Prof. Dr. Otávio Augusto Alves da Silveira

Orientador

Universidade Federal de Santa Catarina (UFSC)

Prof. Dr. Jucélio Tomás Pereira

Universidade Federal do Paraná (UFPR)

Prof. Dr. Leandro Fleck Fadel Miguel

Universidade Federal de Santa Catarina (UFSC) 



\section{Agradecimentos}

Agradeço ao professor Otávio Silveira, meu orientador, pela sua dispobilidade em me orientar neste trabalho. Agradeço aos meus pais, Iolar Paulo Folletto e Cleofani Zatt Folletto, assim como ao meu irmão, Everton Paulo Folletto, pelo apoio incondicional em todas as etapas de minha vida. 



\section{Resumo}

Este trabalho consiste no desenvolvimento de uma metodologia que tem por objetivo a detecção de dano em estruturas utilizando otimização topológica (OT). As informações utilizadas para tal são características dinâmicas do sistema, nomeadamente frequências naturais ressonantes e anti-ressonantes. A formulação utilizada consiste na minimização da diferença entre as frequências ressonantes e anti-ressonantes de uma estrutura danificada e de uma estrutura sem dano, modelada via método dos elementos finitos (FEM). O elemento finito utilizado é o elemento quadrilátero com quatro nós. Foi utilizado o método da Programação Linear Sequencial (SLP) para a otimização das variáveis de projeto, sendo estas as densidades dos elementos. Foram testados alguns exemplos e os resultados mostram que a utilização das informações das frequências ressonantes e anti-ressonantes são importantes para a detecção do dano em estruturas, sendo possível, nos casos estudados, identificar a posição e a geometria do dano em questão. Ainda, foi confirmada a importância da utilização do filtro de sensibilidades, assim como a utilização do método da Redução Progressiva (PR) para a detecção de dano.

Palavras-chave: Detecção de dano. Otimização topológica. Função de resposta em frequência. 



\section{Abstract}

This work consists in developing a methodology that aims at damage detecting to structures by using topology optimization. The information used for such refers to the dynamic characteristics of the system, namely natural resonant frequency and anti-resonant ones. The formulation which is used consists in minimizing the difference between the resonant and the antiresonant frequencies of the damaged structure and of a structure without damaging, shaped via the finite element method (FEM). The finite element used is the four-node quadrilateral element. The method of Sequential Linear Programming was used for the optimization of design variables, which are the densities of the elements. Some examples were tested and the results show the importance of using resonant and anti-resonant frequencies for the detection of damage to structures. In studied cases, it was possible to identify the position and the geometry of the damage in question. In addition, the importance of using the sensitivity filter, as well as the method of Progressive Reduction for the detection of damage was confirmed.

Keywords: Damage detection. Topology optimization. Frequency Response Function. 



\section{Lista de ilustrações}

Figura 1 - Exemplo de falha estrutural: cobertura (treliça espacial) da Hartford Civic Center Arena-EUA. . . . . . . . . . 25

Figura 2 - Representação da análise modal teórica e análise modal experimental. . . . . . . . . . . . . 30

Figura 3 - Relações entre os modelos espacial, modal e de resposta (para o caso não amortecido). . . . . . . . . . . . 31

Figura 4 - Problema inverso de detecção de dano. . . . . . . . . 32

Figura 5 - Classificação dos métodos de análise modal. . . . . . . 35

Figura 6 - Categorias de otimização: a) otimização paramétrica; b) otimização de forma; c) otimização topológica. . . . . 37

Figura 7 - Domínio fixo estendido. . . . . . . . . . . . 39

Figura 8 - Regiões com e sem presença de material. . . . . . . . . 40

Figura 9 - Efeito de diferentes valores de penalizações. . . . . . . 41

Figura 10 - Representação da escala de cinza. . . . . . . . . . . . . 42

Figura 11 - Representação da instabilidade de tabuleiro. . . . . . . 43

Figura 12 - Refinamento da malha com: a) 2700 elementos; b) 4800 elementos; c) 17200 elementos. . . . . . . . . . . . . . 44

Figura 13 - Representação do filtro de sensibilidades. . . . . . . . . 45

Figura 14 - Fluxograma da estratégia PR. . . . . . . . . . . 46

Figura 15 - Esquema de funcionamento da estratégia PR. . . . . . 47

Figura 16 - Exemplos de leituras e excitações nos graus de liber-

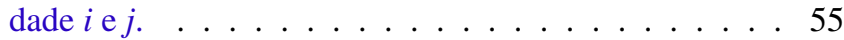

Figura 17 - Fluxograma para calcular a FRF de receptância pontual. 58

Figura 18 - Receptância pontual escala linear. . . . . . . . . . . . . 60

Figura 19 - Receptância pontual em escala logarítmica. . . . . . 60

Figura 20 - Viga biapoiada. . . . . . . . . . . . . 61

Figura 21 - Malha de 3 elementos finitos. . . . . . . . . . . 61

Figura 22 - Indicação do grau de liberdade $12 \ldots$. . . . . . . . 62

Figura 23 - FRF da receptância $\alpha_{12,12} \ldots \ldots \ldots$. . . . . . . 62

Figura 24 - Indicação do grau de liberdade 15. . . . . . . . . . . . 63

Figura 25 - FRF da receptância $\alpha_{15,15} \ldots \ldots$. . . . . . . . . 63

Figura 26 - Fluxograma geral do algoritmo para detecção de dano. . 67

Figura 27 - Fluxograma para o cálculo da sensibilidade da função objetivo. . . . . . . . . . . . . 71

Figura 28 - Fluxograma de atualização dos limites móveis. . . . . . 75

Figura 29 - Exemplos de limites móveis em uma curva. . . . . . . 75

Figura 30 - Fluxograma da SLP. . . . . . . . . . . . . . . 76 
Figura 31 - Exemplo 1: a) estrutura sem dano; b) discretização malha; c) estrutura danificada. . . . . . . . . . . . . . 79

Figura 32 - Modos de vibração: estrutura intacta x estrutura danificada. . . . . . . . . . . . . . 81

Figura 33 - Resultado da otimização. . . . . . . . . . . . . . . 82

Figura 34 - Exemplo 2: a) estrutura sem dano; b) estrutura com dano. 83

Figura 35 - Malha de elementos finitos do exemplo 2. . . . . . . . 84

Figura 36 - FRF - receptância do exemplo 2. . . . . . . . . . . . . 84

Figura 37 - Modos de vibração: estrutura intacta x estrutura danificada. . . . . . . . . . . . . . 8 85

Figura 38 - Histórico da função objetivo do exemplo 2. . . . . . . . 87

Figura 39 - Resultado da otimização. Número de iterações: a) 300; b) 600 ; c) 900 e d) $1200 . \ldots \ldots$. . . . . . . . 87

Figura 40 - Exemplo 2 com filtro de sensibilidades desabilitado. . . 88

Figura 41 - Exemplo 2 com a estratégia PR desabilitada. . . . . . . 88

Figura 42 - Resultado da otimização. Número de frequências ressonantes utilizadas: a) 4; b) 5 ; c) 6 ; d) 7 ; e) 8 ; f) 9 e g)

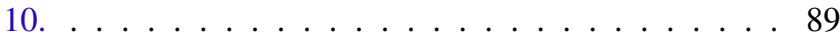

Figura 43 - Exemplo 2 com a adição de ruído de: a) 1\% ; b) 2\%. . . 90 Figura 44 - Exemplo 3: a) estrutura sem dano; b) estrutura com dano. 91 Figura 45 - Malha de elementos finitos do exemplo 3. . . . . . . . 91

Figura 46 - FRF - receptância do exemplo 3. . . . . . . . . . . 92

Figura 47 - Resultado da otimização. Número de iterações: a) 200; b) 400 ; c) 600 ; d) 800 e e) $1000 . \ldots 94$

Figura 48 - Exemplo 3 com a adição de ruído de: a) 1\% ; b) 2\%. . . 95

Figura 49 - Exemplo 4: a) estrutura sem dano; b) estrutura com dano. 96

Figura 50 - Malha de elementos finitos do exemplo 4. . . . . . . 96

Figura 51 - Resultado da otimização. Número de iterações: a) 200; b) 400 ; c) 600 ; d) 800 e e) $1000 . \ldots$. . . . . . . . . 99

Figura 52 - Resultado da otimização. Número de frequências ressonantes/antiressonantes: a) $10 / 9$; b) $9 / 8$; c) $8 / 7$; d) $7 / 6$; e) $6 / 5$ e f) $5 / 4 \ldots \ldots \ldots \ldots \ldots$

Figura 53 - Exemplo 4 com a adição de ruído de: a) 1\% ; b) 2\% . . 101 


\section{Lista de tabelas}

Tabela 1 - Comparação entre frequências das receptâncias $\alpha_{12,12}$

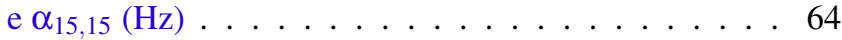

Tabela 2 - Frequências ressonantes da estrutura com e sem dano (Hz). . . . . . . . . . . . . 80

Tabela 3 - Valores dos parâmetros utilizados na otimização. . . . . 80

Tabela 4 - Resultado das frequências naturais com dano teórico e otimizadas. . . . . . . . . . . . . . 81

Tabela 5 - Frequências naturais da estrutura para diferentes níveis de ruído $(\mathrm{Hz}) . \ldots \ldots$. . . . . . . . . . . 82

Tabela 6 - Resultados da otimização das variáveis de projeto (densidades) para diferentes níveis de ruído. . . . . . . . . 82

Tabela 7 - Frequências ressonantes e anti-ressonantes da estrutura com e sem dano $(\mathrm{Hz}) \ldots$. . . . . . . . . . . . 85

Tabela 8 - Valores dos parâmetros utilizados na otimização. . . . . 86

Tabela 9 - Resultado da otimização. . . . . . . . . . . . 86

Tabela 10 - Frequências da estrutura com dano e perturbadas com ruído $(\mathrm{Hz}) \ldots \ldots$. . . . . . . . . . . . . . . 90

Tabela 11 - Frequências ressonantes e anti-ressonantes da estrutura com e sem dano $(\mathrm{Hz}) . \ldots$. . . . . . . . . . . . . 92

Tabela 12 - Valores dos parâmetros utilizados na otimização. . . . . 93

Tabela 13 - Resultado da otimização. . . . . . . . . . . . . . . . 93

Tabela 14 - Frequências da estrutura com dano e perturbadas com ruído $(\mathrm{Hz}) \ldots \ldots$. . . . . . . . . . . . . . . . . . 994

Tabela 15 - Frequências ressonantes e anti-ressonantes da estrutura com e sem dano $(\mathrm{Hz})$. . . . . . . . . . . . . . . . . . 97

Tabela 16 - Valores dos parâmetros utilizados na otimização. . . . . 97

Tabela 17 - Resultado da otimização. . . . . . . . . . . . . . . 98

Tabela 18 - Frequências da estrutura com dano e perturbadas com ruído $(\mathrm{Hz}) \ldots \ldots$. . . . . . . . . . . . . . . . 98 



\section{Lista de abreviaturas e siglas}

FEM Método dos Elementos Finitos ou Finite Element Method

FRF Função de Resposta em Frequência ou Frequency Response Function

LP Programação Linear ou Linear Programming

SLP Programação Linear Sequêncial ou Sequential Linear Programming

PR Redução Progressiva ou Progressive Reduction

SHM Sistema de Monitoramento Estrutural ou System Health Monitoring

SIMP Simple Isotropic Material with Penalization

OT Otimização Topológica ou Topology Optimization

FFT Transformada Rápida de Fourier ou Fast Fourier Transform

MMA Método das Assíntotas Móveis ou Method of Moving Asymptotes

S1GL Sistema com um Grau de Liberdade

SVGL Sistema com Vários Graus de Liberdade

SISO Métodos de Única Entrada/Única Saída ou Single Input/Single Output

SIMO Métodos de Única Entrada/Múltiplas Saídas ou Multiple Input/Multiple Output

MISO Métodos de Múltiplas Entradas/Única Saída ou Multiple Input/Single Output 



\section{Lista de símbolos}

$\mathbf{E}^{0}$

E

$1_{\Omega^{\text {mat }}}$

$\Omega$

$\Omega$

V

$\rho(x)$

$\rho_{\text {min }}$

$p$

$q$

$\rho_{e}$

$\rho_{\text {mat }}$

$\mathbf{K}_{e}$

$\mathbf{K}$

$\mathbf{M}_{e}$

M

$\Delta_{p}$

$\widehat{H}$

dist $(e, i)$ distância entre o centro do elemento $e$ e o centro do elemento $i$

$\frac{\partial \widehat{c}}{\partial \rho_{e}}$

$\frac{\partial c}{\partial \rho_{e}}$

propriedade do material base

propriedades efetivas do material base

função indicadora

região do domínio de projeto que contém material

domínio de projeto

volume

pseudo-densidade

valor mínimo para as pseudo-densidades

coeficiente de penalização da matriz de rigidez

coeficiente de penalização da matriz de massa

densidade do elemento $e$ (variável de projeto)

densidade do material

matriz de rigidez do elemento $e$

matriz de rigidez global da estrutura

matriz de massa do elemento $e$

matriz de massa global da estrutura

incremento do coeficiente de penalização

fator de peso para o filtro de sensibilidades

sensibilidade filtrada

sensibilidade da grandeza $c$ em relação a pseudo-densidade $\rho$

variável utilizada no método da redução progressiva 


\begin{tabular}{|c|c|}
\hline $\mathbf{x}$ & vetor deslocamento \\
\hline$\ddot{\mathbf{x}}$ & vetor aceleração \\
\hline$\lambda$ & $\begin{array}{l}\text { matriz diagonal contendo o quadrado das frequências } \\
\text { naturais }\end{array}$ \\
\hline$\Psi$ & matriz contendo os modos de vibração \\
\hline$\omega_{n}$ & frequência natural ressonante \\
\hline$m_{i}$ & matriz de massa modal \\
\hline$k_{i}$ & matriz de rigidez modal \\
\hline$\phi_{n}$ & modo de vibrar $n$ massa normalizado \\
\hline$\Phi$ & matriz modo de vibrar massa normalizado \\
\hline I & matriz identidade \\
\hline $\mathbf{C}$ & matriz de amortecimento viscoso \\
\hline $\mathbf{D}$ & matriz de amortecimento histerético \\
\hline $\mathbf{H}$ & modelo de resposta \\
\hline $\mathbf{X}$ & amplitude de resposta \\
\hline $\mathbf{F}$ & amplitude de excitação \\
\hline$\alpha(\omega)$ & função de resposta em frequência - receptância \\
\hline$Y(\omega)$ & função de resposta em frequência - mobilidade \\
\hline$A(\omega)$ & função de resposta em frequência - acelerância \\
\hline $\mathbf{Z}(\omega)$ & matriz de rigidez dinâmica \\
\hline $\mathbf{A}$ & constante modal \\
\hline f & vetor força \\
\hline$J(\rho)$ & função objetivo \\
\hline$\lambda_{r, a l v o, i}$ & $\begin{array}{l}\text { quadrado da i-ésima frequência ressonante da estrutura } \\
\text { danificada }\end{array}$ \\
\hline$\lambda_{r, i}$ & quadrado da i-ésima frequência ressonante da estrutura \\
\hline$m 1$ & $\begin{array}{l}\text { número de frequências ressonantes da estrutura danifi- } \\
\text { cada utililizadas para a otimização }\end{array}$ \\
\hline
\end{tabular}




$$
\begin{aligned}
& w_{r, i} \quad \text { fator de ponderação das frequências ressonantes } \\
& \lambda_{a, a l v o, i} \quad \text { quadrado da i-ésima frequência anti-ressonante da es- } \\
& \text { trutura danificada } \\
& \mu_{a l v o, i} \quad \text { i-ésima frequência anti-ressonante da estrutura danifi- } \\
& \text { cada } \\
& \mu_{i}^{2} \quad \text { i-ésima frequência anti-ressonante da estrutra } \\
& \lambda_{r, i} \quad \text { quadrado da i-ésima frequência anti-ressonante da es- } \\
& \text { trutura } \\
& m 2 \quad \text { número de frequências anti-ressonantes da estrutura } \\
& \text { danificada utilizadas na otimização } \\
& w_{a, i} \quad \text { fator de ponderação das frequências anti-ressonantes } \\
& \frac{\partial J(\rho)}{\partial \rho_{j}} \quad \text { sensibilidade da função objetivo em relação a variável } \\
& \text { de projeto } \rho \\
& \frac{\partial \mathbf{K}_{e}}{\partial \rho_{j}} \quad \text { sensibilidade da matriz de rigidez em relação a variável } \\
& \text { de projeto } \rho \\
& \frac{\partial \mathbf{M}_{e}}{\partial \rho_{j}} \quad \text { sensibilidade da matriz de massa em relação a variável } \\
& \text { de projeto } \rho \\
& f(x) \quad \text { função objetivo qualquer a ser minimizada } \\
& c, a, b \quad \text { constantes conhecidas } \\
& x \quad \text { variáveis de projeto } \\
& \nabla f^{T} \quad \text { vetor gradiente na expansão em séries de Taylor } \\
& g(x) \quad \text { restrição de projeto de desigualdade } \\
& h(x) \quad \text { restrição de projeto de igualdade } \\
& \frac{\partial g}{\partial x_{i}} \quad \text { sensibilidade da restrição de desigualdade em relação } \\
& \text { a variável de projeto } \\
& \frac{\partial h}{\partial x_{i}} \quad \text { sensibilidade da restrição de igualdade em relação a } \\
& \text { variável de projeto } \\
& a_{i}^{l} \quad \text { limite inferior do limite móvel } \\
& a_{i}^{u} \quad \text { limite superior do limite móvel }
\end{aligned}
$$


lim variável utilizada para definir os limites móveis

$m \_a \quad$ variável utilizada para aumentar a variável lim

m_s $\quad$ variável utilizada para diminuir a variável lim

$\gamma_{r} \quad$ níveis de perturbação do ruído para as frequências ressonantes

$\gamma_{a} \quad$ níveis de perturbação do ruído para as frequências anti-ressonantes

$\mathrm{R}_{g} \quad$ número aleatório que segue a distribuição de Gauss com média zero e desvio padrão igual a 1

$\omega_{n r} \quad$ frequência ressonante poluída com ruído

$\mu_{n r} \quad$ frequência anti-ressonante poluída com ruído 


\section{Sumário}

INTRODUÇÃO . . . . . . . . . . . . . . . 23

1.1

Motivação . . . . . . . . . . . . . . . . . . . 23

Trabalho relacionados ao tema

Métodos de detecção de dano a partir de respostas dinâmicas . . . . . . . . . . . . . . . . 31

2.3.1 Técnicas baseadas em modelos . . . . . . . . . . . 32

2.3.2 Técnicas baseadas em sinais . . . . . . . . . . . . 33

2.3.3 Identificação modal . . . . . . . . . . . . 33

2.3.3.1 Métodos no domínio da frequência . . . . . . . . . . . . 34

2.3.3.2 Métodos no domínio do tempo . . . . . . . . . . 36

OTIMIZAÇÃO TOPOLÓGICA . . . . . . . . . . . . 37

3.2 Conceitos teóricos da Otimização Topológica . . . . 38

3.2.1 Domínio fixo extendido . . . . . . . . . . . 38

3.2.2 Modelo material ............... 38

3.3 Aspectos numéricos na otimização topológica . . . 42

3.3.1 Escala de cinza . . . . . . . . . . . . . 42

3.3.2 Instabilidade de tabuleiro ............ 43

3.3.3 Dependência de malha .. . . . . . . . . . . 43

3.3.4 Filtro de sensibilidades ... . . . . . . . . . . 44

3.3.5 Estratégia de redução de variáveis de projeto . . . . . 45

4 CARACTERÍSTICAS DINÂMICAS DE ESTRUTURAS . 49

4.1 Análise modal de um sistema com múltiplos graus de liberdade . . . . . . . . . . . . . . . . . . . . . . 49

$4.2 \quad$ Função de resposta em frequência . . . . . . . . . . 51

4.3 Matriz de rigidez dinâmica e matriz de receptância . 53

4.4 Receptância pontual . . . . . . . . . . . . 57 
4.4.1 Propriedades global e local das frequências ressonantes e anti-ressonantes . . . . . . . . . . . . . 6 61

4.5 Aquisição dos dados da estrutura danificada . . . . 64

5 DETECÇÃO DE DANO COMO UM PROBLEMA DE OTIMIZAÇÃO . . . . . . . . . . . . . 65

$5.1 \quad$ Mapeamento da vizinhança . . . . . . . . . 66

$5.2 \quad$ Formulação do problema . . . . . . . . . . 68

$5.3 \quad$ Cálculo de sensibilidades . . . . . . . . . 69

$5.4 \quad$ Programação linear . . . . . . . . . . . . . 70

$5.5 \quad$ Programação linear sequêncial . . . . . . . . . 72

5.5.1 Atualização dos limites móveis . . . . . . . . . . 73

$5.6 \quad$ Adição de ruído nos parâmetros . . . . . . . . 74

$6 \quad$ RESULTADOS . . . . . . . . . . 79

$6.1 \quad$ Exemplo $1 \ldots \ldots \ldots \ldots$

$6.2 \quad$ Exemplo $2 \ldots \ldots \ldots \ldots$

$6.3 \quad$ Exemplo $3 \ldots \ldots \ldots$.................... 90

$6.4 \quad$ Exemplo $4 \ldots \ldots \ldots$. . . . . . . . . 95

7 CONSIDERAÇÕES FINAIS $\ldots \ldots \ldots \ldots$

7.1 Aspectos conclusivos . . . . . . . . . 103

7.1.1 Metodologias utilizadas . . . . . . . . . . 103

7.1.2 Exemplos testados . . . . . . . . . . . . . 104

7.2 Sujestões para trabalhos futuros . . . . . . . 105

REFERÊNCIAS . . . . . . . . . . . . . . 107 


\section{Introdução}

\subsection{Motivação}

A presença de dano em uma estrutura pode contribuir para a geração de alterações no sistema estrutural, que afetam seu desempenho atual ou futuro, podendo, a depender da severidade do dano em questão, comprometer o funcionamento do sistema, e, em casos mais extremos provocar falhas e consequentemente gerar custos, que podem ser, em casos mais graves, vidas. Desta forma, avaliar a integridade estrutural utilizando técnicas baseadas na resposta dinâmica da estrutura tornou-se, nos últimos tempos, um procedimento muito atraente para as indústrias de construção civil e mecânica, pois essas técnicas possibilitam a detecção de dano de forma rápida e econômica, podendo ser propostas e implementadas medidas preventivas para a prevenção de acidentes.

Algumas destas técnicas necessitam de informações preliminares da estrutura em uso para que seja possível identificar alguma modificação no sistema. Essas informações podem ser obtidas com auxílio de algumas metodologias de sistemas de monitoramento da integridade estrutural (SHM), que são observações permantentes e automáticas do comportamento dinâmico das estruturas. Os sistemas de monitoramento estrutural começaram a ter um desenvolvimento considerável na área da construção civil no início dos anos 90. Nos dias atuais, a tecnologia destes sistemas está bem avançada, mas sua utilização ainda não é uma prática comum devido ao custo elevado para tal. Desta forma, até então, nota-se a utilização dos SHM apenas em situações especiais, como por exemplo, grandes pontes, usinas hidrelétricas, etc. Porém, como todas as tecnologias, existe a tendência da viabilização destes sistemas com o passar do tempo.

Para que as informações provenientes dos SHM tenham sentido é necessário que sejam acompanhadas de devidas interpretações, muitas vezes podendo ser utilizadas em conjunto com metologias de detecção de dano, por isso, estudos relacionados a esta área tornam-se importantes. Apesar dos avanços atuais no contexto da avaliação da integridade estrutural, o método de inspeção visual foi a técnica de detecção de dano mais utilizada por um longo período de tempo (este método se encaixa em uma categoria chamada de ensaios não-destrutivos). Mas esse método tradicional pode ser aplicado apenas para estruturas simples, pois necessita que a vizinhança do dano seja conhecida a priori. Assim, em sistemas complexos as inspeções visuais podem não ser possíveis devido a acessibilidade restrita [1]. Desta 
forma, metodologias para detecção de dano em sistemas que não precisem de acesso a estrutura e nem conhecimento prévio da possível localização do dano geram grande interesse nos mais diversos campos da engenharia (mecânica, civil, aeronáutica). Em decorrência disso, muitas pesquisas foram feitas para modelar o sistema de detecção de dano em estruturas, visando utilizar dados de medições para encontrar mudanças estruturais.

Pelo fato de que diferentes estudos sobre detecção de dano produzissem diferentes resultados, Rytter[2] classificou os métodos em quatro categorias, em função da informação que a mesma fornece sobre o dano:

- Nível 1 - Detecção: o método dá uma indicação se o dano pode estar presente na estrutura;

- Nível 2 - Localização: o método fornece informações sobre a provável localização do dano;

- Nível 3 - Avaliação: o método fornece a informação sobre o tamanho do dano;

- Nível 4 - Consequência: o método fornece informações sobre a segurança da estrutura, indicando a previsão de sua vida útil.

A Figura 1 demonstra o resultado da falha da treliça espacial da cobertura da Hartford Civic Center Arena - EUA.

\subsection{Trabalho relacionados ao tema}

De uma forma geral, existem inúmeros trabalhos relacionados a detecção de dano, muitos destes no contexto do modelamento da estrutura através de elementos de barras, como estruturas tipo treliçadas ou vigas. A ideia da maioria destes trabalhos baseia-se no fato de que um dano produz mudanças nas propriedades das estruturas, tais como rigidez, massa e amortecimento, ocasionando variações nas características dinâmicas do sistema, como por exemplo, as frequências naturais e os modos de vibração. Desta forma, então, a detecção do dano pode ser feita através da minimização da diferença entre as características da estrutura danificada (medidas experimentalmente) e aquelas obtidas por um modelo numérico. Muitas discusões já foram feitas com relação ao conteúdo de informações a serem utilizadas. Salawu[4] discutiu sobre o uso das informações de frequências naturais como ferramenta para detecção de dano em estruturas. Kim et al.[5] demonstram uma comparação entre métodos que utilizam as frequências naturais e métodos que utilizam as informações dos modos de vibração. 


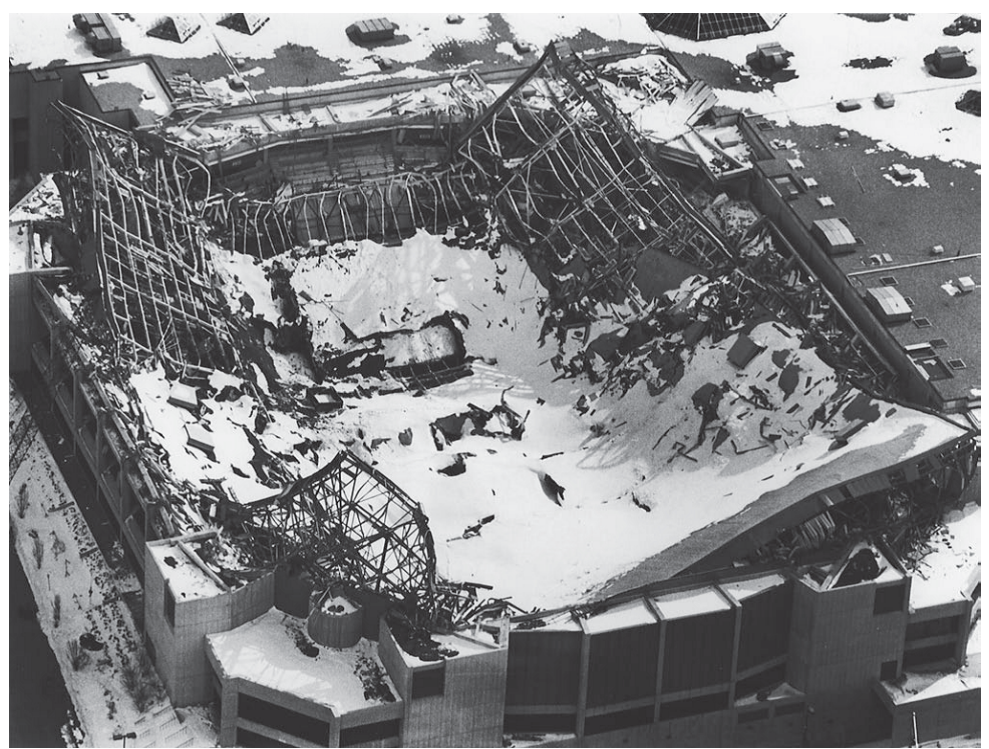

Figura 1 - Exemplo de falha estrutural: cobertura (treliça espacial) da Hartford Civic Center Arena-EUA.

Fonte: Leet, Uang e Gilbert[3]

Nhamage[6] utilizou apenas informações das primeiras frequências naturais para localizar o dano em estruturas não simétricas e utilizou uma formulação baseada na matriz de flexibilidade modal para detectar o dano em estruturas simétricas.

Dilena e Morasi[7] estudaram o uso de frequências ressonantes e anti-ressonantes para detectar dano em vigas. Lee e Shin[8] estudaram técnicas que utilizam a função de resposta em frequência (FRF) para a detecção de danos. Stubbs, Kim e Topole[9] utilizaram conceitos de energia de deformação para a detecção de dano em plataformas offshore. Curadelli et al.[10] estudaram a utilização das características de amortecimento da estrutura para a detecção de dano nas mesmas, e encontraram que o amortecimento apresenta maior sensibilidade ao dano que a frequência natural em estruturas de concreto. Neste trabalho tanto a frequência quanto o amortecimento são determinados desde a aplicação da transformada wavelet sobre um sinal de aceleração tomado a partir de vibrações ambientais. A metodologia proposta consegue determinar unicamente se há ou não a presença de dano na estrutura.

Mas a maioria destas pesquisas está no campo da detecção de danos de estruturas formadas por barras. Conforme Lee, Kim e Kim[11], o 
método de otimização topológica tem sido muito utilizado em aplicações na área de otimização de projeto, mas não na detecção de dano. Não sendo, ainda, muito difundida a detecção de danos em estruturas contínuas. Em 2006, Lee, Kim e Kim[11] fizeram a utilização do método de otimização topológica para identificação do dano estrutural, utilizando as informações contidas na FRF de receptância da estrutura danificada (frequências ressonantes e anti-ressonantes). A formulação utilizada consiste na minimização da diferença entre os valores das frequências da estrutura danificada e estrutura intacta. Para a resolução do problema de otimização foi utilizado o método das assíntotas móveis (MMA). Os autores utilizaram as informações de 6 frequências ressonantes e 5 anti-ressonantes para uma estrutura com um dano "severo" e utilizaram 10 frequências ressonantes e 9 anti-ressonantes para um exemplo de estrutura tipo viga "ligeiramente danificada". Em 2010, Niemann et al.[12] também utilizaram as informações das frequências ressonantes e anti-ressonantes para a detecção de dano e utilizaram uma rotina contida no software MSC Nastran para a otimização do problema. Em 2014, Nishizu, Takezawa e Kitamura[13] estudaram a detecção de danos em estruturas considerando apenas as informações de frequências ressonantes, utilizando para a otimização, também o MMA.

\subsection{Objetivos}

\subsubsection{Objetivo geral}

Desenvolver uma metodologia para detecção de dano em estruturas, utilizando informações das características dinâmicas e otimização topológica.

\subsubsection{Objetivos específicos}

- Avaliar os resultados para a detecção de dano utilizando apenas a informação das frequências naturais da estrutura;

- Avaliar a influência das informações de frequências ressonantes e anti-ressonantes utilizadas simultaneamente para a detecção de dano;

- Avaliar a influência do número de informações de entrada e diferentes resultados de saída;

- Avaliar a influência do filtro de sensibilidades na detecção de dano;

- Avaliar a influência da estratégia PR na otimização da topologia final;

- Avaliar a influência da adição de perturbações nos dados da estrutura danificada e os resultados de saída. 


\subsection{Organização do trabalho}

Neste trabalho os capítulos estão organizados da seguinte forma:

- Capítulo 2: são revistos alguns conceitos relacionados a detecção de dano, como por exemplo modelo espacial, modelo inverso e modelo de resposta, assim como estes modelos se relacionam. Também são vistos conceitos referentes a identificação modal, além de métodos no domínio do tempo e métodos no domínio da frequência;

- Capítulo 3: é realizada uma revisão bibliográfica acerca de aspectos relacionados ao tema de otimização topológica de estruturas; também são explanadas complicações numéricas inerentes ao tema, assim como estratégias para contornar tais problemas; também é apresentada a estratégia da redução de variáveis de projeto, proposta por Lee, Kim e Kim[11].

- Capítulo 4: é apresentada a base teórica para o problema de autovalores e autovetores, cuja solução fornece características dinâmicas da estrutura, nomeadamente frequências de ressonância e modos de vibração. Também é apresentada uma revisão sobre os conceitos da FRF de receptância, dando atenção especial para a receptância pontual, que é objeto de estudo deste trabalho;

- Capítulo 5: é mostrada a formulação do problema para a detecção de dano utilizando otimização topológica, mostrando a função objetivo adotada, assim como as restrições; também é feita uma revisão sobre a Programação Linear (LP) e Programação Linear Sequencial (SLP); são, também, explicados os conceitos de limites móveis utilizados no trabalho.

- Capítulo 6: este capítulo trata da apresentação e discussão dos resultados obtidos. São apresentados quatro exemplos. Para auxiliar, são mostrados gráficos, tabelas e figuras;

- Capítulo 7: são apresentadas as considerações finais do trabalho baseadas nos resultados encontrados no capitulo 6, além de sujestões para trabalhos futuros. 



\section{Detecção de dano}

\subsection{Introdução a caracterização dinâmica de estruturas}

As características dinâmicas de um sistema podem ser determinadas por dois procedimentos, denominados de Análise Modal Teórica e Análise Modal Experimental. O primeiro procedimento consiste na formulação de um modelo matemático da estrutura em estudo através de uma técnica de discretização. O método dos elementos finitos é muito utilizado para esse caso. As características dinâmicas estão contidas em uma distribuição espacial das propriedades de massa, rigidez e amortecimento (modelo espacial), descritas pelas matrizes de massa $\mathbf{M}$, matriz de rigidez $\mathbf{K}$ e amortecimento $\mathbf{C}$ (para o caso de amortecimento viscoso) ou $\mathbf{D}$ (no caso de amortecimento histerético). Então, utilizam-se essas matrizes na formulação de um problema de autovalores e autovetores que quando resolvido resulta no modelo modal, contido nas matrizes $\lambda$ e $\Psi$, as quais possuem informações de frequências naturais e modos de vibração, respectivamente [14].

No segundo procedimento (Análise Modal Experimental), os ensaios fornecem as características da resposta do sistema (modelo de resposta), que são geralmente dadas através de funções de resposta em frequência ou resposta impulsiva [15]. Através dos dados obtidos via experimentos, determinam-se as frequências naturais, fatores de amortecimento modais e modos de vibração. Essas técnicas que permitem a obtenção do modelo modal de um sistema a partir do conhecimento do modelo de resposta experimental são conhecidas como Identificação Modal [14] (item 2.3.3).

Neste trabalho estão "envolvidos" ambos os procedimento mencionados. Os procedimentos relacionados a análise modal teórica são necessários pois o problema de detecção de dano será formulado via método dos elementos finitos, sendo necessária a resolução do problema de autovalores e autovetores cuja resolução fornece as informações das frequências naturais ressonantes e anti-ressonantes, assim como os modos de vibração. Já os procedimentos relacionados a análise modal experimental são importantes pois em uma aplicação real seriam necessários experimentos para a obteção das mesmas informações mencionadas acima, porém, agora, da estrutura danificada.

A Figura 2 representa os passos de cada tipo de análise modal, em que, $\mathbf{M}$ é a matriz de massa, $\mathbf{C}$ é a matriz de amortecimento viscoso, $\mathbf{K}$ é a matriz de rigidez, $\omega$ é a matriz das frequências naturais, $\mathbf{H}(\omega)$ é a matriz 


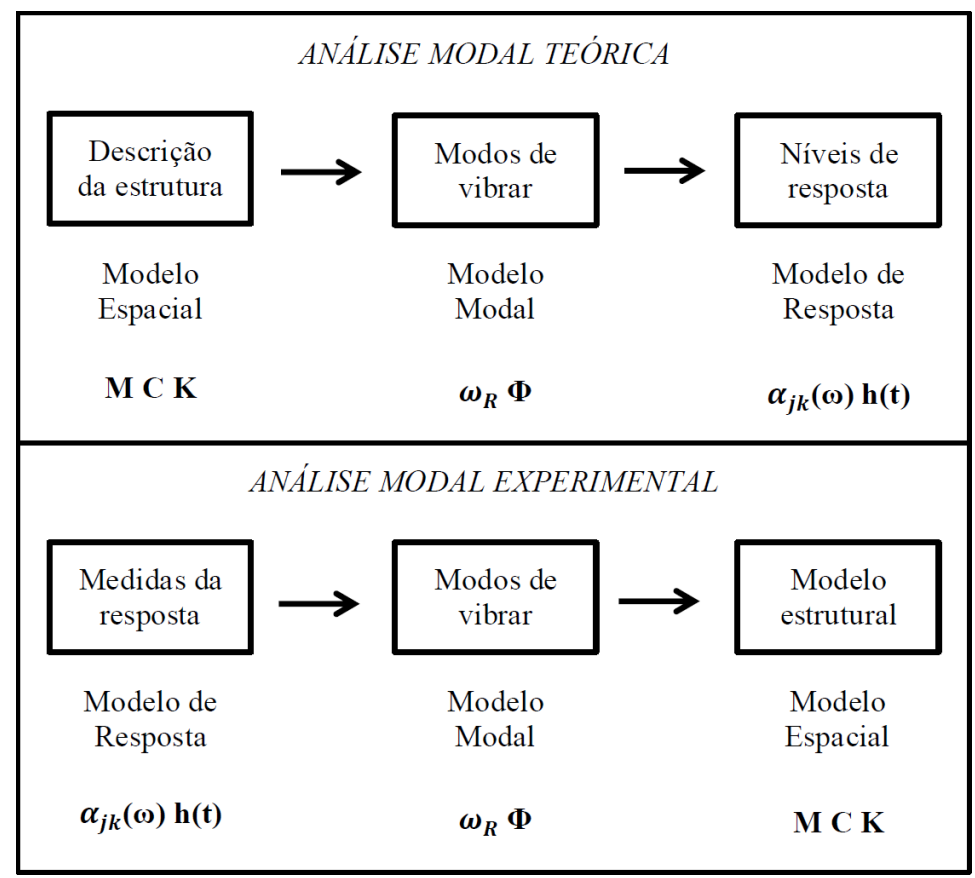

Figura 2 - Representação da análise modal teórica e análise modal experimental.

Fonte: Adaptado de Maia e Silva[16]

função resposta em frequência, $\Phi$ é a matriz modal e $h(f)$ é a resposta da estrutura ao longo do tempo.

Conforme Maia e Silva[16], é possível relacionar o modelo modal com o modelo de resposta obtido experimentalmente através de (para o caso da receptância):

$$
\alpha(\omega)=\Phi\left(\omega_{r}^{2}\left(1+c_{r}\right)-\omega^{2}\right) \Phi^{T}
$$

em que a matriz de receptância $\alpha(\omega)$ é obtida experimentalmente.

A Figura 3 apresenta um esquema mais detalhado da maneira como os modelos se relacionam. 


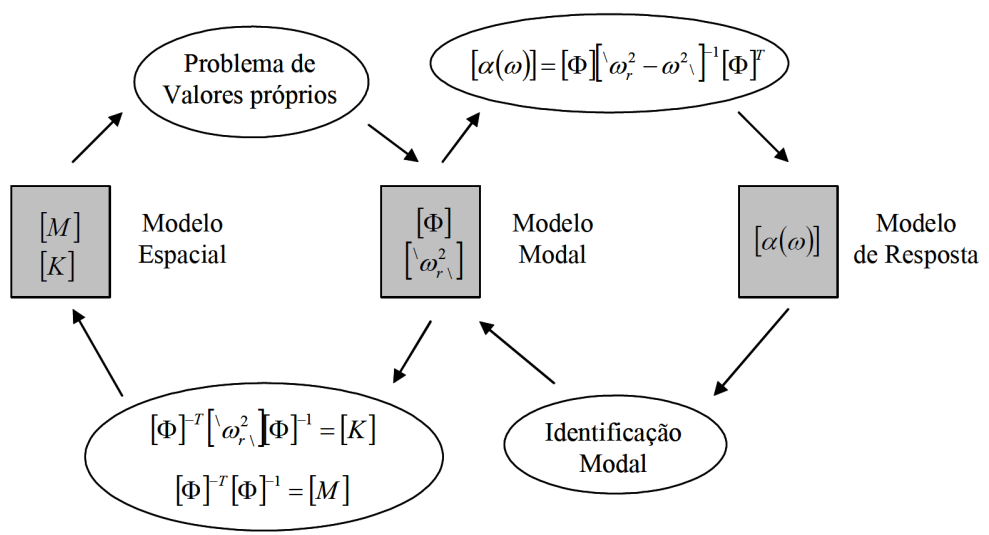

Figura 3 - Relações entre os modelos espacial, modal e de resposta (para o caso não amortecido).

Fonte: Silva[14]

\subsection{Detecção de dano como problema inverso}

O problema da detecção de dano baseado em modelos pode ser definido como um problema inverso, ou seja, tendo informações da estrutura (as quais podem ser deslocamentos, frequências naturais, etc) busca-se identificar os parâmetros do sistema. A Figura 4 mostra um fluxograma da detecção de dano através de um problema de otimização.

Uma das principais dificuldades encontradas na detecção de dano baseada em modelos é a presença de erros, tanto nas medidas experimentais como nos modelos utilizados (de modelagem, na ordem do modelo e nos parâmetros do modelo). $\mathrm{O}$ efeito dos erros experimentais pode ser incorporado, por exemplo, incluindo ruídos nos dados de entrada. Já os erros nos modelos de elementos finitos podem ser reduzidos mediante o emprego de técnicas de ajuste de modelos [17].

\subsection{Métodos de detecção de dano a partir de respostas di- nâmicas}

Segundo Carrillo[17], os métodos de detecção de dano podem ser classificados em dois grandes grupos, de acordo com sua dependência (ou não) de um modelo estrutural, sendo: os métodos baseados em sinais (experimentais) e os métodos baseados em modelos.

Entre os métodos baseados em sinais, pode-se citar alguns, como 


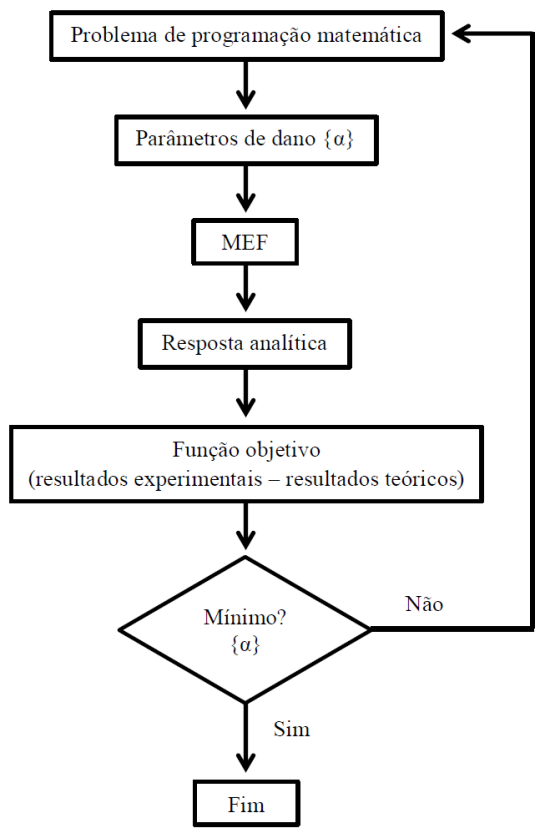

Figura 4 - Problema inverso de detecção de dano.

Fonte: Adaptado de Carrillo[17]

por exemplo, emissão acústica, raio X, inspeção visual, ultra som, etc. Estes métodos necessitam que a vizinhança do dano seja conhecida a priori e que o local da estrutura a ser análisado seja acessível.

Já os métodos baseados em modelos permitem estimar a posição do dano e sua severidade através da utilização de um modelo da estrutura, empregando tanto dados experimentais de vibração (características dinâmicas) quanto deslocamentos estáticos. Uma grande parte das linhas de pesquisa acerca do tema de deteç̧ão de dano utiliza o conceito de que a presença do dano em um sistema altera a resposta dinâmica do mesmo em relação ao seu estado inicial e esta diferença pode ser usada como um indicador da presença de dano (objeto de estudo deste trabalho).

\subsubsection{Técnicas baseadas em modelos}

Os modelos numéricos são amplamente utilizados na engenharia, já que estes permitem estudar fenômenos de interesse, com um custo relativamente baixo, e que não poderiam ser medidos diretamente, ou que o custo para tal poderia inviabilizar sua realização. Com o avanço da 
tecnologia, hoje, estes métodos permitem simular o comportamento de grandes sistemas estruturais, possibilitando a comparação e validação de seus resultados [17].

A ideia das técnicas baseadas em modelos é basicamente a comparação da resposta de dados experimentais com resultados obtidos da análise do modelo da estrutura (no caso de análises estruturais, o modelo mais utilizado é o modelo de elementos finitos), tendo como objetivo a detecção da presença ou não de dano.

Desta forma, uma questão importante que surge neste contexto é a obtenção das características dinâmicas da estrutura a ser analisada. Para tal, é de fundamental importância que a obtenção dos parâmetros que serão utilizados seja feita com a maior precisão possível, para que sejam minimizados os erros eventuais, relacionados aos procedimentos experimentais, de forma a possibilitar um melhor resultado final. Diante disso, muitas pequisas tem dedicado esforços para o desenvolvimento de técnicas que consigam produzir valores confiáveis das propriedades dinâmicas das estruturas a partir de somente dados de resposta. Tais procedimentos foram facilitados com a introdução da Transformada Rápida de Fourier (FFT) e pelo desenvolvimento da instrumentação em geral, permitindo a aquisição e o tratamento de uma larga quantidade de dados. Esses métodos são classificados de acordo com o domínio em que se desenvolvem, ou seja, métodos no domínio do tempo e métodos no domínio da frequência [18].

\subsubsection{Técnicas baseadas em sinais}

A ideia destes métodos é empregar apenas dados experimentais para solucionar o problema de detecção de dano, dispensando assim o uso de modelos. Além das técnicas convencionais, que são as técnicas não destrutivas (inspeção visual, raio-X), pode-se citar os métodos conhecidos como Detecção de Anomalias ou Detecção de Eventos Extremos. A ideia desse método é estabelecer um conjunto de características que definem a condição normal da estrutura, estabelecendo um padrão de operação normal do sistema. Após, durante as etapas posteriores de monitoramento, novas características são estimadas, e então comparadas com a referência, sendo que qualquer diferença entre estas características significa que existe alguma anomalia [17].

\subsubsection{Identificação modal}

Para Soeiro[19], os métodos, tanto no domínio do tempo quanto no domínio da frequiência podem ser divididos em diretos e indiretos. $\mathrm{O}$ termo indireto significa que a identificação das FRF's é baseada no modelo modal, ou seja, sobre os seguintes parâmetros: frequências naturais, razões 
de amortecimento e constantes modais. Já para o caso do método direto, a identificação está baseada no modelo espacial, isto é, sobre a equação matricial do equilíbrio dinâmico, que é a equação primitiva da qual todos os métodos são deduzidos.

A segunda classificação diz respeito ao número de modos que podem ser analisados. Neste caso, podem-se ter as análise de sistemas com um grau de liberdade (S1GL) ou sistemas com múltiplos graus de liberdade (SVGL). No domínio do tempo se tem somente a análise SVGL, já para o caso do domínio da frequência, tem-se análises S1GL e SVGL para os métodos diretos e apenas SVGL para os métodos indiretos.

Geralmente, quando se excita uma estrutura, um conjunto de FRF's é obtido, tendo por base a coleta de uma série de dados medidos. Essas FRF's são o resultado da excitação da estrutura em cada ponto selecionado e a medição da resposta em várias posições ao longo da estrutura. Alguns métodos de análise modal somente podem ser aplicados a uma única FRF de cada vez. Estes métodos são denominados métodos de única entrada/única saída (SISO). Outros métodos permitem que várias FRF's sejam analisadas simultaneamente, com respostas tomadas em vários pontos sobre a estrutura, mas usando uma excitação pontual. Esses são denominados de métodos globais ou métodos de única entrada/múltiplas saídas (SIMO). A filosofia por trás dessa categoria de métodos é que as frequências naturais e os fatores de amortecimento não variam (teoricamente) de uma FRF para outra (elas são propriedades globais da estrutura) e, assim, deveria ser possível obter um conjunto único e consistente daquelas propriedades, processando várias FRF's ao mesmo tempo. Finalmente, existem métodos que podem processar simultaneamente todas as FRF's disponíveis obtidas de posições de várias respostas e excitações. Esses métodos são denominados de polireferência ou múltiplas entradas/múltiplas saídas (MIMO). Situações de múltiplas entradas/única saída (MISO) são também possíveis, mas são pouco usadas.

A Figura 5 mostra um diagrama com várias categorias possíveis de métodos de classificação modal.

\subsubsection{Métodos no domínio da frequência}

Os métodos de identificação modal no domínio da frequência são baseados na conversão dos sinais medidos no domínio do tempo para o domínio da frequência, com o auxílio da transformada de Fourier.

Existem algumas questões a serem tratados quando da aplicação da FFT para transformar os dados do domínio do tempo para o domínio da frequência. Um erro comum introduzido na análise de sinal causado 


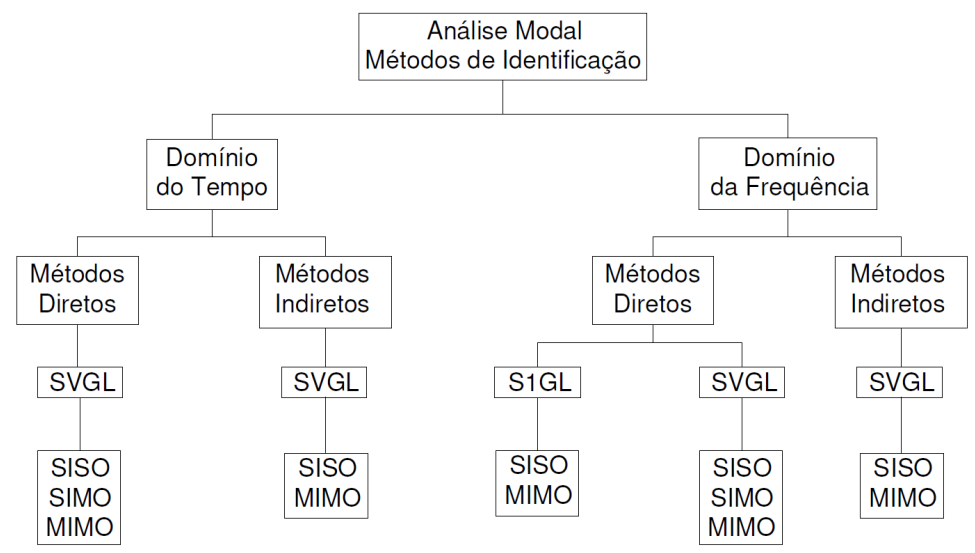

Figura 5 - Classificação dos métodos de análise modal.

Fonte: Adaptado de Soeiro[19]

por algum intervalo impróprio é chamado de mascaramento (aliasing). Uma forma prática para evitar tal fato é através da aplicação de filtros passa-baixa em conjunto com o teorema de Nyquist [18].

Da mesma forma, para possibilitar a análise, o sinal digital é amostrado em um intervalo finito de tempo $N$, podendo provocar outro problema referido como vazamento (leakage), o qual conduz a um aparecimento de amplitudes errôneas de frequências na densidade espectral de potência. Esse efeito provoca um aumento aparente do amortecimento no modo correspondente, na análise no domínio da frequência, além de impossibilitar a separação de modos com frequências muito próximas, especialmente se uma das frequências de ressonância possui amplitude pequena em respeito à outra. $\mathrm{O}$ vazamento pode ser atenuado através da multiplicação do sinal original por uma função chamada de função janela (window function), forçando que tal sinal se torne zero fora do intervalo de amostragem [18].

Inúmeros são os métodos no domínio da frequência que estão disponíveis na literatura. Entre os métodos SISO pode-se citar o Método da Amplitude de Pico, Método de Ajuste do Círculo, Método Inverso, Método de Dobson, Método dos Mínimos Quadrados, Método dos Mínimos Quadrados Melhorado, entre outros. Como exemplo de método SIMO pode-se citar o Método de Ajustamento Iterativo Simultâneo do Conjunto de FRF's. Entre os métodos citados, o Método da Amplitude de Pico é o mais simples para identificar os parâmetros modais de uma estrutura. As frequências são identificadas simplesmente observando-se os picos da curva de magnitude da resposta. Os fatores de amortecimento são calculados com a espessura 
destes picos e as formas modais são obtidas com a razão das amplitudes de pico em vários pontos da estrutura. De modo a levar em conta a amplitude da força de excitação, o uso da Receptância representa um melhoramento do método. Esse método assume que os modos são reais e, embora seja bastante simplório, ele pode fornecer resultados razoáveis se os modos são bem separados e se o amortecimento não é muito alto [19] [18].

\subsubsection{Métodos no domínio do tempo}

Conforme Miguel[18], os problemas encontrados nos métodos do domínio da frequência, como os efeitos nocivos provocados pelo fenômeno de vazamento e as restrições impostas para casos com frequências naturais muito próximas, desencadearam uma procura por análises alternativas para extração de informações modais de estruturas. Os métodos no domínio do tempo são mais apropriados para identificar frequências naturais iguais ou muito próximas, oferecendo também um caminho mais simples para determinar o número de graus de liberdade da estrutura a ser analisada, geralmente identificando um número maior de frequências naturais que os métodos no domínio da frequência. Esses métodos constroem uma matriz com valores de resposta computando numericamente as características dinâmicas através da solução de um problema de autovalores.

Assim como existem inúmeros métodos de identificação modal no domínio da frequência, também existem vários métodos no domínio do tempo. Entre os quais podem ser citados o Método da Exponencial Complexa, o Método da Exponencial Complexa - Mínimos Quadrados, método de Ibrahim, entre outros. 


\section{Otimização Topológica}

Neste capítulo é feita uma revisão acerca do assunto de otimização topológica, pelo fato da mesma ser uma ferramenta utilizada neste trabalho. Muitos conceitos utilizados em problemas de otimização topológica foram também utilizados aqui neste trabalho, ou seja, no contexto da detecção de dano.

\subsection{Introdução}

Existem diferentes abordagens que podem ser aplicadas no processo de otimização estrutural, as três principais são: otimização paramétrica, otimização de forma e otimização topológica, como mostra a Figura 6.

O método de otimização paramétrica consiste em definir inicialmente uma estrutura, mantendo suas condições de carregamento e restrições de graus de liberdade fixa. Por exemplo, a estrutura mostrada na Figura 6.a é discretizada com elementos de treliça, e pode-se utilizar um grupo de características geométricas como variáveis otimizáveis, como a área de seção transversal ou coordenadas geométricas. Tais variáveis podem ser otimizadas respeitando determinadas restrições impostas ao problema como por exemplo, tensões máximas, deslocamentos limites, etc.

No método de otimização de forma (Figura 6.b), os contornos externos e internos da estrutura são parametrizados por curvas do tipo splines, onde os parâmetros desta curva constituem as variáveis de projeto.

a)
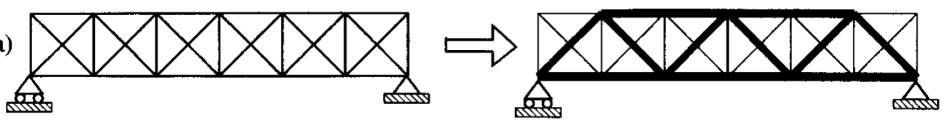

b)
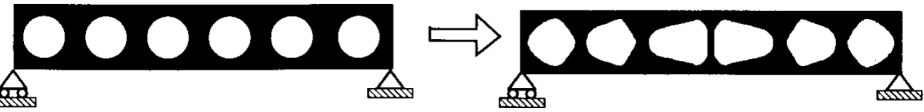

c)
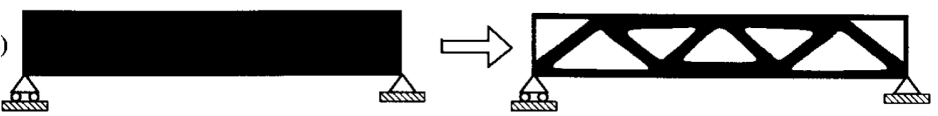

Figura 6 - Categorias de otimização: a) otimização paramétrica; b) otimização de forma; c) otimização topológica.

Fonte: Bendsoe e Sigmund[20] 
Ou seja, são apenas alterados os contornos dos furos, não havendo criação de novos destes na estrutura, mas apenas sua otimização, de tal forma que satisfaçam uma determinada função objetivo, por exemplo, maximização da rigidez, e consequentemente obtendo a forma ótima da estrutura. Nesse método, devido às formas complexas que podem ser obtidas, a análise é realizada utilizando-se o FEM, e, como existem alterações da forma da estrutura durante o processo de otimização, a malha é distorcida, sendo necessário um remalhamento do domínio durante a otimização, o que pode gerar resultados ruins.

No método de otimização topológica (Figura 6.c), existe uma nova distribuição de material dentro de um domínio fixo de projeto, permitindo sua adição ou remoção. Ou seja, ao contrário da otimização de forma, este método permite determinar a presença de novos furos na estrutura, podendo reduzir a quantidade de material consumido, melhorando o seu desempenho. A otimização topológica é a mais genérica, sendo possível uma caracterização mais ampla da geometria da estrutura otimizada, tendo como resultado a localização e forma (a depender do refinamento da malha) dos furos. Assim, o número de variáveis de projeto neste método é geralmente grande, estando estas relacionadas com o refinamento da malha de elementos finitos.

\subsection{Conceitos teóricos da Otimização Topológica}

A OT baseia-se em dois conceitos teóricos principais: domínio fixo estendido e modelo de material, os quais serão tratados na sequência.

\subsubsection{Domínio fixo extendido}

O domínio fixo estendido é região na qual a estrutura resultante da otimização deve estar contida. Como pode ser visualizado na Figura 7, o domínio fixo estendido é delimitado pelos pontos de apoio da estrutura e pelos pontos de aplicação do carregamento.

Ou seja, o problema de otimização topológica consiste em encontrar a distribuição ótima das propriedades dos materiais no domínio fixo estendido, sem ter qualquer informação sobre a geometria final da estrutura, sendo influenciado pelas restrições de deslocamento e pela aplicação das cargas.

\subsubsection{Modelo material}

O modelo material é uma equação que permite definir uma mistura em micro-escala de dois ou mais materiais (um deles pode ser "vazio"), 


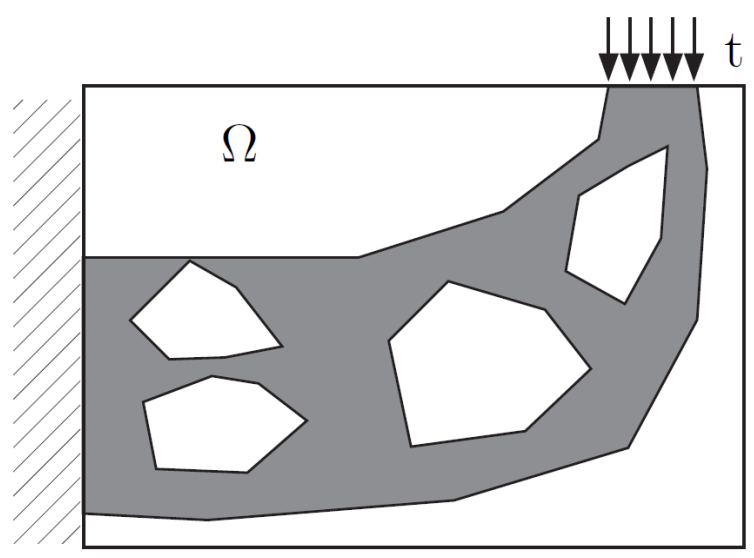

Figura 7 - Domínio fixo estendido.

Fonte: Kiyono[21]

permitindo passar da condição de zero material ("buraco") a sólido em cada ponto do domínio.

Conforme Bendsoe e Sigmund[20], para materiais isotrópicos, podese escrever:

$$
\begin{gathered}
\mathbf{E}(x)=1_{\Omega^{\text {mat }}}(x) \mathbf{E}^{0}, 1_{\Omega^{\text {mat }}}=\left\{\begin{array}{l}
1 \text { se } x \in \Omega^{\text {mat }} \\
0 \text { se } x \in \Omega
\end{array}\right. \\
\int_{\Omega} 1_{\Omega^{\text {mat }}} d \Omega=\operatorname{Vol}(\Omega) \leq V,
\end{gathered}
$$

onde $\mathbf{E}^{0}$ é o tensor constitutivo que representa as propriedades de um material base isotrópico, $\mathbf{E}$ é o tensor constitutivo com as propriedades efetivas do material, $V$ é o volume de material e $1_{\Omega^{\text {mat }}}$ é uma função discreta que caracteriza a estrutura a ser otimizada, sendo definida em cada ponto $x$ do domínio $\Omega$. A Figura 8 mostra regiões do domínio com e sem material.

O problema discreto com valores de 0 ou 1 torna-se mal posto, que tem como característica não possuir solução única e apresentar dependência da discretização do problema, sendo necessária a relaxação para o problema contínuo. Essa relaxação consiste em permitir que as variáveis de projeto assumam valores intermediário entre 0 e 1 , através de uma variável de projeto, que no modelo de material é denominada pseudo-densidade $\rho(x)$ e representa as propriedades de um dado material isotrópico [20]. 


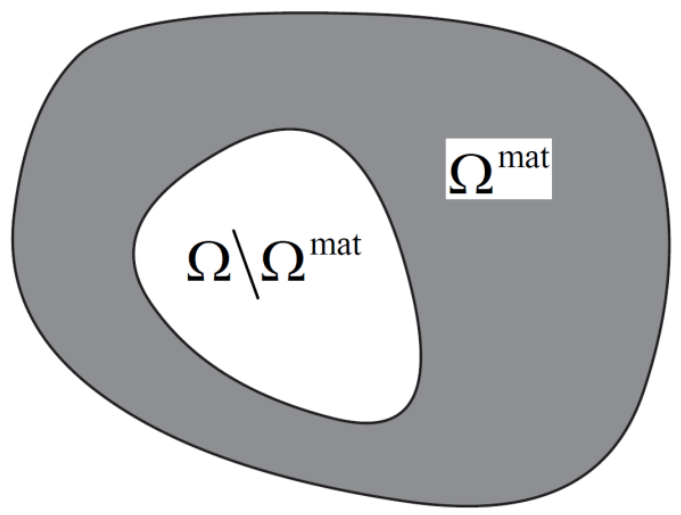

Figura 8 - Regiões com e sem presença de material.

Fonte: Kiyono[21]

A relaxação do problema pode ser feita através da utilização do método das densidades, utilizando a formulação SIMP (Solid Isotropic Material with Penalization), a qual é dada por:

$$
\begin{gathered}
\mathbf{E}(x)=\rho(x)^{p} \mathbf{E}^{0} \\
\int_{\Omega} \rho(x) d \Omega \leq V \quad 0 \leq \rho(x) \leq 1 \quad x \in \Omega,
\end{gathered}
$$

onde $\rho(x)$ é a variável de projeto (pseudo-densidade), $\mathbf{E}^{0}$ representa as propriedades do material base isotrópico e $\mathbf{E}$ é a propriedade efetiva do material, $V$ é o volume disponível de material e $p$ é o coeficiente de penalização.

As Equações 3.2 definem que a partir da propriedade do material base isotrópico $\mathbf{E}^{0}$ é possível definir propriedades intermediárias $\mathbf{E}(x)$ variando de 0 até $\mathbf{E}^{0}$ - de acordo com o valor da pseudo-densidade $\rho(x)\left(\rho_{\min } \leq \rho(x) \leq 1\right)$. O valor de $\rho_{\min }$ é inserido para evitar instabilidades numéricas (neste trabalho foi utilizado $\rho_{\min }=10^{-4}$ ).

Como visto, as variáveis de projeto (pseudo-densidades) podem assumir valores intermediários entre 0 e 1 . Para uma determinada situação em que a pseudo-densidade assume o valor de 0 (ou $\rho_{\text {min }}$ ) significa ausência de material (cor branca), e quando a mesma assume o valor de 1 significa material sólido (cor preta); então, é intuitivo que quando uma pseudodensidade assumir um valor intermediário sua cor será cinza, que do ponto 


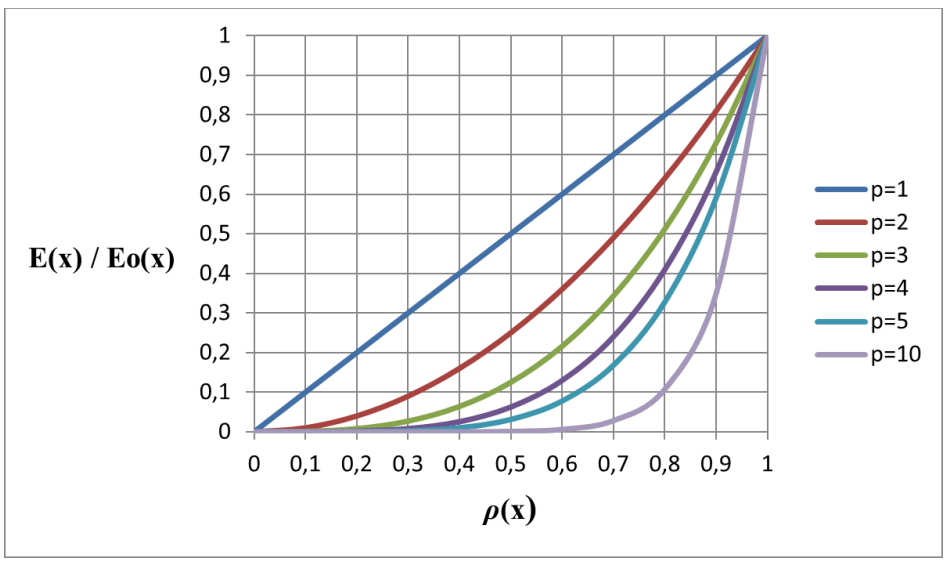

Figura 9 - Efeito de diferentes valores de penalizações.

de vista prático é difícil de ser pós-fabricado. Tal fato gera um problema conhecido como "escala de cinza" (item 3.3.1). Para evitar o excesso de ocorrência de pseudo-densidades intermediárias, penalizam-se os valores intermediários de $\rho(x)$ através do expoente $p$ ou $q$.

Neste trabalho, o domínio é discretizado com elementos finitos, sendo as penalidades aplicadas nas matrizes de rigidez e de massa. $\mathrm{O}$ coeficiente $p$ corresponde a penalização da matriz de rigidez e o coeficiente $q$ corresponde a penalização da matriz de massa, como mostram as Equações 3.3 e 3.4:

$$
\begin{gathered}
\mathbf{K}_{e}=\int_{\Omega_{e}} \mathbf{B}^{T} \mathbf{E} \mathbf{B} d \Omega_{e}=\rho_{e}^{p} \int_{\Omega_{e}} \mathbf{B}^{T} \mathbf{E}^{0} \mathbf{B} d \Omega_{e} \\
\mathbf{M}_{e}=\int_{\Omega_{e}} \rho_{m a t} \mathbf{N}^{T} \mathbf{N} d \Omega_{e}=\rho_{e}^{q} \int_{\Omega_{e}} \rho_{m a t} \mathbf{N}^{T} \mathbf{N} d \Omega_{e},
\end{gathered}
$$

onde $\rho_{\text {mat }}$ é a densidade do material, $p$ e $q$ são os fatores que penalizam as pseudo-densidades, fazendo com que os valores intermediários se aproximem de 0 e 1 . A Figura 9 permite observar o efeito da penalização sobre o valor das pseudo-densidades em relação aos valores das propriedades do módulo de elasticidade. Pode-se observar que quanto maior for o valor da penalidade, mais os valores da propriedade do material se aproximam de 0 ou 1.

A maioria dos problemas de otimização topológica são não convexos, ou seja, dentro do espaço de solução existem muitos mínimos locais, 
o que acarreta em diferentes soluções ótimas para o mesmo problema quando se parte de diferentes soluções iniciais ou escolhem-se diferentes parâmetros de otimização [20]. Segundo Kiyono[21], para que a solução não convirja para um mínimo local indesejado pode ser utilizado o método da continuação, no qual o valor da penalização é modificado do seu valor inicial até o seu valor limite (Equação 3.5)

$$
p_{i+1}=p_{i}+\Delta p
$$

em que $\Delta p$ é o incremento de penalização.

\subsection{Aspectos numéricos na otimização topológica}

Neste item serão apresentados alguns aspectos numéricos que tem muita importância no método de otimização topológica, sendo que esses precisam ser solucionados para a obtenção de bons resultados.

\subsubsection{Escala de cinza}

A presença de materiais intermediários dá origem ao problema conhecido como "escala de cinza", que por apresentar materiais intermediários torna difícil sua fabricação. Tal problema ocorre quando um problema é relaxado, com o objetivo de contornar a não existência de solução do problema discreto (0-1). A Figura 10 demonstra um exemplo de uma situação em que o problema da escala de cinza pode ser visualizado.

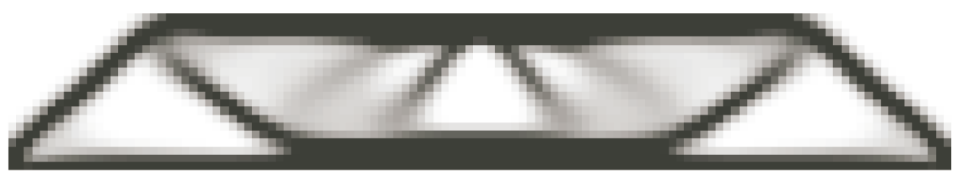

Figura 10 - Representação da escala de cinza.

Fonte: Kiyono[21]

Uma alternativa para contornar o problema da escala de cinza é o método da continuação das penalidades, que é feito ao longo do processo iterativo. Normalmente começa-se com um valor, por exemplo, $p=1 \mathrm{e}$ após convergir para uma solução, o valor de $p$ é aumentado, para então convergir a uma segunda solução. Este procedimento é repetido até que $p$ atinja seu valor limite, que, em geral, é de $p=3$ ou $p=4$ [20]. 


\subsubsection{Instabilidade de tabuleiro}

A instabilidade de tabuleiro é caracterizada pela formação de regiões com material sólido (pseudo-densidade igual ou próximo a 1) e sem material (pseudo-densidade igual ou próximo a 0), assemelhando-se a um tabuleiro de xadrez, como mostrado na Figura 11.
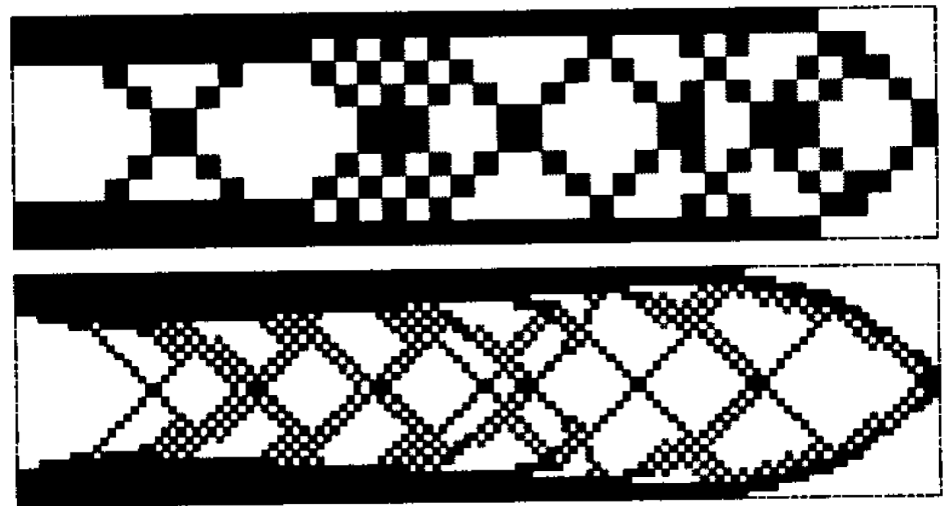

Figura 11 - Representação da instabilidade de tabuleiro.

Fonte: Bendsoe e Sigmund[20]

Conforme Bendsoe e Sigmund[20], a origem dos padrões de tabuleiro de xadrez está relacionado com a característica de aproximação do método dos elementos finitos e devido a má modelação numérica que sobrestima a rigidez dos tabuleiros.

Existem algumas técnicas para solucionar o problema da instabilidade de tabuleiro. Uma delas é aumentar a ordem do elemento finito, porém, esta é uma solução que pode ser muito cara computacionalmente. Outra possibilidade é utilizar métodos de filtragem ou de controle de gradientes das pseudo-densidades no domínio. Um exemplo de filtragem é a técnica do Filtro de Sensibilidades [22]. Essa técnica é descrita no item 3.3.4

\subsubsection{Dependência de malha}

Outro problema associado à otimização topológica é a dependência da malha. Teoricamente o resultado da tipologia da otimização deveria ser igual independente do refinamento da malha, mas não é isso que se observa. Quanto maior é o refinamento da malha, maior é o número de membros do resultado da otimização, ou seja, diferentes refinamentos da malha de elementos finitos geram diferentes tipologias. 
É possível visualizar o problema da dependência de malha observandose a Figura 12, na qual se observa que quando se aumenta o número de elementos finitos, altera-se a tipologia final da estrutura. O problema da dependência de malha pode ser solucionado utilizando o filtro de sensibilidades (item 3.3.4).
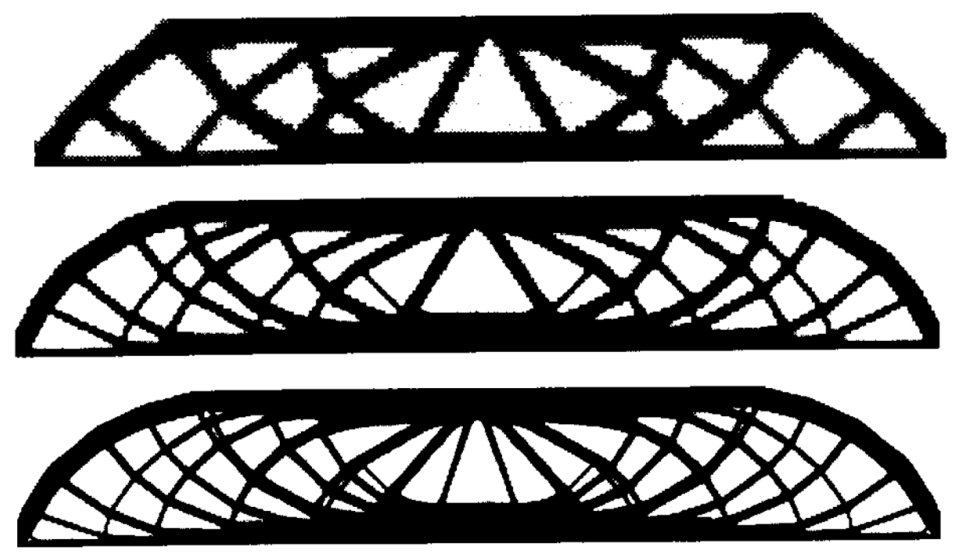

Figura 12 - Refinamento da malha com: a) 2700 elementos; b) 4800 elementos; c) 17200 elementos.

Fonte: Bendsoe e Sigmund[20]

\subsubsection{Filtro de sensibilidades}

O filtro de sensibilidades consiste em modificar a sensibilidade de um elemento específico, baseado na média ponderada das sensibilidades vizinhas. Estudos tem mostrado que a filtragem das informações de sensibilidade do problema de otimização é uma maneira eficiente para assegurar a independência da malha e também resolver a instabilidade de tabuleiro [20].

A Equação 3.6 demonstra a expressão para o filtro de sensibilidades:

$$
\frac{\partial \widehat{c}}{\partial \rho_{e}}=\frac{1}{\rho_{e} \sum_{i=1}^{N} \widehat{H}_{i}} \sum_{i=1}^{N} \widehat{H}_{i} \rho_{i} \frac{\partial c}{\partial \rho_{i}},
$$

em que:

$\frac{\partial \widehat{c}}{\partial \rho_{e}}$ - nova sensibilidade; 
$N$ - número toral de elementos da malha;

$\widehat{H}_{i}$ - fator peso, dado pela Equação 3.7:

$$
\widehat{H}_{i}=r_{\text {min }}-\operatorname{dist}(e, i), \quad\left\{i \in N \mid \operatorname{dist}(e, i) \leq r_{\text {min }}\right\},
$$

em que o operador dist $(e, i)$ é definido como a distância entre o centro do elemento $e$ até o centro do elemento $i$. O fator peso $\widehat{H}_{i}$ é zero fora da área do filtro. É possível visualizar na expressão acima que a sensibilidade decai linearmente com a distância do elemento $i$, tendendo para a sensibilidade original quando o raio de filtragem $r_{\min }$ vai a zero e todas as sensibilidades são iguais quando $r_{\min }$ tende ao infinito.

A Figura 13 mostra uma representação do filtro de sensibilidade em uma malha de elementos finitos. Na Figura 13.a estão indicadas as variáveis $r_{\text {min }}$ e dist $(e, i)$, assim como também estão indicados os centros dos elementos. Como se pode observar, alguns elementos estão com o seu centro dentro do círculo de raio $r_{\text {min }}$, estes serão incluídos no filtro de sensibilidades (Figura 13.b).

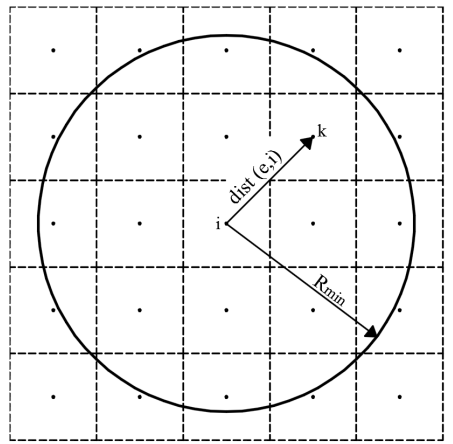

a)

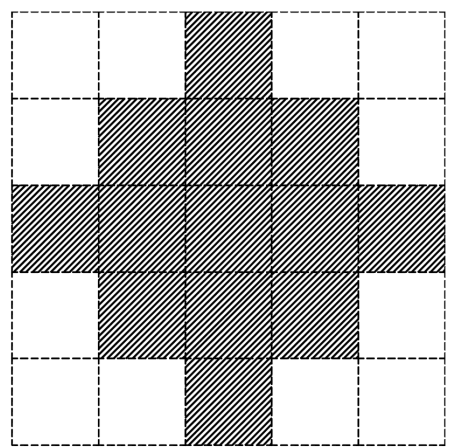

b)

Figura 13 - Representação do filtro de sensibilidades.

\subsubsection{Estratégia de redução de variáveis de projeto}

Conforme Lee, Kim e Kim[11] se o dano em uma estrutura for grave, este pode ser facilmente encontrado. Caso contrário, o mesmo pode ser consideravelmente difícil de ser encontrado ainda que utilizando métodos avançados. Nesses últimos, muitas variáveis de projeto intermediárias podem aparecer no final do processo de otimização, dificultando a identificação dos elementos danificados. 
No PR, o método de otimização é aplicado várias vezes durante o processo, enquanto isso o número de variáveis de projeto (que são as densidades dos elementos) pode diminuir através do critério mostrado pelas Equações 3.8 e 3.9:

$$
\text { se } \rho_{e}>\eta \rightarrow \text { deixa de ser variável e } \rho_{e}=1
$$

$$
\text { se } \rho_{e} \leq \eta \rightarrow \text { contínua variável de projeto }
$$

$O$ valor de $\eta$ é determinado heuristicamente, sendo que o mesmo pode ter um valor apropriado para cada tipo de problema. Esta pode ser uma desvantagem da técnica PR. Em [11], os valores de $\eta=0,8-0,9$ mostraram resultados satisfatórios. No presente trabalho, utilizando-se valores de $\eta=0,7$ os resultados foram satisfatórios. Ainda, este procedimento é aplicado apenas após um número considerável de iterações do algoritmo.

A Figura 14 apresenta a organização da estratégia através de um fluxograma. Já a Figura 15 mostra uma visão esquemática geral da estratégia PR.

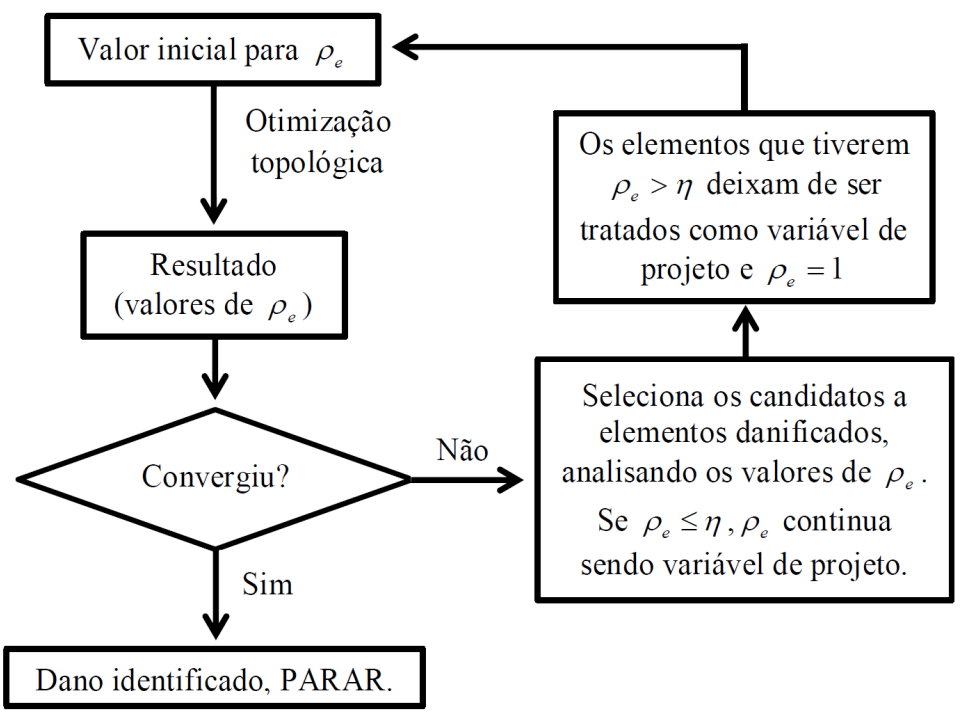

Figura 14 - Fluxograma da estratégia PR.

Fonte: Adaptado de Lee, Kim e Kim[11] 


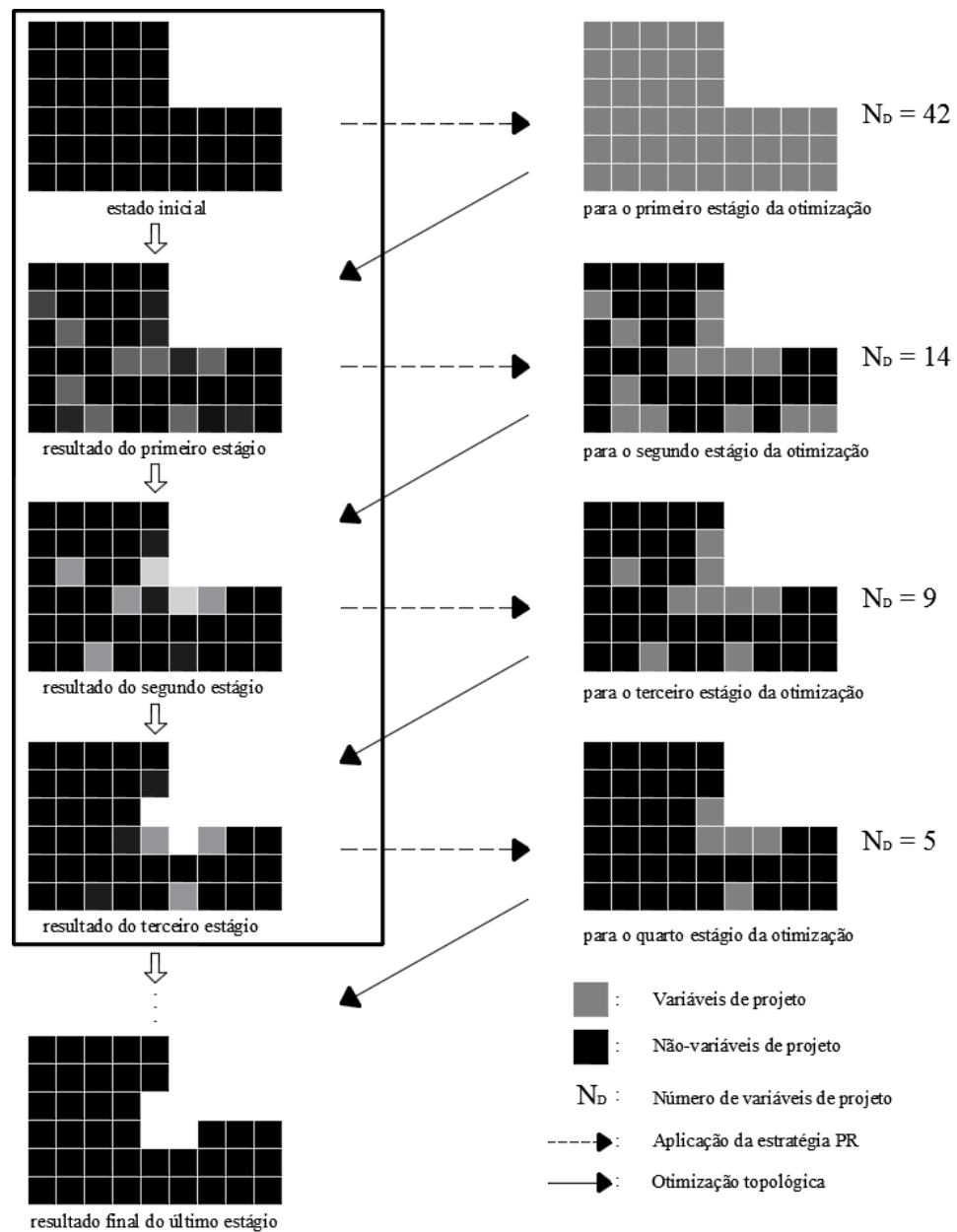

Figura 15 - Esquema de funcionamento da estratégia PR.

Fonte: Adaptado de Lee, Kim e Kim[11] 



\section{Características Dinâmicas de Estruturas}

Este capítulo aborda assuntos relacionados a caraterização dinâmica de sistemas. Inicialmente é feita uma apresentação do problema de autovalores e autovetores cuja resolução fornece as frequências naturais e modos de vibração para um sistema livre não amortecido. Na sequência são apresentadas algumas formas de FRF, entre elas a receptância. São apresentadas duas maneiras de determinação da receptância: a primeira através da utilização da informação da matriz de rigidez dinâmica, cuja inversa é igual a matriz de receptância (Equação 4.27); a segunda é através das informações dos modos de vibração e frequências naturais (Equação 4.35). Ambas as metodologias permitem desenhar o diagrama da receptância pontual - neste trabalho o gráfico de receptância pontual (por exemplo, Figura 19) é utilizada apenas para visualizar graficamente a diferença entre as frequências da estrutura alvo (danificada) e da estrutura intacta. Na sequência é demostrada a forma de obtenção das frequências anti-ressonantes utilizada neste trabalho, que consiste na resolução de um problema de autovalor e autovetor reduzido na ordem $\mathrm{N}-1$, em que $\mathrm{N}$ é o número de graus de liberdade do modelo. Apresenta-se também um exemplo para verificar as características globais e locais, das frequências ressonantes e anti-ressonantes, respectivamente (item 4.4.1). Ao final são discutidos aspectos relacionados a obtenção de dados da resposta de uma estrutura danificada.

\subsection{Análise modal de um sistema com múltiplos graus de liberdade}

A vibração livre não amortecida para sistemas dinâmicos com múltiplos graus de liberdade pode ser escrita pela equação diferencial de segunda ordem:

$$
\mathbf{M} \ddot{\mathbf{x}}+\mathbf{K x}=0,
$$

onde $\mathbf{M}$ é a matriz de massa, $\mathbf{K}$ é a matriz de rigidez, $\mathbf{x}$ é o vetor de deslocamentos e $\ddot{\mathbf{x}}$ é o vetor aceleração.

A equação de movimento livre para um sistema com $n$ graus de liberdade pode ser escrita sob a forma de um problema de autovalor e 
autovetor:

$$
(\mathbf{K}-\lambda \mathbf{M}) \Psi=0
$$

As matrizes $\mathbf{K}$ e $\mathbf{M}$ são simétricas, dessa forma temos $n$ raízes reais. A solução da Equação 4.2 é composta de $n$ autovalores $\lambda$ e de $n$ autovetores $\Psi_{r}(r=1,2, \ldots, n)$.

Normalmente, em análise modal, representam-se os autovalores e autovetores em forma de matrizes. Desta forma, então, a resolução da Equação 4.2 fornece duas matrizes, $\lambda$ e $\Psi$. A primeira contém em sua diagonal os valores de $\lambda_{n}$, que representam o quadrado da frequência natural $n\left(\lambda_{n}=\omega_{n}^{2}\right)$ - Equação 4.3. Já a segunda matriz representa os modos de vibração associados às frequências naturais, sendo que cada coluna da matriz de representa um modo de vibrar da estrutura - Equação 4.4.

$$
\begin{gathered}
\lambda=\left[\begin{array}{cccc}
\omega_{1}^{2} & & & \\
& \omega_{2}^{2} & & \\
& & \ddots & \\
& & & \omega_{1}^{2}
\end{array}\right] \\
\Psi=\left[\begin{array}{cccc}
\Psi_{11} & \Psi_{12} & \ldots & \Psi_{1 n} \\
\Psi_{21} & \Psi_{22} & \ldots & \Psi_{2 n} \\
\vdots & \vdots & \vdots & \vdots \\
\Psi_{n 1} & \Psi_{n 2} & \ldots & \Psi_{n n}
\end{array}\right]
\end{gathered}
$$

Normalmente, os modos de vibrar (autovetores) são normalizados em relação à massa. Um modo de vibrar massa-normalizado é um modo normalizado usando a massa modal. Sabendo que o princípio da ortogonalidade pode ser escrito matricialmente (Equações 4.5 e 4.6):

$$
\begin{gathered}
\Psi^{T} \mathbf{M} \Psi=m_{i}=\left[\begin{array}{cccc}
m_{1} & 0 & \cdots & 0 \\
0 & m_{2} & \cdots & 0 \\
\vdots & \vdots & \ddots & \vdots \\
0 & 0 & \cdots & m_{n}
\end{array}\right] \\
\Psi^{T} \mathbf{K} \Psi=k_{i}=\left[\begin{array}{cccc}
k_{1} & 0 & \cdots & 0 \\
0 & k_{2} & \cdots & 0 \\
\vdots & \vdots & \ddots & \vdots \\
0 & 0 & \cdots & k_{n}
\end{array}\right]
\end{gathered}
$$


A matriz $m_{i}$ é denominada matriz de massa modal, e $k_{i}$ é chamada de matriz de rigidez modal. Então, desde que $\Psi_{r}^{T} \mathbf{M} \Psi_{r}=m_{r}(r=1,2, \ldots$, $n$ ), os modos de vibrar $\Psi_{r}$ podem ser normalizados da seguinte forma:

$$
\phi_{r}=\frac{1}{\sqrt{m_{r}}} \Psi_{r}(r=1,2, \ldots, n),
$$

onde $\phi_{r}$ é chamado de modo de vibrar massa-normalizado do sistema. A Equação 4.7 pode ser escrita na forma:

$$
\Phi=\Psi m_{i}^{-1 / 2}
$$

a equação 4.8 pode ser escrita matricialmente:

$$
\Phi=\left[\begin{array}{cccc}
\frac{\phi_{11}}{\sqrt{m 1}} & \frac{\phi_{12}}{\sqrt{m 2}} & \cdots & \frac{\phi_{1 n}}{\sqrt{m n}} \\
\vdots & \vdots & \ddots & \vdots \\
\frac{\phi_{n 1}}{\sqrt{m 1}} & \frac{\phi_{n 2}}{\sqrt{m 2}} & \cdots & \frac{\phi_{n n}}{\sqrt{m n}}
\end{array}\right]
$$

Desta forma, é possível escrever as relações 4.10 e 4.11 :

$$
\begin{gathered}
\Phi^{T} \mathbf{M} \Phi=\mathbf{I}=\left[\begin{array}{llll}
1 & 0 & 0 & 0 \\
0 & 1 & 0 & 0 \\
0 & 0 & \ddots & 0 \\
0 & 0 & 0 & 1
\end{array}\right] \\
\Phi^{T} \mathbf{K} \Phi=\lambda=\left[\begin{array}{cccc}
\omega_{1}^{2} & 0 & 0 & 0 \\
0 & \omega_{2}^{2} & 0 & 0 \\
0 & 0 & \ddots & 0 \\
0 & 0 & 0 & \omega_{n}^{2}
\end{array}\right],
\end{gathered}
$$

em que I é a matriz identidade. As matrizes modo de vibrar massanormalizadas $\Phi$ são únicas para um sistema de múltiplos graus de liberdade. A importância dos modos de vibrar massa-normalizados recai no fato de que a FRF de um sistema de múltiplos graus de liberdade não-amortecido pode ser expressa em termos dos modos de vibrar massa-normalizados e das frequências naturais.

\subsection{Função de resposta em frequência}

O modelo de Resposta $\mathbf{H}(\omega)$ é resultado de experimentação. A Função de Resposta em Frequência é uma função de transferência expressa 
no domínio da frequência, relacionando a resposta de um ponto $i$ a uma excitação de um ponto $j$. Essa grandeza é descrita como uma matriz $H_{i j}(\omega)$, sendo muito utilizada para a análise de vibrações:

$$
\mathbf{H}(\omega)=\frac{X(\omega)}{F(\omega)}
$$

em que $X$ e $F$ são as amplitudes de resposta e excitação, respectivamente. A função $\mathbf{H}(\omega)$ é uma característica intrínseca do sistema dinâmico em estudo. A resposta do sistema pode ser medida com deslocamentos, velocidade ou aceleração. Os sinais de resposta obtidos em um ensaio dinâmico são obtidos por acelerômetros ou transdutores de força, os quais são obtidos no domínio do tempo. O analisador converte os sinais analógicos do domíno do tempo em dados digitais no domínio da frequência. Um analisador comumente utilizado é denominado analisador de transformada rápida de Fourier. Ele calcula os espectros de frequência discreta de sinais individuais, bem como espectros cruzados entre a entrada e os diferentes sinais de saída. Os sinais analisados podem ser usados para determinar as frequências naturais, fatores de amortecimento e as formas modais em forma numérica ou gráfica [23].

A vibração de uma forma geral é medida em termos de movimento e, portanto, a FRF pode ser escrita com as variáveis de deslocamento, velocidade ou aceleração.

A FRF que relaciona deslocamento com excitação é chamada de Receptância, Equação 4.13:

$$
\alpha(\omega)=\frac{\text { deslocamento }}{\text { força }}=\frac{X(\omega)}{F(\omega)}
$$

A FRF que relaciona velocidade com excitação é chamada de Mobilidade, como mostra a Equação 4.14:

$$
Y(\omega)=\frac{\text { velocidade }}{\text { força }}=\frac{V(\omega)}{F(\omega)}
$$

A FRF que relaciona aceleração com excitação é chamada de Acelerância, mostrada na Equação 4.15:

$$
A(\omega)=\frac{\text { aceleração }}{\text { força }}=\frac{A(\omega)}{F(\omega)}
$$


Sabendo que o deslocamento, a velocidade e a aceleração são quantidades de resposta relacionadas matematicamente, pode-se, a partir de uma FRF com base em algum dos parâmetros conhecidos, obter as outras formas de FRF.

\subsection{Matriz de rigidez dinâmica e matriz de receptância}

Um sistema forçado não amortecido com múltiplos graus de liberdade tem a seguinte equação de movimento:

$$
\mathbf{M} \ddot{\mathbf{x}}(t)+\mathbf{K x}(t)=f(t)
$$

o vetor $f(t)$ tem dimensões $n \times 1$, de $n$ forças externas. Se estas forças são harmônicas, com a mesma frequência e fase (assume-se fase zero), então:

$$
f(t)=\left[\begin{array}{c}
F_{1} \\
F_{2} \\
\vdots \\
F_{n}
\end{array}\right] \sin (\omega t)
$$

em que $F_{r}(r=1,2, \ldots, n)$ são as amplitudes das forças harmônicas.

A resposta do sistema terá a forma:

$$
x(t)=\left[\begin{array}{c}
X_{1} \\
X_{2} \\
\vdots \\
X_{n}
\end{array}\right] \sin (\omega t)=X \sin (\omega t)
$$

e

$$
\ddot{x}(t)=-\omega^{2}\left[\begin{array}{c}
X_{1} \\
X_{2} \\
\vdots \\
X_{n}
\end{array}\right] \sin (\omega t)=-\omega^{2} \ddot{X} \sin (\omega t)
$$

Substituíndo as expressões 4.18 e 4.19 em 4.16, tem-se:

$$
-\omega^{2} \mathbf{M} X \sin (\omega t)+\mathbf{K} X \sin (\omega t)=\mathbf{F} \sin (\omega t),
$$


a Equação 4.20 pode ser escrita como:

$$
\left(\mathbf{K}-\omega^{2} \mathbf{M}\right) X \sin (\omega t)=\mathbf{F} \sin (\omega t),
$$

ou ainda

$$
\left(\mathbf{K}-\omega^{2} \mathbf{M}\right) X=\mathbf{F}
$$

O termo $\left(\mathbf{K}-\omega^{2} \mathbf{M}\right)$ é conhecido como matriz de rigidez dinâmica de um sistema com múltiplos graus de liberdade não amortecido, podendo ser escrito na forma:

$$
\mathbf{Z}(\omega)=\mathbf{K}-\omega^{2} \mathbf{M}
$$

Desta forma, pode-se reescrever a Equação 4.22 na forma:

$$
\mathbf{Z}(\omega) X=F
$$

ou,

$$
\mathbf{Z}(\omega)=\frac{F}{X}
$$

ou ainda:

$$
\mathbf{Z}(\omega)^{-1}=\frac{X}{F}
$$

Ou seja, o inverso da matriz de rigidez dinâmica é igual à matriz de receptância $\left(\alpha(\omega)=\mathbf{Z}(\omega)^{-1}\right)$ :

$$
\alpha(\omega)=\mathbf{Z}(\omega)^{-1}=\left[\begin{array}{cccc}
\alpha_{11}(\omega) & \alpha_{12}(\omega) & \cdots & \alpha_{1 n}(\omega) \\
\alpha_{21}(\omega) & \alpha_{22}(\omega) & \cdots & \alpha_{2 n}(\omega) \\
\vdots & \vdots & \ddots & \vdots \\
\alpha_{n 1}(\omega) & \alpha_{n 2}(\omega) & \cdots & \alpha_{n n}(\omega)
\end{array}\right]
$$

A matriz de receptância é simétrica, pois a matriz de rigidez dinâmica é simétrica. Desta forma, a resposta medida no grau de liberdade $i$ devido a uma excitação aplicada no grau de liberdade $j$, é igual à resposta medida no grau de liberdade $j$ devido a uma excitação aplicada no grau de 
liberdade $i$, essa propriedade diz respeito à reciprocidade de Maxwell, ou seja:

$$
\alpha_{i j}=\frac{X_{i}}{F_{j}}=\alpha_{j i}=\frac{X_{j}}{F_{i}}
$$

A Figura 16 auxilia na visualização da matriz de receptância. A Figura 16.a mostra a receptância $\alpha_{11}$ em que a leitura e a excitação se fazem no grau de liberdade 1. Já Figura 16.b mostra a receptância $\alpha_{12}$, ou seja, quando a leitura é feita no grau de liberdade 1 e a excitação no grau de liberdade 2. Já a Figura 16.c mostra a receptância $\alpha_{13}$, que diz respeito a uma leitura feita no grau de liberdade 1 e excitação no grau de liberdade 3.

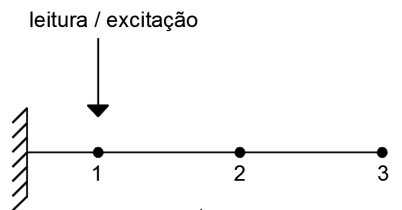

a)

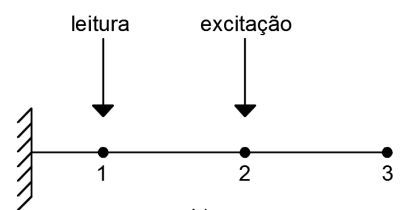

b)

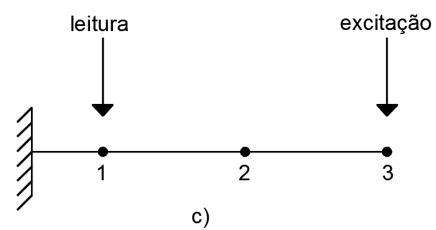

Figura 16 - Exemplos de leituras e excitações nos graus de liberdade $i$ e $j$.

Entretanto, o procedimento para obtenção da FRF mostrado na expressão 4.27 necessita que, para cada frequência, uma matriz de rigidez dinâmica $n \times n$ tenha que ser invertida. Este procedimento é bastante caro computacionalmente. Então, utilizando-se o princípio da ortogonalidade de um sistema de múltiplos graus de liberdade, a matriz de receptância pode ser derivada utilizando-se características modais do sistema, nomeadamente matrizes de frequências naturais e modos de vibrar.

A partir da Equação 4.22 podemos escrever:

$$
\left(\mathbf{K}-\omega^{2} \mathbf{M}\right)=\frac{\mathbf{F}}{X}
$$


substituindo a expressão 4.12 em 4.29, tem-se:

$$
\left(\mathbf{K}-\omega^{2} \mathbf{M}\right)=\mathbf{H}^{-1}(\omega)
$$

Multiplicando-se os dois lados da igualdade de 4.30 por $\Phi^{T}$ e posteriormente multiplicando por $\Phi$ :

$$
\Phi^{T}\left(\mathbf{K}-\omega^{2} \mathbf{M}\right) \Phi=\Phi^{T} \mathbf{H}^{-1}(\omega) \Phi
$$

Substituindo-se as relações 4.10 e 4.11 na Equação 4.31, e isolandose $\mathbf{H}(\omega)$ :

$$
\mathbf{H}(\omega)=\Phi\left(\lambda-\omega^{2} \mathbf{I}\right)^{-1} \Phi^{T}
$$

ou

$$
\mathbf{H}(\omega)=\Phi\left(\omega_{k}^{2}-\omega^{2}\right)^{-1} \Phi^{T}
$$

A resposta final do sistema é um somatório das respostas dos $N$ modos de vibrar, ficando então a relação 4.33 escrita, para cada um de seus termos:

$$
\mathbf{H}_{i j}(\omega)=\frac{X_{i}}{F_{j}}=\sum_{k=1}^{N} \frac{\Phi_{k i} \Phi_{k j}}{\omega_{k}^{2}-\omega^{2}},
$$

em que $\Phi_{k i}$ e $\Phi_{k j}$ são, respectivamente, o i-ésimo e j-ésimo termo do késimo modo de vibração do sistema e $N$ é o número de graus de liberdade.

A FRF que relaciona deslocamentos e forças é chamada de receptância (Equação 4.13), a mesma então pode ser escrita:

$$
\alpha_{i j}(\omega)=\frac{X_{i}}{F_{j}}=\sum_{k=1}^{N} \frac{A_{i j}^{k}}{\omega_{k}^{2}-\omega^{2}},
$$

em que:

$\alpha_{i j}$ : receptância medida no grau de liberdade $i$, provocada por uma excitação aplicada no grau de liberdade $j$;

$N$ : número de graus de liberdade do modelo;

$A_{i j}=\phi_{i k} \phi_{j k}$ : constante modal. Em que $\phi_{i k}$ e $\phi_{j k}$ são os elementos $i$ e $j$ do vetor modal $\phi_{k}$

$\omega_{k}$ : frequência natural relativa ao k-ésimo modo de vibração;

$\omega$ : frequência do carregamento. 
A expressão 4.35 pode ser reescrita então:

$$
\alpha_{i j}(\omega)=\frac{X_{i}}{F_{j}}=\sum_{k=1}^{N} \frac{\phi_{i k} \phi_{j k}}{\omega_{k}^{2}-\omega^{2}}
$$

\subsection{Receptância pontual}

Nota-se que a diagonal da matriz de receptância, possui FRF's em que $i=j$. Ou seja, o grau de liberdade de leitura da resposta é mesmo que o grau de liberdade de aplicação da excitação. Para estes casos, tem-se uma situação chamada de resposta em frequência pontual. É comum utilizar a medição e a excitação no mesmo grau de liberdade para se verificar a existência de frequências anti-ressonantes. A Equação 4.37 mostra a expressão para a receptância pontual de um sistema não amortecido (objeto de estudo deste trabalho).

$$
\alpha_{i i}(\omega)=\sum_{k=1}^{N} \frac{A_{i i}}{\omega_{k}^{2}-\omega^{2}},
$$

em que:

$\alpha_{i i}$ : receptância medida no grau de liberdade $i$, provocada por uma excitação aplicada no grau de liberdade $i$;

$N$ : número de graus de liberdade do modelo;

$A_{i i}=\phi_{i k} \phi_{i k}:$ constante modal;

$\omega_{k}$ : frequência natural relativa ao k-ésimo modo de vibração;

$\omega$ : frequência do carregamento.

Utilizando essa notação, a expressão para a obtenção da FRF de receptância pontual poderia ser reescrita sob a forma:

$$
\alpha_{i i}(\omega)=\sum_{k=1}^{N} \frac{\phi_{i k} \phi_{i k}}{\omega_{k}^{2}-\omega^{2}},
$$

ou seja, cada FRF pode ser escrita sob a forma de soma de uma série de termos, cada um dos quais diz respeito à contribuição de cada modo de vibração a resposta total.

A Figura 17 mostra o fluxograma desenvolvido para o cálculo da FRF de receptância pontual, considerando que o grau de liberdade de aplicação da excitação e leitura da resposta é o 1. Neste caso, a variável ini é a frequência inicial do diagrama, passo é o intervalo das frequências e fin é o valor da frequência final do diagrama. 


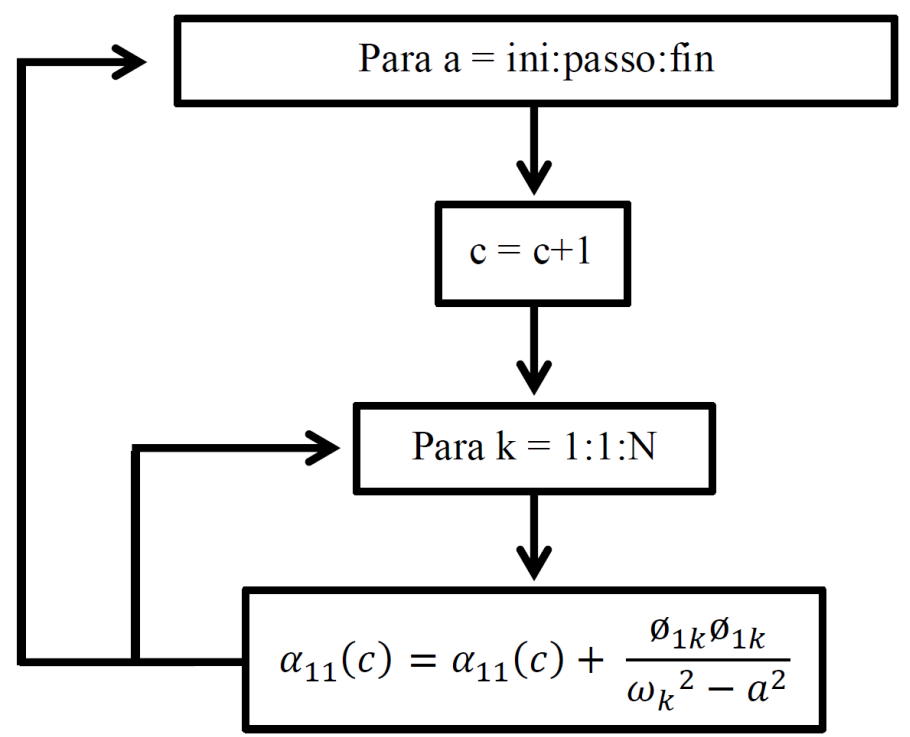

Figura 17 - Fluxograma para calcular a FRF de receptância pontual.

Conforme Afolabi[24], a frequência de ressonância de uma FRF de receptância $\alpha_{i j}$, para um sistema não amortecido, é definido como a frequência para qual a amplitude do deslocamento do grau de liberdade $i$ tende ao infinito quando a amplitude da excitação aplicada no grau de liberdade $j$ tende à zero (Equação 4.39):

$$
\omega_{n}=\omega\left(x_{i} \rightarrow \infty, f_{j} \rightarrow 0\right) ; f_{k}=0, k \neq j
$$

Por outro lado, para o caso da frequência anti-ressonante de uma FRF de receptância $\alpha_{i j}$, o deslocamento no grau de liberdade $i$ tende à zero, enquanto a excitação aplicada no grau de liberdade $j$ possa tender ao infinito (Equação 4.40). Ou seja, para um sistema sem amortecimento, a frequência anti-ressonante corresponde a ausência de movimento em todas as coordenadas onde a resposta está sendo medida.

$$
\mu_{i j, n}=\omega\left(x_{i} \rightarrow 0, f_{j} \rightarrow \infty\right) ; f_{k}=0, k \neq j
$$

Para determinar as frequências ressonantes $\alpha_{i j}$, é necessário fazer $f_{j}=0$ na expressão 4.24. No entanto, a força é nula em todas as outras coordenadas $f_{k}=0(k \neq j)$, dessa forma, a condição imposta para se determinar a ressonância $\alpha_{i j}$ é que o vetor de forças $\mathbf{f}$ seja nulo. Este 
requisito é o mesmo para todas as funções de transferência. Assim, a ressonância é uma característica global da estrutura. Ou seja, os valores das frequências ressonantes independem da posição da leitura das coordenadas, assim como da aplicação da excitação.

Similarmente, para se determinar as anti-ressonâncias de $\alpha_{i j}$ é necessário que se faça $x_{j}=0$ na Equação 4.24. Isso é equivalente a eliminar a coluna $i$ nessa equação. Por outro lado, para satisfazer $f_{j} \rightarrow \infty$ sendo que $f_{k}=0(k \neq j)$ é necessário eliminar a linha $j$ na Equação 4.24, já que:

$$
\frac{Z_{i j}}{f_{j}} \rightarrow 0, f_{j} \rightarrow \infty, f_{k}=0(k \neq j), i=1 \ldots N
$$

Dessa forma, para se determinar as frequências das anti-ressonâncias de $\alpha_{i j}$ é necessário inicialmente reduzir a matriz de rigidez dinâmica da ordem $N$ para a ordem $N-1$ e fazer o vetor $\mathbf{f}$ um vetor nulo. Isso significa resolver um problema de autovalores (Equação 4.2) reduzido, em que se eliminam a coluna $i$ e a linha $j$ da matriz de rigidez dinâmica $\mathbf{Z}$. Os autovalores da matriz reduzida de dimensão $N-1$ são as anti-ressonâncias $\mu_{i j}$ de $\alpha_{i j}$. Dessa forma, pode-se verificar que as frequências anti-ressonantes não são características globais, e sim características locais da estrutura. Em outras palavras, os valores de $\mu_{i j}$ dependem da localização dos graus de liberdade $i$ e $j$, ou seja, do grau de liberdade de leitura dos dados e do grau de liberdade aplicação da excitação.

Em geral, o número máximo de frequências anti-ressonantes que uma receptância $\alpha_{i j}$ pode ter é dado pela Equação 4.42:

$$
m=(N-1)-|i-j|
$$

Para o caso de receptância pontual (caso em que $i=j$ ), existem exatamente $N-1$ anti-ressonâncias, cada um das quais intercalada por uma frequência ressonante no espectro completo do sistema.

A FRF de um sistema de múltiplos graus de liberdade não-amortecido pode ser mostrado de diferentes formas. Uma seleção apropriada de gráficos pode dar ênfase em alguns aspectos que se queiram chamar a atenção na FRF. Gráficos de magnitude, gráficos de magnitude log-log e da inversa da FRF são várias formas usuais de se mostrar uma FRF. A Figura 18 mostra a receptância para um sistema com três graus de liberdade, sem amortecimento, usando uma escala linear. É possível visualizar que existem três picos da amplitude, correspondendo a cada uma das três frequências naturais do sistema. No entanto, detalhes da curva são ofuscados por causa da proeminência dos picos de ressonância. 


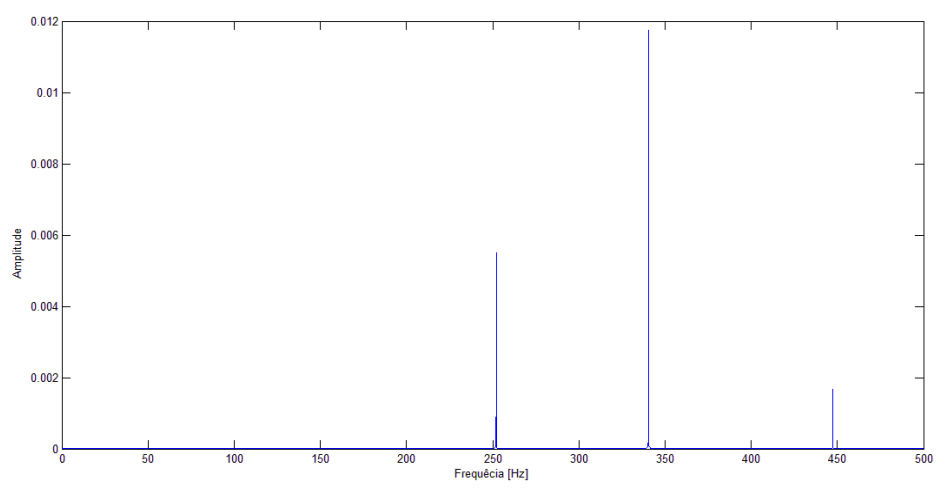

Figura 18 - Receptância pontual escala linear.

Alterando a escala da magnitude da receptância de linear para logarítmica, torna-se possível a observação de detalhes nos níveis de resposta mais baixos, ou seja, é possível perceber que, além dos picos referentes às ressonâncias (destacados com a cor preta), existem picos inferiores (destacados em vermelho), que serão referentes às frequências anti-ressonantes, como mostra a Figura 19.

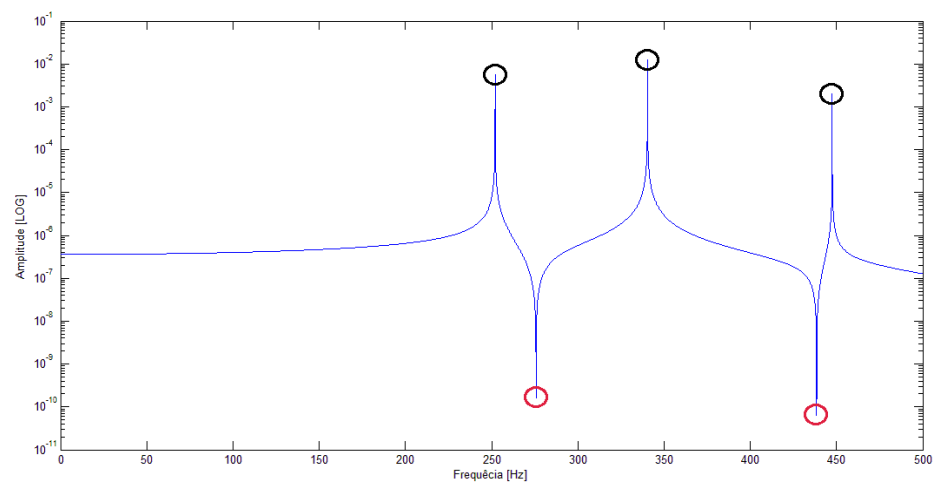

Figura 19 - Receptância pontual em escala logarítmica.

Para determinar os gráficos demonstrados nas Figuras 18 e 19, podese escrever a expressão 4.37 da seguinte forma (considerando que trata-se, 
por exemplo, de uma receptância $\alpha_{11}$ ):

$$
\alpha_{11}(\omega)=\frac{A_{11}^{1}}{\omega_{1}^{2}-\omega^{2}}+\frac{A_{11}^{2}}{\omega_{2}^{2}-\omega^{2}}+\frac{A_{11}^{3}}{\omega_{3}^{2}-\omega^{2}},
$$

a expressão 4.43 pode ser resscrita conforme nomenclatura da expressão 4.38:

$$
\begin{aligned}
\alpha_{11}(\omega) & =\frac{\phi_{11} \phi_{11}}{\omega_{1}^{2}-\omega^{2}}+\frac{\phi_{12} \phi_{12}}{\omega_{2}^{2}-\omega^{2}}+\frac{\phi_{13} \phi_{13}}{\omega_{3}^{2}-\omega^{2}} \\
& =\frac{\phi_{11}^{2}}{\omega_{1}^{2}-\omega^{2}}+\frac{\phi_{12}^{2}}{\omega_{2}^{2}-\omega^{2}}+\frac{\phi_{13}^{2}}{\omega_{3}^{2}-\omega^{2}}
\end{aligned}
$$

4.4.1 Propriedades global e local das frequências ressonantes e anti-ressonantes

A fim de verificar a propriedade de que as frequências ressonantes são características globais do sistema e que as frequências anti-ressonantes são características locais dos sistema, considera-se a viga da Figura 20.

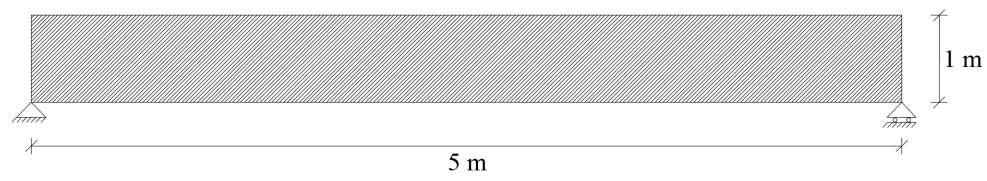

Figura 20 - Viga biapoiada.

Considerando uma modelação via métodos dos elementos finitos composta por três elementos, como mostra a Figura 21, o sistema terá 8 nós e 16 graus de liberdade no total, sendo que 13 destes são graus de liberdade livres.

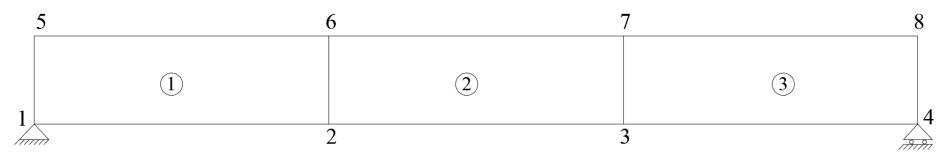

Figura 21 - Malha de 3 elementos finitos. 
Considera-se inicialmente que tanto a aplicação da excitação quanto a leitura da resposta se dará no grau de liberdade 12 (ou seja, $\alpha_{12,12}$ ), como mostra a Figura 22.

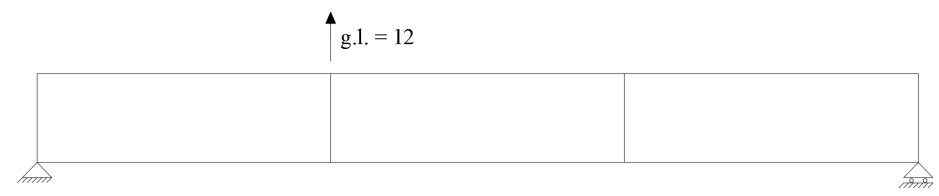

Figura 22 - Indicação do grau de liberdade 12.

A expressão para a determinação da receptância pode ser escrita, para cada frequência, como:

$$
\alpha_{12,12}(\omega)=\frac{\phi_{12,1}^{2}}{\omega_{1}^{2}-\omega^{2}}+\frac{\phi_{12,2}^{2}}{\omega_{2}^{2}-\omega^{2}}+\cdots+\frac{\phi_{12,13}^{2}}{\omega_{13}^{2}-\omega^{2}}
$$

O gráfico para a receptância $\alpha_{12,12}$ é mostrado na Figura 23 .

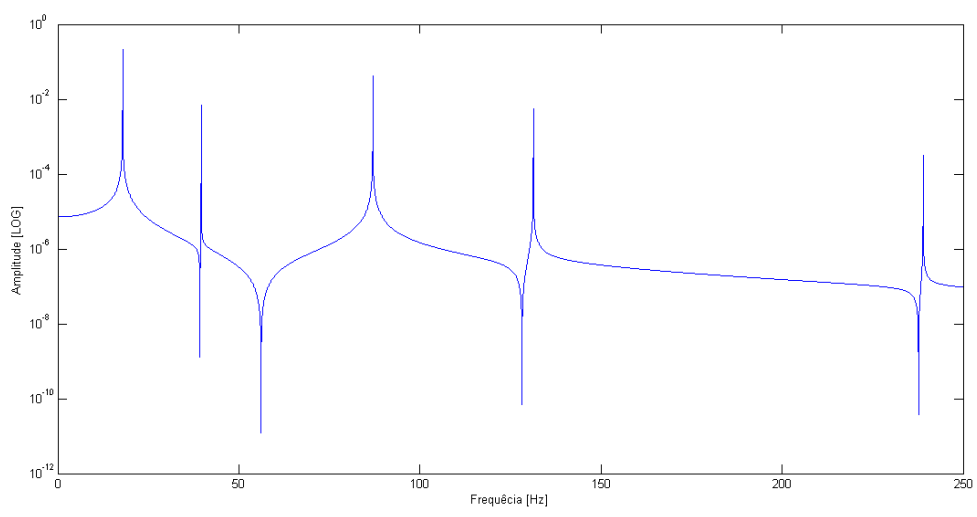

Figura 23 - FRF da receptância $\alpha_{12,12}$.

Em um segundo momento, faz-se o mesmo procedimento feito anteriormente, porém, agora, muda-se o grau de liberdade de aplicação da excitação e da leitura da resposta. Agora, adota-se o grau de liberdade 15, como mostra a Figura 24. 
g.1. $=15$

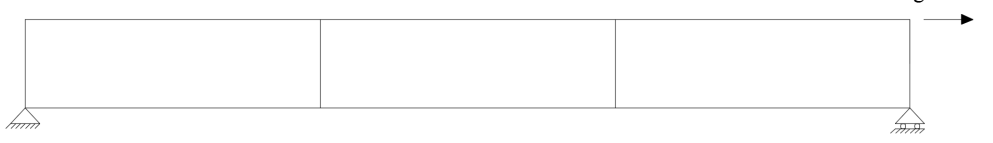

Figura 24 - Indicação do grau de liberdade 15.

A expressão para a determinação da receptância pode ser escrita, para cada frequência, como:

$$
\alpha_{15,15}(\omega)=\frac{\phi_{15,1}^{2}}{\omega_{1}^{2}-\omega^{2}}+\frac{\phi_{15,2}^{2}}{\omega_{2}^{2}-\omega^{2}}+\cdots+\frac{\phi_{15,13}^{2}}{\omega_{13}^{2}-\omega^{2}}
$$

O gráfico para a receptância $\alpha_{15,15}$ é mostrado na Figura 25 .

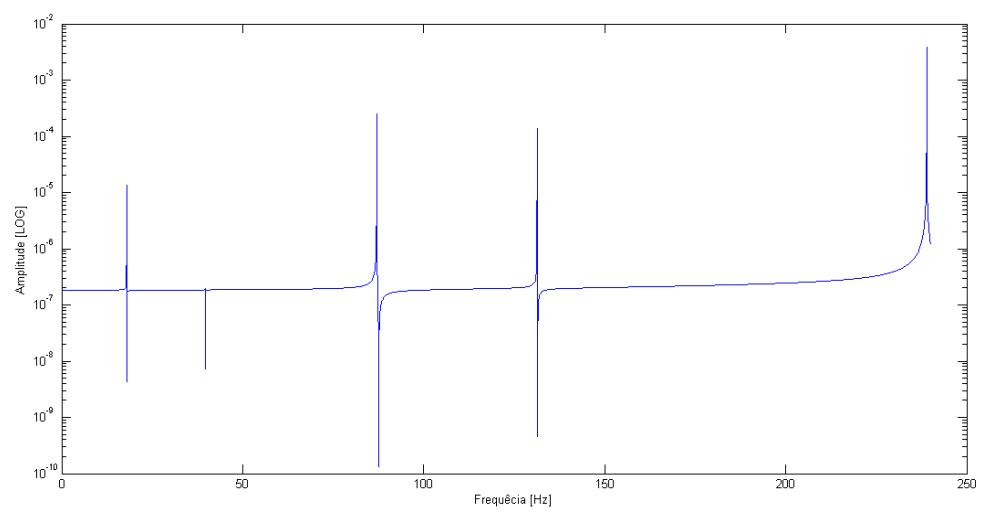

Figura 25 - FRF da receptância $\alpha_{15,15}$.

Os dados reunidos na tabela 1 podem confirmar o fato de que as ressonâncias são características globais do sistema, ou seja, seus valores independem do grau de liberdade de aplicação da excitação e da leitura da resposta. Tal fato não é observado para o caso das frequências antiressonantes, demonstrando que as mesmas são características locais do sistema. Este exemplo possui 13 graus de liberdade livres, logo, apresentará 13 frequências ressonantes; e como trata-se de uma receptância pontual apresentará 12 frequências anti-ressonantes. Porém, por simplificação, serão apresentadas apenas as 5 e 4 primeiras frequências ressonantes e anti-ressonantes, respectivamente. 


\begin{tabular}{cc|cc}
\hline \multicolumn{2}{c|}{$\alpha_{12,12}$} & \multicolumn{2}{c}{$\alpha_{15,15}$} \\
\hline$\omega_{r}$ & $\omega_{a}$ & $\omega_{r}$ & $\omega_{a}$ \\
17.905 & 39.245 & 17.905 & 17.926 \\
39.573 & 55.728 & 39.573 & 39.573 \\
86.993 & 128.056 & 86.993 & 87.570 \\
131.306 & 237.319 & 131.306 & 131.49 \\
238.941 & & 238.941 & \\
\hline
\end{tabular}

Tabela 1 - Comparação entre frequências das receptâncias $\alpha_{12,12}$ e $\alpha_{15,15}$ $(\mathrm{Hz})$

\subsection{Aquisição dos dados da estrutura danificada}

Uma questão a ser determinada na resolução do problema é os dados da estrutura alvo (danificada). Os mesmos devem ser obtidos via experimentação. No código desenvolvido foi considerado apenas a situação de receptância pontual, a qual consiste em excitar a estrutura e ler a resposta no mesmo ponto (ou muito próximo). Para tal, é necessário de uma fonte de excitação, que pode ser feita através de um excitador eletrodinâmico (Shaker) e de um leitor de resposta (acelerômetro, por exemplo). A excitação deve ser feita em uma faixa de frequências de interesse. A determinação das frequências ressonantes e anti-ressonantes pode ser feita analisando graficamente a resposta (exemplo da Figura 19). 


\section{Detecção de dano como um problema de otimização}

$\mathrm{Na}$ formulação via elementos finitos, as características da estrutura são definidas em termos de matrizes de rigidez $\mathbf{K}$, amortecimento $\mathbf{C}$ e massa M. Um eventual dano que possa estar presente na estrutura pode alterar essas matrizes e consequentemente a resposta da mesma, seja estática ou dinâmica, em termos, por exemplo, de deslocamentos, frequências naturais, modos de vibrar.

A detecção de dano consiste em, tendo algumas informações da estrutura real, conseguir detectar um eventual dano. Para realizar tal tarefa, diferentes estudos (item 1.2) já utilizaram diferentes conteúdos de informações da estrutura danificada. A situação ideal seria conseguir detectar o dano com uma precisão aceitável utilizando a menor quantidade de informações possíveis, ou então com aquelas de mais fácil acesso.

Os parâmetros modais têm sido os mais popularmente utilizados na detecção de dano. Eles tornaram-se populares porque a análise modal numérica ou experimental é relativamente fácil de realizar quando comparado com outros tipos de análise, e possuem uma alta precisão [12], [25].

A utilização apenas das frequências naturais pode não fornecer informações suficientes para uma detecção e localização correta do dano em uma estrutura, pois as frequências ressonantes não são muito sensíveis ao dano estrutural, a menos que este seja grave [11], [26].

Neste trabalho, a maneira utilizada para representar o dano é a mesma que foi utilizada para explicar os conceitos relacionados a Otimização Topológica (item 3.2.2), ou seja, através da relaxação de uma função discreta $(\rho=0$ ou $\rho=1)$ para uma função contínua $\left(\rho_{\text {min }} \leq \rho(x) \leq 1\right)$, permitindo que as variáveis de projeto assumam valores intermediários entre 0 e 1 .

A variável de projeto aqui é um multiplicador das propriedades de rigidez e massa da estrutura. Para isso, é utilizado a pseudo-densidade $\rho(x)$, já introduzida na metodologia SIMP. Desta forma, o problema torna-se encontrar as pseudo-densidades que minimizam a função objetivo.

Assim, a matriz de rigidez e a matriz de massa passam a ser escritas levando-se em conta a variável de projeto, como mostram as Equações 5.1 
e 5.2, para as matrizes de rigidez e massa, respectivamente:

$$
\begin{gathered}
\mathbf{K}=\sum_{i=1}^{N} \rho(x)_{i}^{p} \mathbf{K}_{e, i} \\
\mathbf{M}=\sum_{i=1}^{N} \rho(x)_{i}^{q} \mathbf{M}_{e, i},
\end{gathered}
$$

em que:

$N$ - número de elementos da malha;

M - matriz de massa global da estrutura;

K - matriz de rigidez global da estrutura;

$\rho(x)$ - pseudo densidade;

$\mathbf{M}_{e, i}$ - matriz de massa do i-ésimo elemento;

$\mathbf{K}_{e, i}$ - matriz de rigidez do i-ésimo elemento;

$p$ - coeficiente de penalização da pseudo-densidade para a matriz de rigidez;

$q$ - coeficiente de penalização da pseudo-densidade para a matriz de massa.

A pseudo-densidade é um valor que está dentro do intervalo $\left(\rho_{\min } \leq\right.$ $\rho(x) \leq 1$ ). No contexto da Otimização Topológica, o valor de $\rho(x)=0$ (ou $\rho_{\text {min }}$ ) significa ausência de material e para o caso de $\rho(x)=1$, significa a existência de material. Já para o contexto deste trabalho, em que trata-se da detecção de dano, o valor de $\rho(x)=0$ (ou $\rho_{\text {min }}$ ) significa elemento danificado e para o caso de $\rho(x)=1$ elemento intacto.

\subsection{Mapeamento da vizinhança}

A utilização do filtro de sensibilidades no método de otimização topológica requer um mapeamento da vizinhança de todos os elementos da malha. Esse procedimento, dependendo do número de elementos e do $r_{\text {min }}$ (item 3.3.4) utilizado, pode ser bastante caro computacionalmente. Uma metodologia interessante para melhorar essa situação é a retirada do mapeamento da vizinhança de dentro do loop de otimização. Fazendo-se esse preparo prévio, o mapeamento é executado apenas uma vez [27]. Desta forma, a aplicação do filtro de sensibilidades dentro do loop de otimização passa a se resumir em apenas uma multiplicação de matrizes, reduzindo o custo computacional consideravelmente.

O fluxograma da Figura 26 apresenta uma visão geral do código desenvolvido, em linguagem Matlab. 


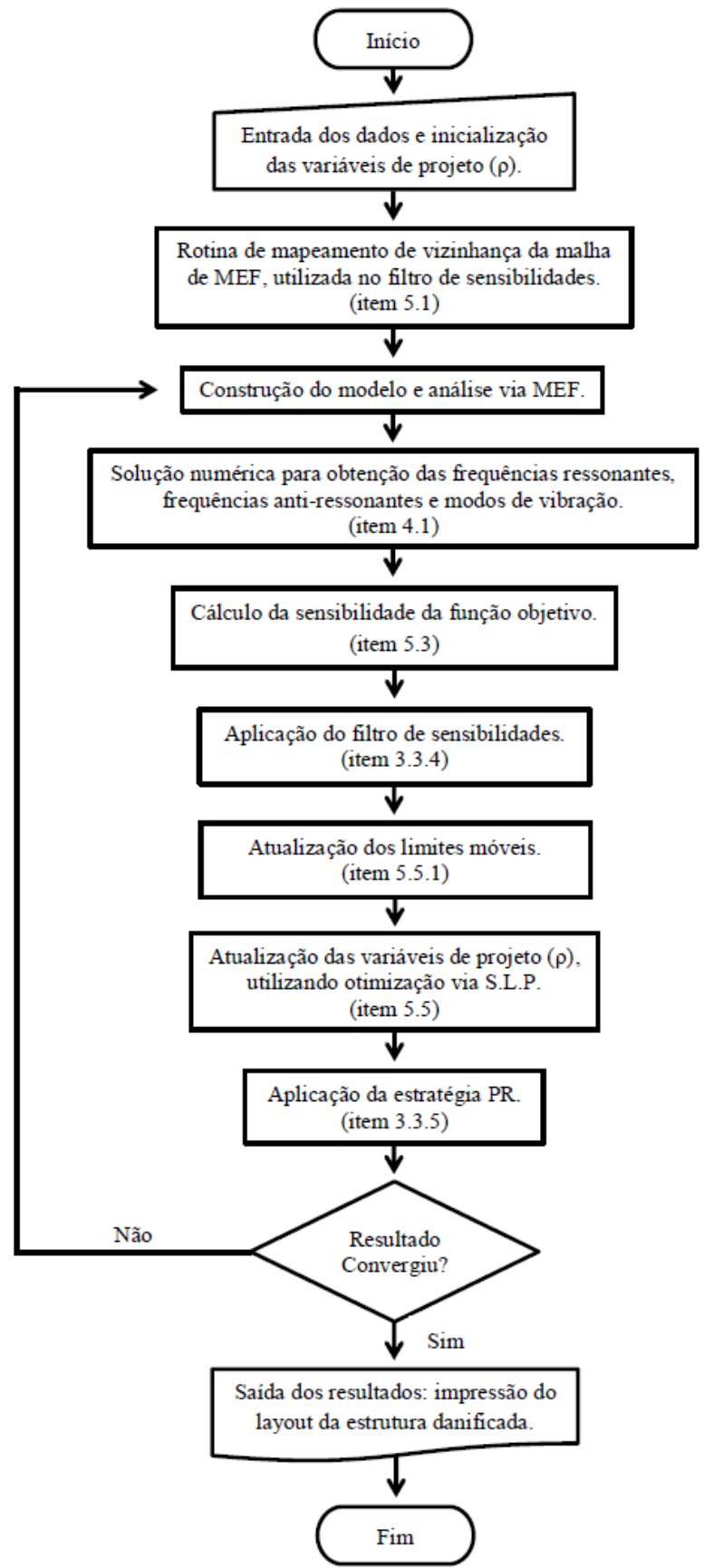

Figura 26 - Fluxograma geral do algoritmo para detecção de dano. 


\subsection{Formulação do problema}

Nishizu, Takezawa e Kitamura[13] escreveram o problema de detecção de dano utilizando apenas as informações modais de frequências ressonantes da estrutura. O problema fica como mostrado nas Equações 5.3:

$$
\operatorname{Minimizar} \mathbf{J}(\rho)
$$

$$
\text { Sujeito a: } 0<\rho_{i} \leq 1 \text {, para } \mathrm{i}=1, \ldots, \mathrm{n}
$$

onde $n$ é o número de elementos da malha de elementos finitos. A função objetivo $J(\rho)$ é formulada em função da diferença entre frequências da estrutura danificada e intacta, dada pela Equação 5.4:

$$
J(\rho)=\sum_{i=1}^{m 1} w_{r, i} \frac{\left(\lambda_{r, a l v o, i}-\lambda_{r, i}\right)^{2}}{\lambda_{r, a l v o, i}}
$$

onde:

$\lambda_{r, a l v o, i}=\omega_{a l v o, i}^{2}$ - quadrado da i-ésima frequência natural da estrutura danificada;

$\lambda_{r, i}=\omega_{i}^{2}$ - quadrado da i-ésima frequência natural da estrutura;

$m l$ - número de frequências naturais da estrutura danificada;

$w_{r, i}$ - fator de ponderação das frequências naturais.

Como já comentado, apenas as informações de frequências naturais muitas vezes não são suficientes para a detecção do dano em estruturas, a depender da severidade do mesmo. Por isso, o presente trabalho também mostra resultados obtidos utilizando na formulação, além das frequências ressonantes, informações contidas na FRF, neste caso, as frequências antiressonantes.

Desta forma, a função objetivo - Equação 5.4 - foi reescrita adicionandose na mesma uma parcela que se refere às informações das frequências anti-ressonantes, como mostra a Equação 5.5:

$$
J(\rho)=\sum_{i=1}^{m 1} w_{r, i} \frac{\left(\lambda_{r, a l v o, i}-\lambda_{r, i}\right)^{2}}{\left(\lambda_{r, a l v o, i}\right)^{2}}+\sum_{i=1}^{m 2} w_{a, i} \frac{\left(\lambda_{a, a l v o, i}-\lambda_{a, i}\right)^{2}}{\left(\lambda_{a, a l v o, i}\right)^{2}}
$$

em que:

$\lambda_{r, a l v o, i}=\omega_{a l v o, i}^{2}$ - quadrado da i-ésima frequência ressonante da estrutura 
danificada;

$\lambda_{a, a l v o, i}=\mu_{a l v o, i}^{2}$ - quadrado da i-ésima frequência anti-ressonante da estrutura danificada;

$\lambda_{r, i}=\omega_{i}^{2}$ - quadrado da i-ésima frequência ressonante da estrutura;

$\lambda_{a, i}=\mu_{i}^{2}$ - quadrado da i-ésima frequência anti-ressonante da estrutura;

$m 1$ - número de frequências ressonantes da estrutura danificada;

$m 2$ - número de frequências anti-ressonantes da estrutura danificada;

$w_{r, i}$ - fator de ponderação das frequências ressonantes;

$w_{a, i}$ - fator de ponderação das frequências anti-ressonantes.

\subsection{Cálculo de sensibilidades}

Os gradientes (ou derivadas) da função objetivo e restrições são chamados de sensibilidades do problema de otimização. A necessidade de linearização da função objetivo em relação às variáveis de projeto do problema se dá em função da metodologia utilizada na SLP. Diante disso, então, serão apresentadas as sensibilidades das funções objetivo mostradas anteriormente (item 5.2).

A sensibilidade da Equação 5.4 é dada por:

$$
\frac{\partial J(\rho)}{\partial \rho_{j}}=-2 \sum_{i=1}^{m} w_{i} \frac{\left(\lambda_{r, a l v o, i}-\lambda_{r, i}\right)}{\left(\lambda_{r, a l v o, i}\right)^{2}} \frac{\partial \lambda_{r, i}(\rho)}{\partial \rho_{j}}
$$

em que a sensibilidade da i-ésima frequência natural em relação a j-ésima variável de projeto é dada pela Equação 5.7 [13]:

$$
\frac{\partial \lambda_{r, i}(\rho)}{\partial \rho_{j}}=\Phi_{i}^{T}\left(\frac{\partial \mathbf{K}_{e}}{\partial \rho_{j}}-\lambda_{r, i} \frac{\partial \mathbf{M}_{e}}{\partial \rho_{j}}\right) \Phi_{i},
$$

em que:

$\Phi_{i}^{T}$ - modo de vibração da i-ésima frequência natural;

$\frac{\partial \mathbf{K}_{e}}{\partial \rho_{j}}$ - sensibilidade da matriz de rigidez, dada pela Equação 5.8:

$$
p \cdot \rho_{e}^{p-1} \cdot \mathbf{K}_{e}
$$

$\frac{\partial \mathbf{M}_{e}}{\partial \rho_{j}}$ - sensibilidade de massa, dada pela Equação 5.9:

$$
q \cdot \rho_{e}^{q-1} \cdot \mathbf{M}_{e}
$$


Já sensibilidade da Equação 5.5 é dada por:

$$
\begin{aligned}
\frac{\partial J(\rho)}{\partial \rho_{j}} & =-2 \sum_{i=1}^{m 1} w_{r, i} \frac{\left(\lambda_{r, a l v o, i}-\lambda_{r, i}\right)}{\left(\lambda_{r, a l v o, i}\right)^{2}} \frac{\partial \lambda_{r, i}(\rho)}{\partial \rho_{j}} \\
& -2 \sum_{i=1}^{m 2} w_{a, i} \frac{\left(\lambda_{a, a l v o, i}-\lambda_{a, i}\right)}{\left(\lambda_{a, a l v o, i}\right)^{2}} \frac{\partial \lambda_{a, i}(\rho)}{\partial \rho_{j}}
\end{aligned}
$$

em que $\frac{\partial \lambda_{r, i}(\rho)}{\partial \rho_{j}}$ e $\frac{\partial \lambda_{a, i}(\rho)}{\partial \rho_{j}}$ são calculadas como detalhado na Equação 5.7

A Figura 27 mostra o fluxograma para o cálculo da sensibilidade da função objetivo 5.5, que é dada pela expressão 5.10. Nessa equação, as variáveis $s \_a$ e $s \_r$ são utilizadas como auxiliar para acumular o somatório de 1 até $m 1$ e de 1 até $m 2$, respectivamente; $n f r$ é o número de frequências ressonantes da estrutura danificada da estrutura e $n f a$ é o número de frequências anti-ressonantes da estrutura danificada.

\subsection{Programação linear}

Segundo Arora[28], um problema de otimização em que a função custo e as restrições são lineares é chamado de problema de programação linear. Muitos problemas com essa característica surgem nos campos da engenharia, como engenharia de sistemas, gestão de recursos, etc. Uma função linear $f(x)$ com $n$ variáveis pode ser escrita da maneira como mostra a Equação 5.11:

$$
f(x)=c_{1} x_{1}+c_{2} x_{2}+\ldots+c_{n} x_{n}=\sum_{i=1}^{n} c_{i} x_{i}=\mathbf{c}^{T} \mathbf{x}
$$

onde $c_{i}, \mathrm{i}=1, \ldots, \mathrm{n}$ são as constantes.

As restrições lineares podem ser desigualdades ou igualdades (Equações 5.12):

$$
\begin{aligned}
& a_{i 1} y_{1}+\ldots+a_{i k} y_{k} \leq b_{i} \\
& a_{i 1} y_{1}+\ldots+a_{i k} y_{k}=b_{i} \\
& a_{i 1} y_{1}+\ldots+a_{i k} y_{k} \geq b_{i},
\end{aligned}
$$

onde $a_{i j}$ e $b_{i}$ são as constantes conhecidas. 


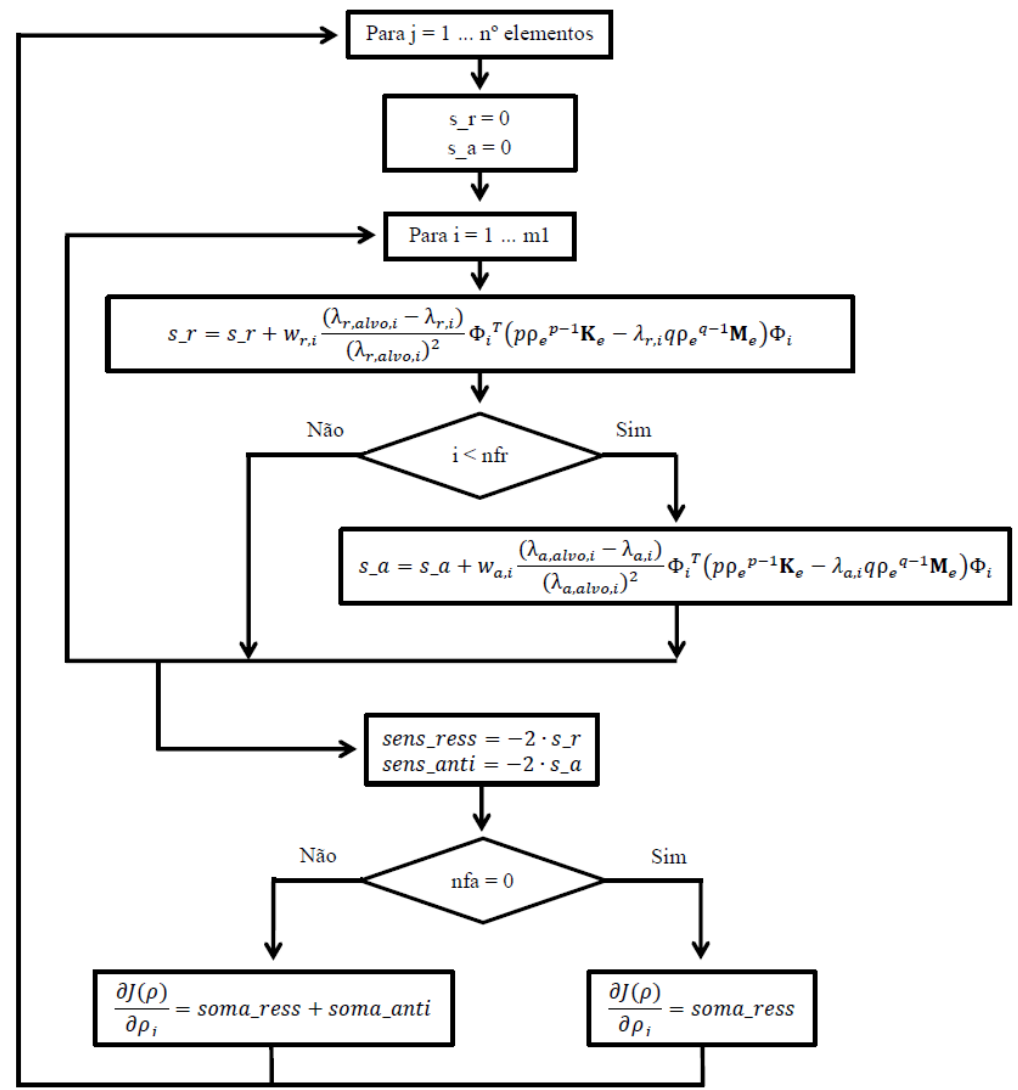

Figura 27 - Fluxograma para o cálculo da sensibilidade da função objetivo.

Um exemplo da forma padrão do problema de otimização linear é dado por [28]:

$\operatorname{Minimizar} f=\mathbf{c}^{T} \mathbf{x}$

Sujeito à: $A x=b$

$$
b \geq 0
$$

$$
x \geq 0
$$


onde $\mathbf{A}=a_{i j}$ é uma matriz de $m$ x $n$, com $m$ restrições, c e $\mathbf{x}$ são vetores de dimensão $n$ e b é um vetor de dimensão $m$. A matriz A pode ser composta por restrições de igualdade e desigualdade. Sendo que as restrições de desigualdades são transformadas em restrições de igualdade através da introdução de variáveis de folga [28].

\subsection{Programação linear sequêncial}

O método de programação linear é utilizado, como já visto anteriormente (item 5.4), para problemas em que as funções objetivo e restrições são lineares. Porém, a metodologia da LP também pode ser utilizada para resolver problemas em que estas funções não são lineares, isto é feito dividindo-se o problema não linear em subproblemas lineares, obtendo a solução após um número suficiente de iterações.

A linearização de um problema não linear é feita através de uma expansão em série de Taylor, utilizando apenas os termos de primeira ordem.

Considerando uma função $\mathrm{f}(\mathrm{x})$, a expansão em série de Taylor ao redor de um ponto $x^{*}$ é dada pela expressão:

$$
f(x)=f\left(x^{*}\right)+\nabla f^{T}\left(x-x^{*}\right),
$$

onde $x=\left(x_{1}, x_{2}, \ldots, x_{n}\right), x^{*}=\left(x_{1}^{*}, x_{2}^{*}, \ldots, x_{n}^{*}\right)$ e $\nabla f$ é o vetor gradiente.

Pelo fato de que o algoritmo resolve apenas problemas lineares, a série de Taylor é truncada após os termos lineares. Dessa forma, a informação referente a matriz Hessiana é desprezada.

Assim, o problema da Equação 5.13 é escrito fazendo-se expansões em série de Taylor tanto para a função objetivo, quanto para as funções de restrição, ficando:

$$
\begin{gathered}
\text { Minimizar } \\
f\left(x^{*}\right)+\sum_{i=1}^{n}\left(x_{i}-x_{i}^{*}\right)\left(\frac{\partial f}{\partial x_{i}}\right)_{x^{*}}
\end{gathered}
$$

Sujeito à:

$$
g(x)=g\left(x^{*}\right)+\sum_{i=1}^{n}\left(x_{i}-x_{i}^{*}\right)\left(\frac{\partial g}{\partial x_{i}}\right)_{x^{*}} \leq 0
$$




$$
\begin{gathered}
h(x)=h\left(x^{*}\right)+\sum_{i=1}^{n}\left(x_{i}-x_{i}^{*}\right)\left(\frac{\partial h}{\partial x_{i}}\right)_{x^{*}}=0 \\
a_{i}^{l} \leq x_{i}-x_{i}^{*} \leq a_{i}^{u},
\end{gathered}
$$

em que $n$ é o numero de variáveis de projeto. A última restrição refere-se aos limites móveis. Os mesmos são adicionados ao problema pelo fato da linearização em série de Taylor ser válida apenas na vizinhança de $x^{*}$. Esses limites móveis são muito importantes no método de resolução via SLP, sendo os mesmos atualizados a cada iteração do algoritmo (item 5.5.1).

\subsubsection{Atualização dos limites móveis}

Como mencionado anteriormente, na resolução via SLP é necessário atualizar os limites móveis a cada iteração. Se os valores dos mesmos forem muito pequenos, o custo computacional do processo para obter o ponto ótimo pode se tornar muito grande. Já para o caso em que os limites móveis forem muito grandes, pode-se perder o ponto ótimo.

Com relação aos valores dos limites móveis, algumas propostas de escolhas desses limites foram propostas, como por exemplo a proposta por Chen[29] que propõe que se considere as informações das derivadas das funções objetivo e restrições. Lamberti e Pappalettere[30] fizeram algumas propostas de mudança nos métodos propostos por Chen[29]. Wujek e Renauld[31] também utilizaram as informações das derivadas para propor atualizações dos limites móveis e apresentaram uma revisão acerca desse assunto.

Neste trabalho é utilizado uma atualização dos limites móveis baseada na história das iterações anteriores, aumentando ou reduzindo os valores dos limites móveis dependendo de como estão se comportando as variáveis de projeto. A atualização é realizada através de uma variável denominada lim que deve ser subtraída do valor da variável na iteração $i$, para o caso do limite inferior, e adicionado ao valor da variável na iteração $i$, para o caso do limite superior, como mostrado na Equação 5.16.

$$
\begin{array}{r}
a_{i}^{l}=\max \left(\rho_{e, i}-\lim _{e}, 0.00001\right) \rightarrow \text { limite inferior } \\
a_{i}^{u}=\min \left(\rho_{e, i}+\lim _{e}, 1\right) \rightarrow \text { limite superior }
\end{array}
$$


A variável lim é atualizada a cada iteração. Caso o sinal da diferença entre o valor da variável de projeto na iteração $i-2$ e $i-1$ for igual ao sinal da diferença entre os valores nas iterações $i-1$ e i, o valor da variável lim é aumentado multiplicando-se o mesmo por um coeficiente de aumento, denominado $m \_a$ (Equação 5.17.a). Caso a afirmação acima não seja confirmada, a variável limite é atualizada conforme demonstra a Equação 5.17.b, em que multiplica-se a mesma por um coeficiente denominado m_d:

$$
\begin{gathered}
\lim _{e}=\min \left(\lim _{e} \cdot m \_a, 0.01\right) \\
\lim _{e}=\max \left(\lim _{e} \cdot m \_d, 0.00001\right)
\end{gathered}
$$

A Figura 28 demonstra um fluxograma que esquematiza a atualização dos limites móveis descrita. Já a Figura 29 mostra uma expansão em série de Taylor para uma função com uma variável ao redor do ponto $d$, assim como os limites móveis $d_{i}^{\min }$ e $d_{i}^{\max }$ (Na Equação 5.16 denominados de $a_{i}^{l}$ e $\left.a_{i}^{u}\right)$.

Os valores dos limites móveis podem ser atualizados em diferentes iterações do algoritmo. Uma maneira, é alterar os valores dos limites conforme a suavidade da curva da função. Por exemplo, em curvas mais acentuadas pode-se diminuir os limites móveis, e em curvas mais suaves aumentá-los.

A Figura 30 mostra o fluxograma para a SLP, adaptado de Arora[28]:

\subsection{Adição de ruído nos parâmetros}

A presença de ruídos em medições afetam a capacidade de uma metodologia de detecção de dano em identificá-lo, pois oculta as mudanças na resposta da estrutura e leva a cenários de danos incorretos. Desta forma, quanto maior for a confiabilidade dos dados obtidos, mais confiável será a sua aplicação no contexto da detecção de dano [26].

Neste trabalho, a adição de ruídos foi feita como mostram as Equações 5.18, as quais efetuam perturbações nos valores das frequências ressonantes e anti-ressonantes da estrutura, que são utilizadas na formulação da função objetivo 5.5.

$$
\omega_{n r}=\omega_{n} \times\left(1+\mathrm{R}_{g} \times \gamma_{r}\right)
$$




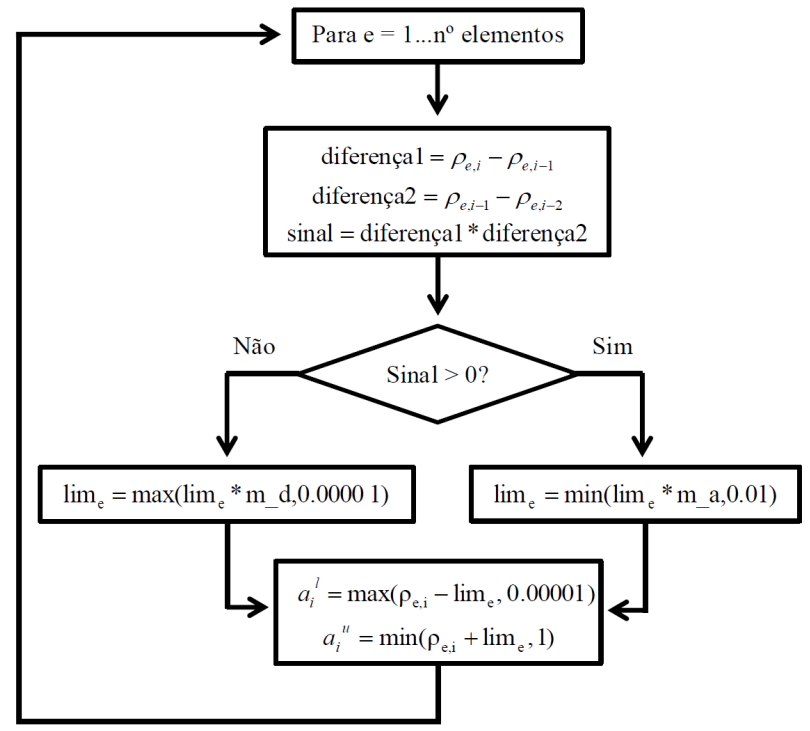

Figura 28 - Fluxograma de atualização dos limites móveis.

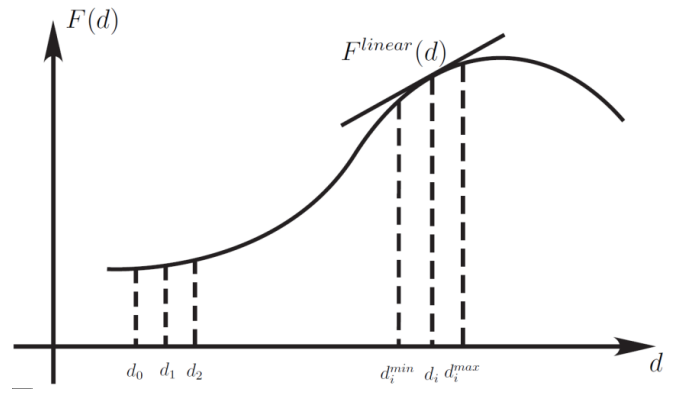

Figura 29 - Exemplos de limites móveis em uma curva.

Fonte: Kiyono[21] 


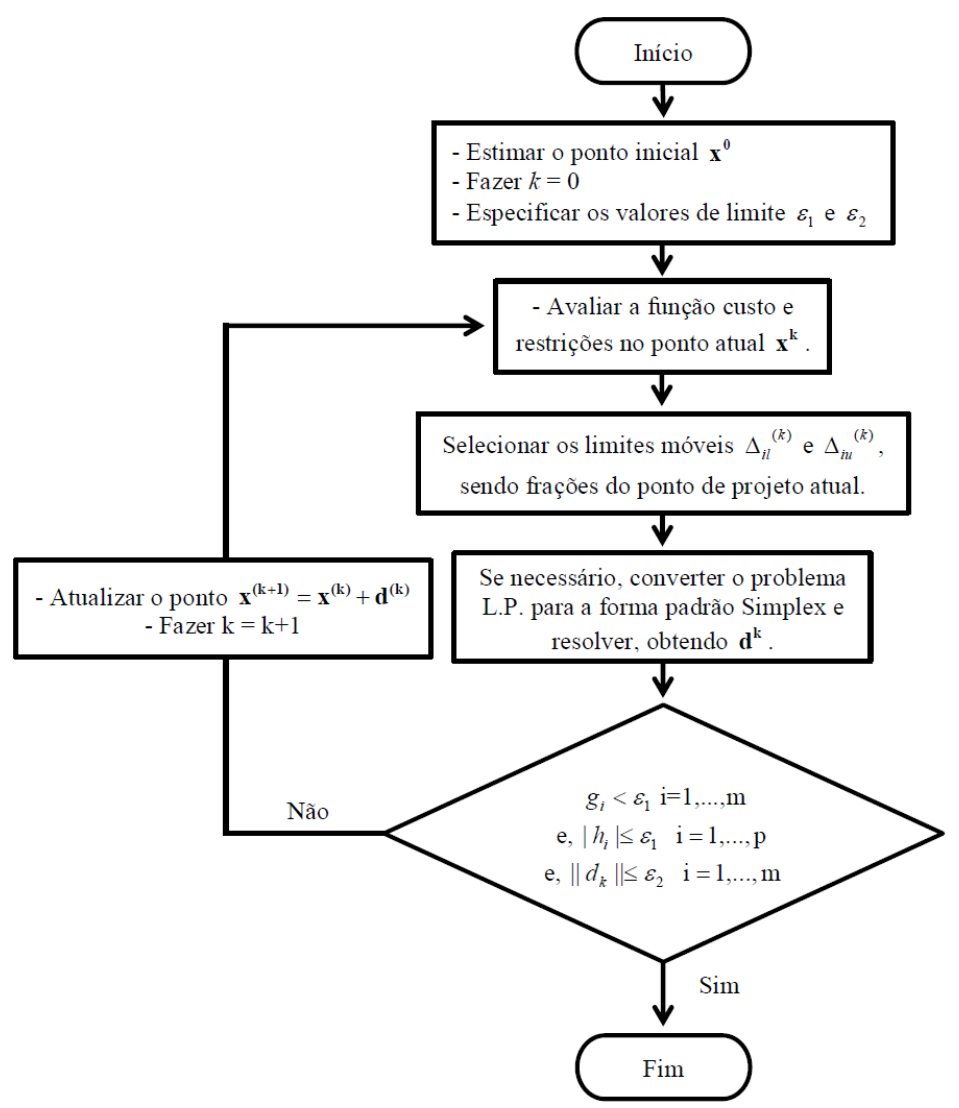

Figura 30 - Fluxograma da SLP.

Fonte: Arora[28]

$$
\mu_{n r}=\mu_{n} \times\left(1+\mathrm{R}_{g} \times \gamma_{a}\right),
$$

em que $\omega_{n r}$ e $\mu_{n r}$ são as frequências ressonantes e anti-ressonantes, respectivamente, contaminadas com ruído. Os parâmetros $\gamma_{r}$ e $\gamma_{a}$ são os níveis de perturbação do ruído para as frequências ressonantes e anti-ressonantes, respectivamente. $\mathrm{R}_{g}$ é um número aleatório que segue a distribuição de Gauss com média zero e desvio padrão igual a 1.

Neste trabalho foi utilizada a mesma metodologia adotada por Nhamage[6], em que assume-se a existência de uma série de dados das frequências ressonantes e anti-ressonantes. Assim, os valores finais dos 
parâmetros contaminados com ruído são obtidos pela média da série de dados considerados. Admitiu-se para cada frequência ressonante e antiressonante existir uma série de 100 dados. 



\section{Resultados}

Neste item são apresentados os resultados obtidos para a detecção de dano utilizando otimização topológica. Os códigos foram desenvolvidos em ambiente Matlab. Para os 4 exemplos mostrados, foi considerando módulo de elasticidade $E=21 \mathrm{e} 7 \mathrm{kN} / \mathrm{m}^{2}$, coeficiente de Poisson $\mathrm{v}=0.3 \mathrm{e}$ densidade do material $=78 \mathrm{kN} / \mathrm{m}^{3}$.

\subsection{Exemplo 1}

Este exemplo trata de uma viga bi-apoiada, com comprimento muito maior que sua altura. Neste caso, o modelamento da estrutura poderia ser feito com elementos finitos de barras (neste trabalho utilizou-se o elemento quadrilateral com 4 nós). O objetivo é verificar a capacidade do código desenvolvido em encontrar a presença de dano utilizando apenas as informações das primeiras frequências ressonantes. As dimensões da viga são de $6 \mathrm{~m}$ de comprimento x 0,2m de altura (Figura 31.a). A Figura 31.b mostra o refinamento de malha utilizado, o qual é composto por 15 elementos de dimensões $0,4 \mathrm{~m} \times 0,2 \mathrm{~m}$. Para o dano, foi considerado um cenário de dano de $20 \%$ no elemento 5 (Figura 31.c).

A presença de dano em estruturas pode alterar a resposta da mesma,

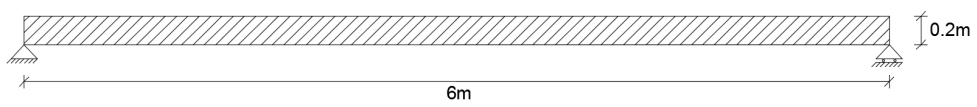

a)

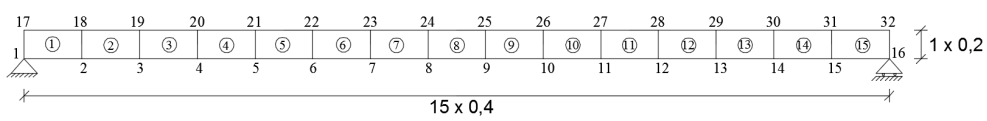

b)

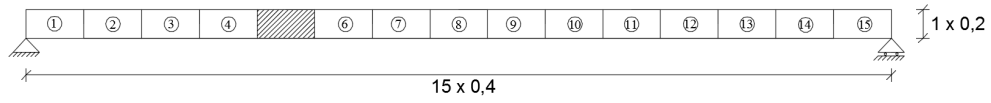

c)

Figura 31 - Exemplo 1: a) estrutura sem dano; b) discretização malha; c) estrutura danificada. 


\begin{tabular}{ccc}
\hline Sem dano & Com dano & Diferença (\%) \\
$\omega_{r}$ & $\omega_{r}$ & $\omega_{r}$ \\
\hline 6.7065 & 6.6939 & $-0,19$ \\
26.6983 & 26.6448 & $-0,20$ \\
56.4753 & 56.3562 & $-0,21$ \\
69.8195 & 69.4172 & $-0,58$ \\
111.7245 & 111.5579 & $-0,15$ \\
& Média & 0,26 \\
\hline
\end{tabular}

Tabela 2 - Frequências ressonantes da estrutura com e sem dano $(\mathrm{Hz})$.

\begin{tabular}{cc}
\hline Parâmetro & Valor utilizado \\
\hline raio (item 3.3.4) & 0,95 \\
$\mathrm{n}^{\mathrm{o}}$ ressonâncias (item 5.2) & 5 \\
$\mathrm{n}^{\mathrm{o}}$ anti-ressonâncias (item 5.2) & 0 \\
coeficiente $p$ (item 3.2.2) & 1 \\
coeficiente $q$ (item 3.2.2) & 1 \\
$\eta$ (item 3.3.5) & 0,98 \\
fator de ponderação $w_{r, i}$ (item 5.2) & 1 \\
fator de ponderação $w_{a, i}$ (item 5.2) & 1 \\
lim (item 5.5.1) & 0,0001 \\
$m \_a$ (item 5.5.1) & 1,001 \\
$m \_d$ (item 5.5.1) & 0,9 \\
\hline
\end{tabular}

Tabela 3 - Valores dos parâmetros utilizados na otimização.

seja esta estática ou dinâmica. A quantificação do dano em sistemas pode se dar, por exemplo, pela comparação dos valores das frequências ressonantes da estrutura com dano e sem dano. A Tabela 2 mostra estes valores, assim como a diferença percentual entre os mesmos. Verifica-se que a presença de dano alterou as frequências ressonantes, sendo que a maior variação ocorreu na quarta $(-0,58 \%)$. A média de variação foi de $0,26 \%$.

Outro parâmetro de reposta da estrutura que pode ser afetado pela presença de um dano são os modos de vibrar da estrutura. Na Figura 32, os modos de vibrar localizados na parte esquerda referem-se a estrutura sem dano, e os mostrados na parte direita os da estrutura com dano.

Os valores atribuídos aos diversos parâmetros para a otimização deste primeiro exemplo estão demonstrados na Tabela 3.

A Tabela 4 mostra a comparação dos resultados das frequências ressonantes e anti-ressonantes da estrutura danificada de modo teórico e os resultados obtidos após a otimização, assim como a diferença entre os 


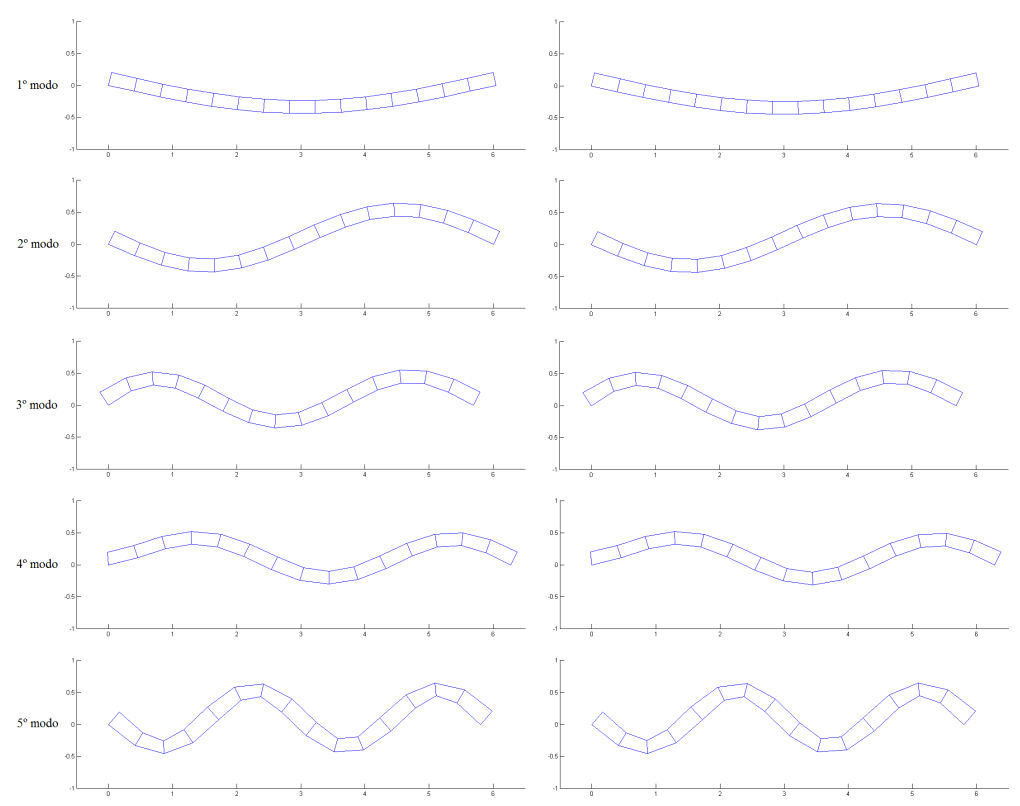

Figura 32 - Modos de vibração: estrutura intacta x estrutura danificada.

\begin{tabular}{ccc}
\hline Dano teórico & Dano encontrado & Diferença (\%) \\
$\omega_{r}$ & $\omega_{r}$ & $\omega_{r}$ \\
\hline 6.6939 & 6.6938 & 0,00 \\
26.6448 & 26.6447 & 0,00 \\
56.3562 & 56.3564 & 0,00 \\
69.4172 & 69.4172 & 0,00 \\
111.5579 & 111.558 & 0,00 \\
\hline
\end{tabular}

Tabela 4 - Resultado das frequências naturais com dano teórico e otimizadas.

valores.

A Figura 33 mostra o resultado impresso pelo programa quando não é considerado nenhum nível de ruído nos dados. Pode-se verificar que o elemento 5 apresenta uma característica cinza, correspondente ao dano simulado. Os resultados foram satisfatórios (Tabela 5), sendo o código, capaz de encontrar o dano de $20 \%$ no elemento 5.

A Tabela 5 mostra os valores das frequências ressonantes quando considerados diferentes níveis de ruído nos dados da segunda coluna da 
Figura 33 - Resultado da otimização.

\begin{tabular}{ccccc}
\hline $\mathbf{1 \%}$ & $\mathbf{2 \%}$ & $\mathbf{3 \%}$ & $\mathbf{4 \%}$ & $\mathbf{5 \%}$ \\
$\omega_{r}$ & $\omega_{r}$ & $\omega_{r}$ & $\omega_{r}$ & $\omega_{r}$ \\
\hline 6,695 & 6,696 & 6,698 & 6,699 & 6,700 \\
26,632 & 26,619 & 26,606 & 26,593 & 26,580 \\
56,344 & 56,332 & 56,330 & 56,307 & 56,295 \\
69,374 & 69,332 & 69,289 & 69,246 & 69,203 \\
111,541 & 111,524 & 111,506 & 111,489 & 111,472 \\
\hline
\end{tabular}

Tabela 5 - Frequências naturais da estrutura para diferentes níveis de ruído $(\mathrm{Hz})$.

\begin{tabular}{ccccccc}
\hline Elem. & S/ Ruído & $\mathbf{1 \%}$ & $\mathbf{2 \%}$ & $\mathbf{3 \%}$ & $\mathbf{4 \%}$ & $\mathbf{5 \%}$ \\
\hline 1 & 1 & 1 & 1 & 0,96 & 0,96 & 0,96 \\
2 & 1 & 1 & 1 & 1 & 0,98 & 0,97 \\
3 & 1 & 1 & 1 & 1 & 1 & 1 \\
4 & 1 & 1 & 1 & 1 & 1 & 1 \\
5 & 0,8 & 0,79 & 0,77 & 0,78 & 0,78 & 0,77 \\
6 & 1 & 1 & 1 & 1 & 1 & 1 \\
7 & 1 & 1 & 1 & 0,96 & 0,96 & 0,94 \\
8 & 1 & 1 & 0,98 & 1 & 0,95 & 0,95 \\
9 & 1 & 1 & 1 & 0,94 & 0,94 & 0,94 \\
10 & 1 & 1 & 1 & 0,94 & 0,92 & 0,9 \\
11 & 1 & 1 & 1 & 1 & 1 & 1 \\
12 & 1 & 1 & 1 & 1 & 1 & 1 \\
13 & 1 & 1 & 1 & 1 & 1 & 1 \\
14 & 1 & 1 & 1 & 1 & 1 & 1 \\
15 & 1 & 1 & 1 & 1 & 1 & 1 \\
\hline
\end{tabular}

Tabela 6 - Resultados da otimização das variáveis de projeto (densidades) para diferentes níveis de ruído.

Tabela 2.

A Tabela 6 mostra os valores para as densidades dos elementos após a otimização, quando são considerados os níveis de ruído indicados.

Pode-se observar que a precisão do método diminui conforme o nível de ruído aumenta. 


\subsection{Exemplo 2}

O segundo exemplo trata de uma viga com dimensões de $5 \mathrm{~m}$ de comprimento e $1 \mathrm{~m}$ de altura. As vinculações tem característica de não simetria, sendo apoios de segundo gênero na face esquerda e livre na extremidade direita, como mostra a Figura 34.a. A Figura 34.b mostra a viga com um dano na parte superior central da viga, com dimensões de $0,375 \mathrm{~m}$ por $0,1875 \mathrm{~m}$. A área deste dano é $0,070 \mathrm{~m}^{2}$, que corresponde a $1,41 \%$ da área da viga.

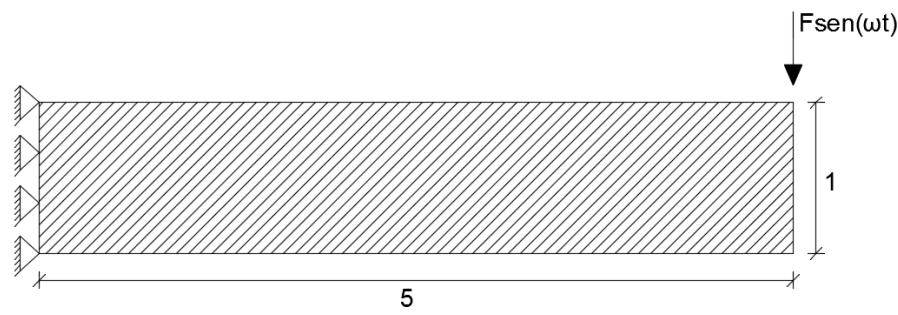

a)

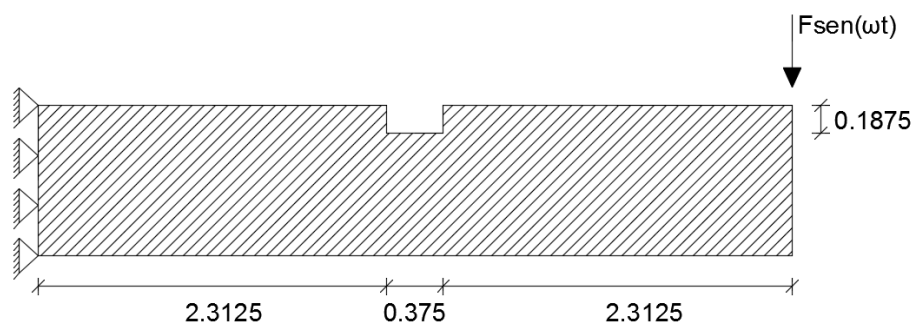

b)

Figura 34 - Exemplo 2: a) estrutura sem dano; b) estrutura com dano.

O refinamento da malha foi feito com elementos quadrilaterais de quatro nós. Sendo a dimensão horizontal composta por 80 divisões e a dimensão vertical composta por 16 divisões, resultando em um total de 1280 elementos quadrados de $0,0625 \mathrm{~m} \times 0,0625 \mathrm{~m}$. A malha de elementos finitos é mostrada na Figura 35.

O gráfico da FRF da receptância para este exemplo é mostrada na Figura 36. O ponto escolhido para a leitura dos deslocamentos é o mesmo ponto de aplicação da excitação, o que caracteriza a receptância pontual (item 4.4).

A Tabela 7 mostra os valores das frequências ressonantes $\left(\omega_{r}\right)$ e 


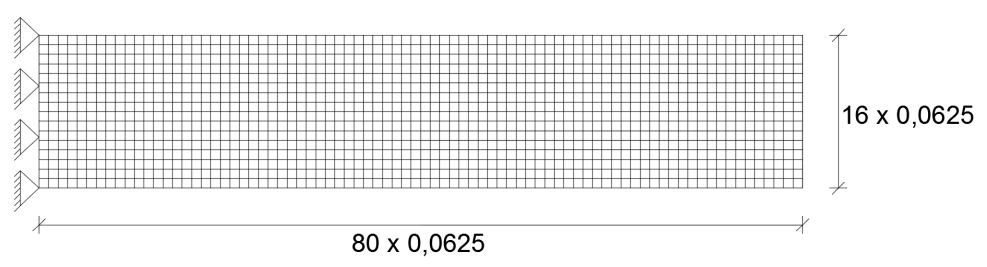

Figura 35 - Malha de elementos finitos do exemplo 2.

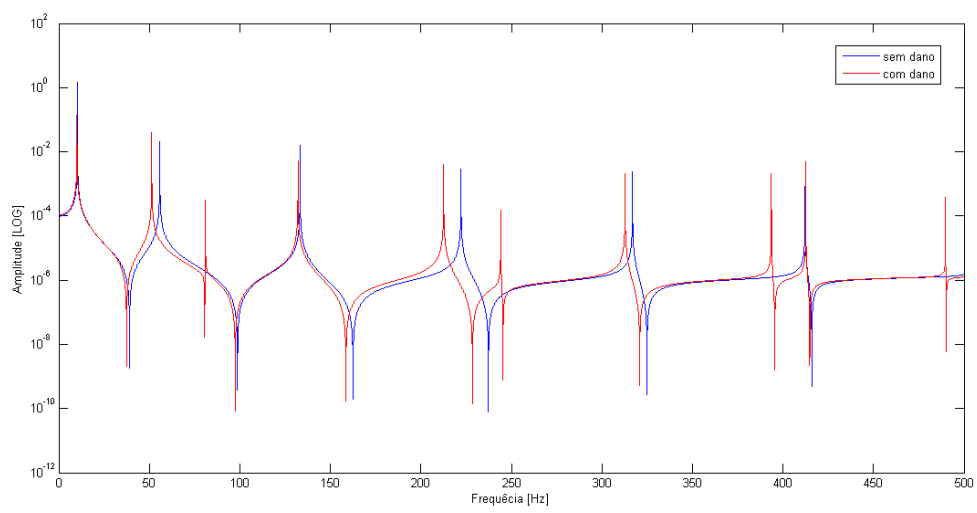

Figura 36 - FRF - receptância do exemplo 2.

anti-ressonantes $\left(\omega_{a}\right)$ da estrutura sem dano e da estrutura com dano, assim como a diferença percentual entre os mesmos. Pode-se verificar que a presença de dano alterou as características dinâmicas da estrutura. Observase que as maiores variações foram: $-7,94 \%$ para a segunda frequência ressonante e $-4,16 \%$ para a primeira frequência anti-ressonante. A média da variação das frequências ressonantes foi de 3,0\% e para as frequências anti-ressonantes foi de $2,7 \%$.

Outro parâmetro de reposta da estrutura que pode ser afetado pela presença de um dano são os modos de vibrar da estrutura. Na Figura 37, os modos de vibrar localizados na parte esquerda referem-se a estrutura sem dano, e os mostrados na parte direita os da estrutura com dano.

Os valores atribuídos aos diversos parâmetros para a otimização deste exemplo estão demonstrados na Tabela 8.

A Tabela 9 mostra a comparação dos resultados das frequências ressonantes e anti-ressonantes da estrutura danificada de modo teórico e os resultados obtidos após a otimização, assim como a diferença entre os 


\begin{tabular}{cc|cc|cc}
\hline \multicolumn{2}{c|}{ Sem dano } & \multicolumn{2}{c|}{ Com dano } & \multicolumn{2}{c}{ Dif. (\%) } \\
$\omega_{r}$ & $\omega_{a}$ & $\omega_{r}$ & $\omega_{a}$ & $\omega_{r}$ & $\omega_{a}$ \\
\hline 10,320 & 39,062 & 10,054 & 37,438 & $-2,58$ & $-4,16$ \\
55,776 & 82,224 & 51,348 & 80,605 & $-7,94$ & $-1,97$ \\
82,224 & 98,682 & 80,998 & 97,424 & $-1,49$ & $-1,27$ \\
133,278 & 162,436 & 132,135 & 158,534 & $-0,86$ & $-2,40$ \\
222,135 & 237,237 & 212,584 & 228,425 & $-4,30$ & $-3,71$ \\
245,971 & & 244,136 & & $-0,75$ & \\
& & & Média & 3,0 & 2,7 \\
\hline
\end{tabular}

Tabela 7 - Frequências ressonantes e anti-ressonantes da estrutura com e sem dano $(\mathrm{Hz})$.

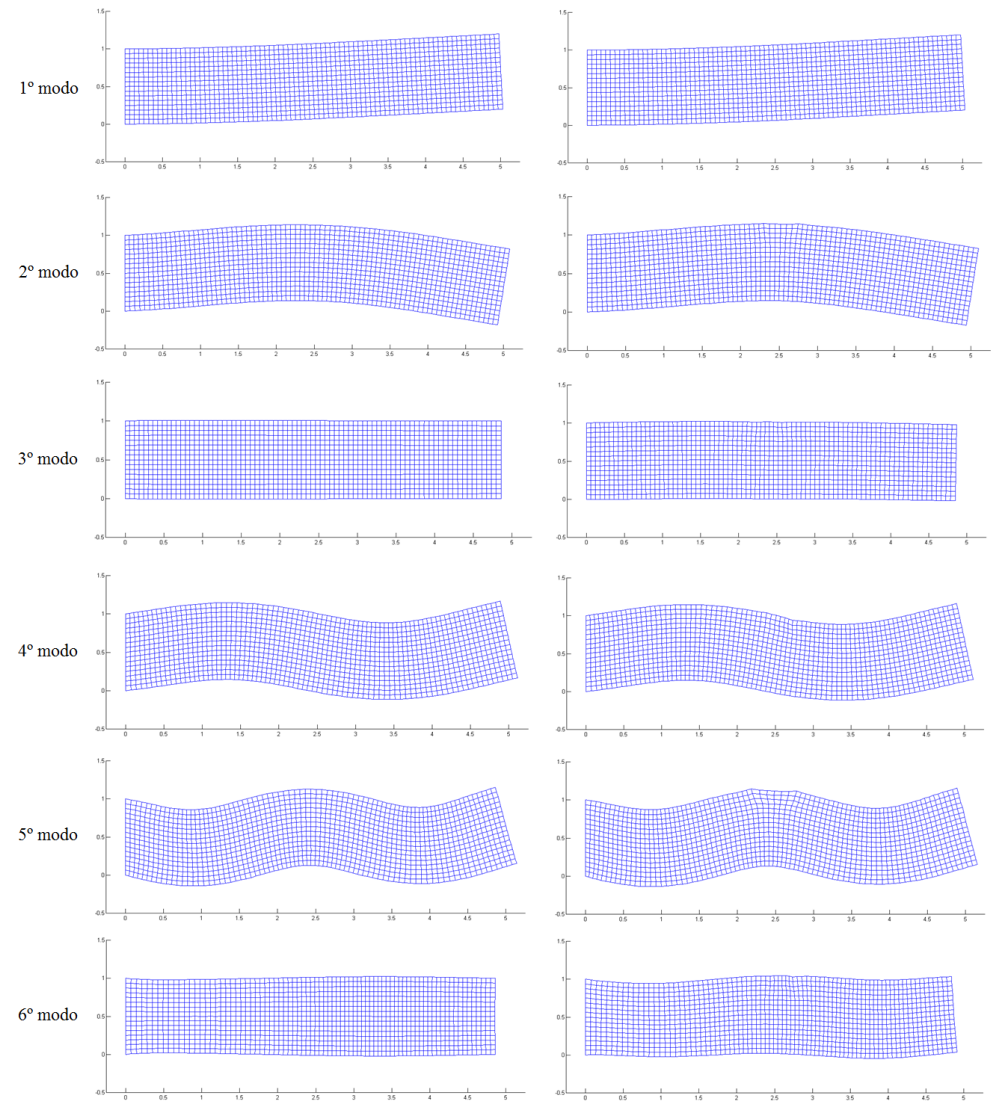

Figura 37 - Modos de vibração: estrutura intacta x estrutura danificada. 


\begin{tabular}{cc}
\hline Parâmetro & Valor utilizado \\
\hline raio (item 3.3.4) & 0,28 \\
$\mathrm{n}^{\mathrm{o}}$ ressonâncias (item 5.2) & 6 \\
$\mathrm{n}^{\mathrm{o}}$ anti-ressonâncias (item 5.2) & 5 \\
coeficiente $p$ (item 3.2.2) & 1 \\
coeficiente $q$ (item 3.2.2) & 1 \\
$\eta$ (item 3.3.5) & 0,7 \\
fator de ponderação $w_{r, i}$ (item 5.2) & 1 \\
fator de ponderação $w_{a, i}$ (item 5.2) & 1 \\
lim (item 5.5.1) & 0,001 \\
$m \_a$ (item 5.5.1) & 1,01 \\
$m \_d$ (item 5.5.1) & 0,9 \\
\hline
\end{tabular}

Tabela 8 - Valores dos parâmetros utilizados na otimização.

\begin{tabular}{cc|cc|cc}
\hline \multicolumn{2}{c|}{ Dano teórico } & \multicolumn{2}{c|}{ Dano otimizado } & \multicolumn{2}{c}{ Dif. (\%) } \\
$\omega_{r}$ & $\omega_{a}$ & $\omega_{r}$ & $\omega_{a}$ & $\omega_{r}$ & $\omega_{a}$ \\
\hline 10,054 & 37,438 & 10,054 & 37,450 & 0,01 & 0,03 \\
51,348 & 80,605 & 51,372 & 80,612 & 0,05 & 0,01 \\
80,998 & 97,424 & 81,003 & 97,423 & 0,01 & 0,00 \\
132,135 & 158,534 & 132,161 & 158,581 & 0,02 & 0,03 \\
212,584 & 228,425 & 212,594 & 228,422 & 0,00 & 0,00 \\
244,136 & & 244,147 & & 0,00 & \\
\hline
\end{tabular}

Tabela 9 - Resultado da otimização.

valores. Pode-se verificar que as diferenças entre os resultados teóricos e aqueles encontrados pelo código foram muito pequenas.

O histórico da função objetivo é mostrado na Figura 38. Como se pode observar, na iteração 500 ocorre um salto no histórico da função objetivo. Tal fato ocorre devido a aplicação da estratégia PR (item 3.3.5).

A variação dos resultados para diferentes iterações está mostrada na Figura 39. Nota-se, através da Figura 39.d, que com 1200 iterações obtevese um resultado satisfatório quando do objetivo de detectar a posição e geometria do dano. Porém, com 300 iterações (Figura 39.a) já é possível se ter uma ideia da localização do dano.

Para avaliar a influência do filtro de sensibilidades (item 3.3.4), este exemplo foi avaliado com os mesmos parâmetros (Tabela 8), porém com o filtro de sensibilidades desabilitado. O resultado obtido após 1200 iterações pode se verificar na Figura 40. É possível verificar através da mesma que o filtro de sensibilidades se mostra muito importante para a correta detecção 


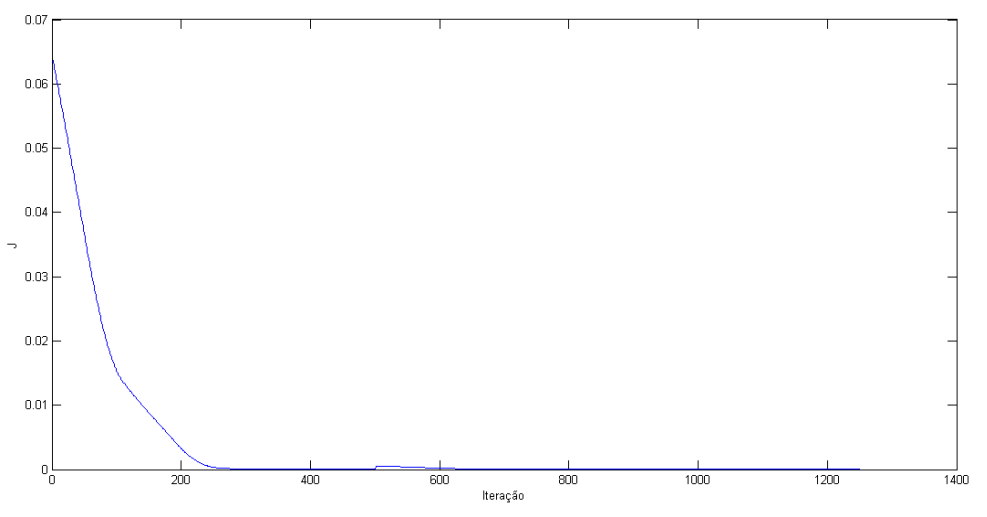

Figura 38 - Histórico da função objetivo do exemplo 2.

a)

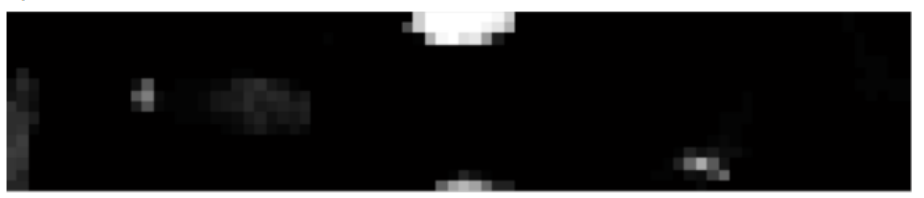

b)

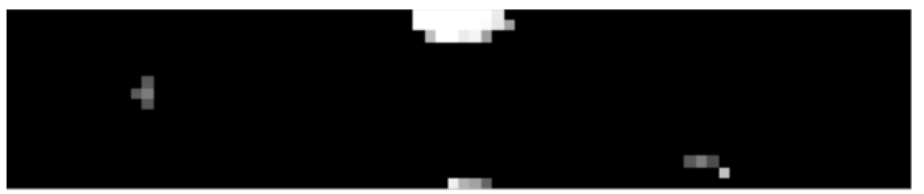

c)

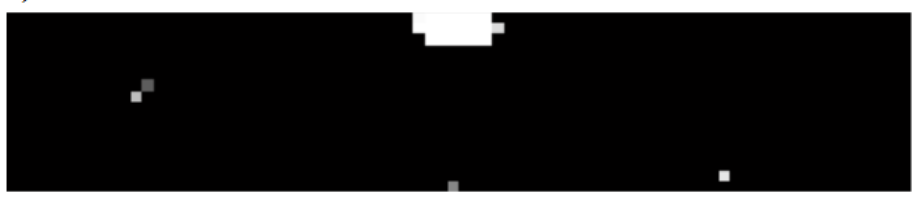

d)

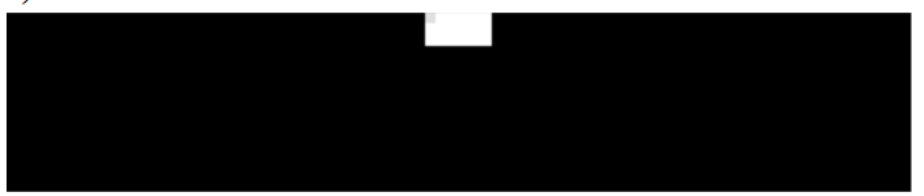

Figura 39 - Resultado da otimização. Número de iterações: a) 300; b) 600; c) 900 e d) 1200 . 


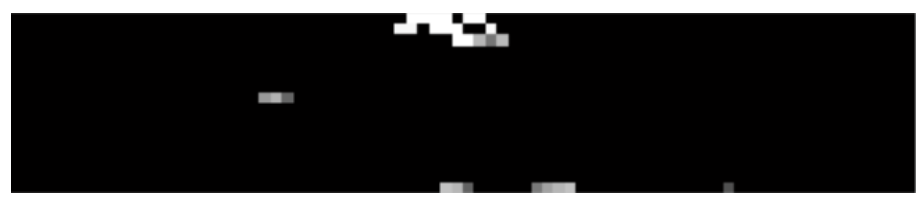

Figura 40 - Exemplo 2 com filtro de sensibilidades desabilitado.

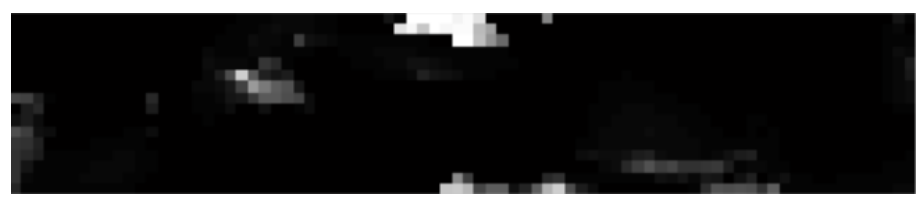

Figura 41 - Exemplo 2 com a estratégia PR desabilitada.

do dano.

Com a finalidade de avaliar a influência da utilização da estratégia PR (item 3.3.5), avaliou-se este exemplo com os mesmos valores para as variáveis de entrada (Tabela 8), porém, desabilitando a rotina da estratégia PR. O resultado pode ser visualizado na Figura 41. Observa-se que a utilização da estratégia PR traz grandes benefícios para o resultado final da detecção do dano nas estruturas.

Afim de avaliar a influência das informações das frequências antiressonantes, o mesmo exemplo foi avaliado utilizando-se apenas as informações das frequências ressonantes. Os resultados podem ser avaliados na Figura 42. Todos esses resultados ocorreram com 1200 iterações. Observase que ao utilizar apenas as informações de frequências ressonantes, não foi possível realizar a identificação do dano.

Para avaliar a influência da presença de ruído nos dados utilizados na detecção do dano, foi aplicada a metodologia detalhada no item 5.6. Adotou-se perturbações de $\gamma_{r}=\gamma_{a}=1 \%$ e $\gamma_{r}=\gamma_{a}=2 \%$. As frequências perturbadas pela presença de ruído estão detalhadas na Tabela 10.

A Figura 43 mostra os resultados obtidos quando considerados os ruídos mostrados na Tabela 10. Pode-se observar que os resultados foram afetados pela presença de ruído, porém, ainda sendo possível uma identificação da posição do dano. 
a)

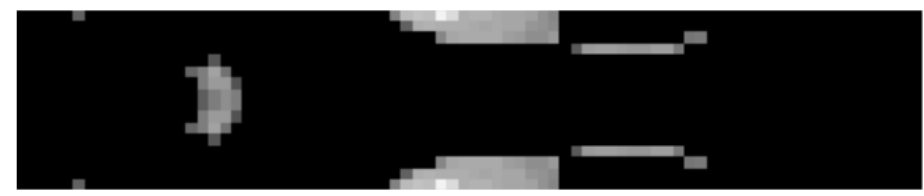

b)

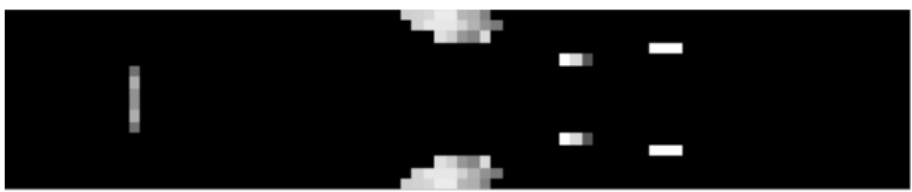

c)

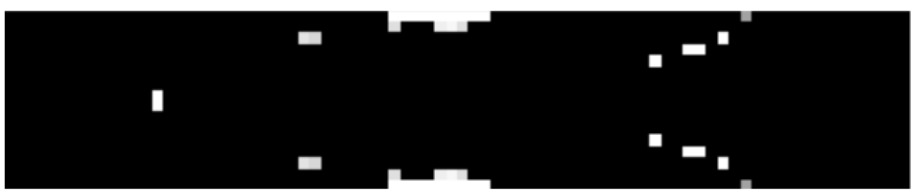

d)

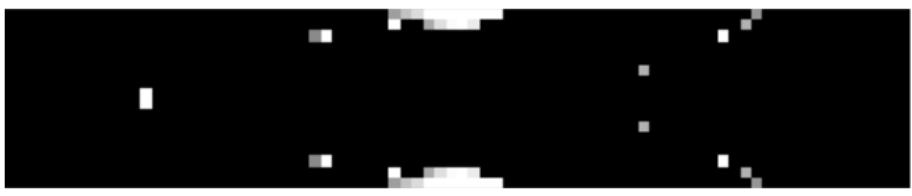

e)

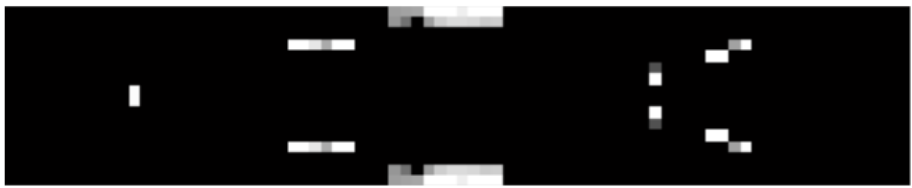

f)

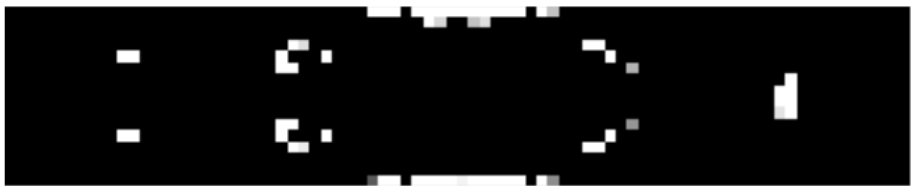

g)

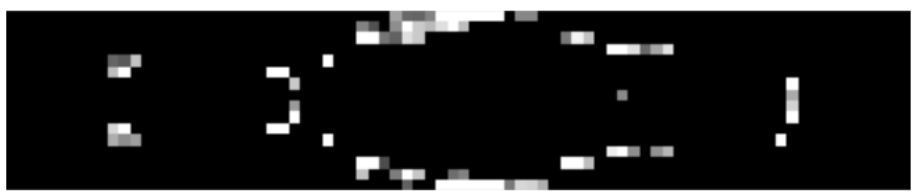

Figura 42 - Resultado da otimização. Número de frequências ressonantes utilizadas: a) 4; b) 5; c) 6; d) 7; e) 8; f) 9 e g) 10 . 


\begin{tabular}{cc|cc}
\hline \multicolumn{2}{c|}{ Ruído 1\% } & \multicolumn{2}{c}{ Ruído 2\% } \\
$\omega_{r}$ & $\omega_{a}$ & $\omega_{r}$ & $\omega_{a}$ \\
\hline 10,056 & 37,421 & 10,059 & 37,440 \\
51,339 & 80,587 & 51,349 & 80,499 \\
80,973 & 97,492 & 81,070 & 97,272 \\
132,071 & 158,529 & 131,964 & 158,662 \\
212,589 & 228,262 & 212,460 & 228,253 \\
244,331 & & 243,414 & \\
\hline
\end{tabular}

Tabela 10 - Frequências da estrutura com dano e perturbadas com ruído $(\mathrm{Hz})$.

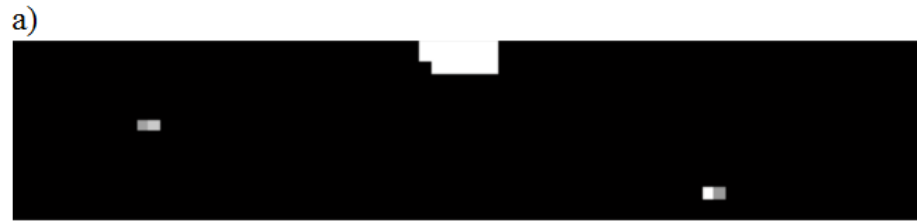

b)

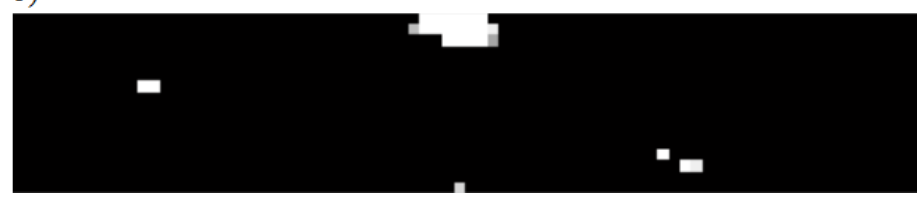

Figura 43 - Exemplo 2 com a adição de ruído de: a) $1 \%$; b) $2 \%$.

\subsection{Exemplo 3}

Este exemplo trata de uma viga com dimensões de $5 \mathrm{~m}$ de comprimento e $1 \mathrm{~m}$ de altura. As vinculações são caracterizadas por não possuir simetria, sendo compostas por um apoio de segundo gênero na extremidade inferior esquerda, e apoios horizontais na face direita da estrutura, como mostra a Figura 44.a. A Figura 44.b mostra a viga com um dano na parte inferior central da viga, o qual possui as mesmas dimensões do dano do exemplo 2 (item 6.2).

A malha de elementos finitos é mostrada na Figura 45.

O gráfico da FRF da receptância pontual para este exemplo é mostrada na Figura 46.

A Tabela 11 mostra os valores das frequências ressonantes $\left(\omega_{r}\right)$ e anti-ressonantes $\left(\omega_{a}\right)$ da estrutura sem dano e com dano teórico, assim como a diferença percentual entre os mesmos. As frequências que so- 


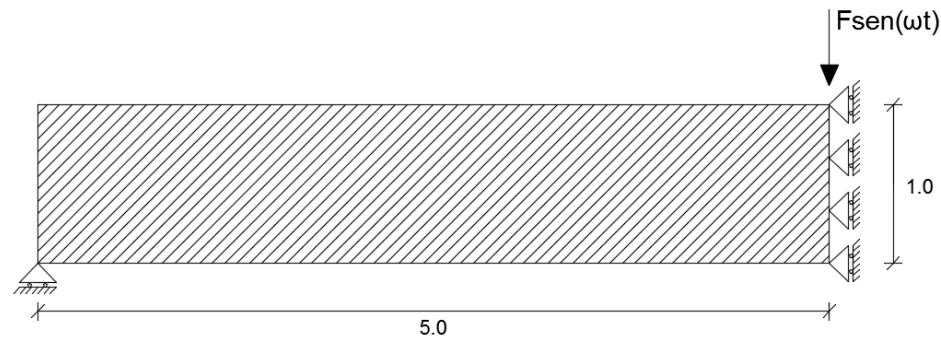

a)

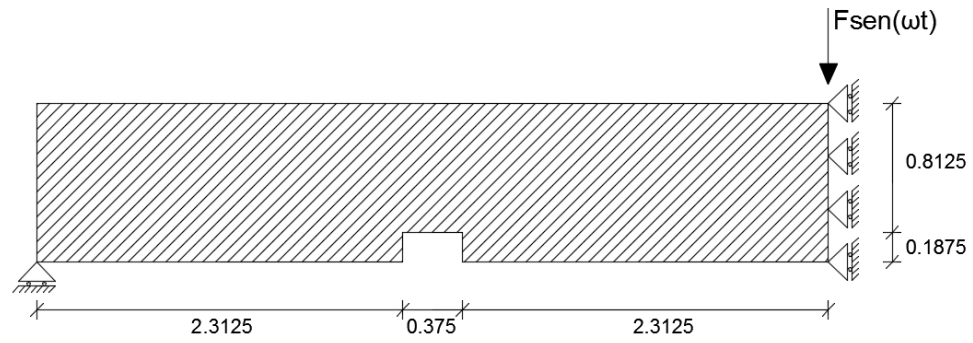

b)

Figura 44 - Exemplo 3: a) estrutura sem dano; b) estrutura com dano.

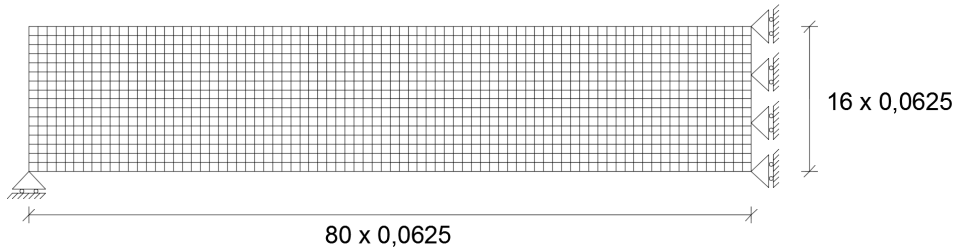

Figura 45 - Malha de elementos finitos do exemplo 3. 


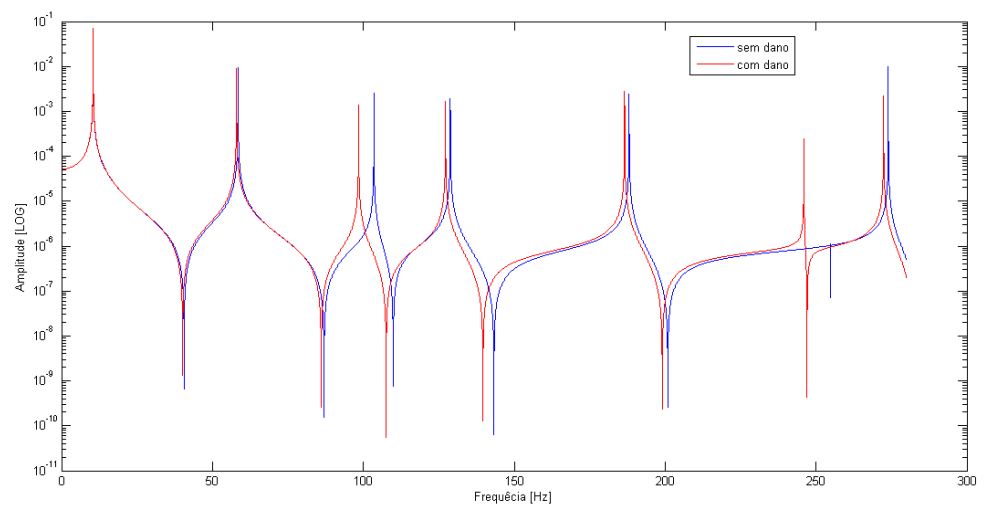

Figura 46 - FRF - receptância do exemplo 3.

\begin{tabular}{cc|cc|cc}
\hline \multicolumn{2}{c|}{ Sem dano } & \multicolumn{2}{c|}{ Com dano } & \multicolumn{2}{c}{ Dif. (\%) } \\
$\omega_{r}$ & $\omega_{a}$ & $\omega_{r}$ & $\omega_{a}$ & $\omega_{r}$ & $\omega_{a}$ \\
\hline 10,465 & 40,606 & 10,484 & 40,113 & 0,18 & $-1,21$ \\
58,506 & 86,962 & 58,004 & 86,033 & $-0,86$ & $-1,07$ \\
103,508 & 109,913 & 98,434 & 107,546 & $-4,9$ & $-2,15$ \\
128,825 & 143,261 & 127,234 & 139,624 & $-1,23$ & $-2,54$ \\
188,076 & 200,888 & 186,587 & 199,049 & $-0,79$ & $-0,92$ \\
254,839 & 254,840 & 245,984 & 247,029 & $-3,47$ & $-3,07$ \\
273,961 & & 272,417 & & $-0,56$ & \\
& & & Média & 1,72 & 1,83 \\
\hline
\end{tabular}

Tabela 11 - Frequências ressonantes e anti-ressonantes da estrutura com e sem dano $(\mathrm{Hz})$.

freram as maiores variações foram a terceira $(-4,9 \%)$ para a frequência ressonante e a sexta $(-3,07 \%)$ para a frequência anti-ressonante. As médias das varições foram de $1,72 \%$ e $1,83 \%$, para as frequências ressonantes e anti-ressonantes, respectivamente.

Os valores atribuídos aos diversos parâmetros para a otimização deste exemplo estão demonstrados na Tabela 12.

A Tabela 13 mostra a comparação dos resultados das frequências ressonantes e anti-ressonantes da estrutura danificada de modo teórico e os resultados obtidos após a otimização, assim como a diferença entre os valores.

A variação dos resultados para diferentes iterações está mostrada na Figura 47. Como se observa (Figura 47.e), com 1000 iterações obteve- 


\begin{tabular}{cc}
\hline Parâmetro & Valor utilizado \\
\hline raio(item 3.3.4) & 0,28 \\
$\mathrm{n}^{\mathrm{o}}$ ressonâncias(item 5.2) & 7 \\
$\mathrm{n}^{\mathrm{o}}$ anti-ressonâncias(item 5.2) & 6 \\
coeficiente $p$ (item 3.2.2) & 1 \\
coeficiente $q$ (item 3.2.2) & 1 \\
$\eta($ item 3.3.5) & 0,7 \\
fator de ponderação $w_{r, i}$ (item 5.2) & 1 \\
fator de ponderação $w_{a, i}$ (item 5.2) & 1 \\
lim (item 5.5.1) & 0,0001 \\
$m \_a$ (item 5.5.1) & 1,01 \\
$m \_d$ (item 5.5.1) & 0,9 \\
\hline
\end{tabular}

Tabela 12 - Valores dos parâmetros utilizados na otimização.

\begin{tabular}{cc|cc|cc}
\hline \multicolumn{2}{c|}{ Com dano teórico } & \multicolumn{2}{c|}{ Dano otimizado } & \multicolumn{2}{c}{ Dif. (\%) } \\
$\omega_{r}$ & $\omega_{a}$ & $\omega_{r}$ & $\omega_{a}$ & $\omega_{r}$ & $\omega_{a}$ \\
\hline 10,484 & 40,113 & 10,487 & 40,101 & 0,03 & $-0,03$ \\
58,004 & 86,033 & 57,995 & 86,071 & $-0,02$ & 0,04 \\
98,434 & 107,546 & 98,417 & 107,526 & $-0,02$ & $-0,02$ \\
127,234 & 139,624 & 127,172 & 139,657 & $-0,05$ & 0,02 \\
186,587 & 199,049 & 186,480 & 198,978 & $-0,06$ & $-0,04$ \\
245,984 & 247,029 & 246,028 & 247,056 & 0,02 & 0,01 \\
272,417 & & 272,358 & & $-0,02$ & \\
\hline
\end{tabular}

Tabela 13 - Resultado da otimização.

se um resultado satisfatório quando do objetivo de detectar a posição e geometria do dano. Porém, avalia-se que com 600 iterações (Figura 47.c) já é possível ter uma ideia da localização do dano.

A Tabela 14 reescreve os valores de frequências da terceira e quarta coluna da Tabela 11, porém, com a adição de perturbações nos dados.

A Figura 48 mostra o resultado obtido quando considerado o ruído mostrado na Tabela 14. Pode-se observar que o resultado foi afetado pela presença de dano, porém, ainda sendo possível uma identificação da posição do dano. 
a)

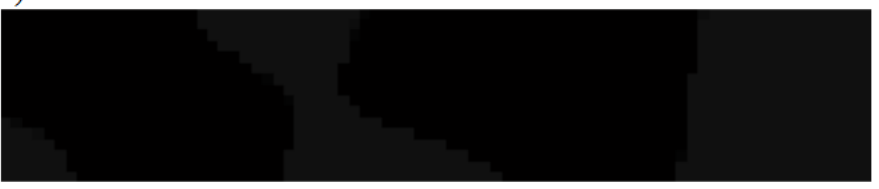

b)

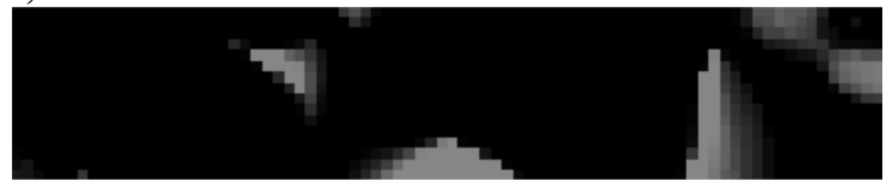

c)

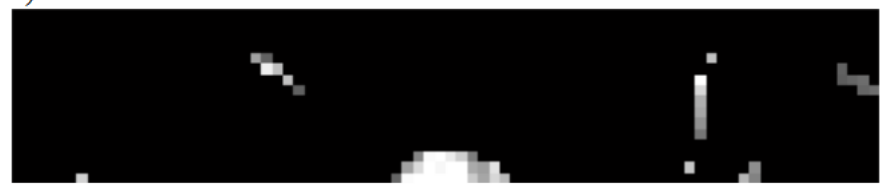

d)

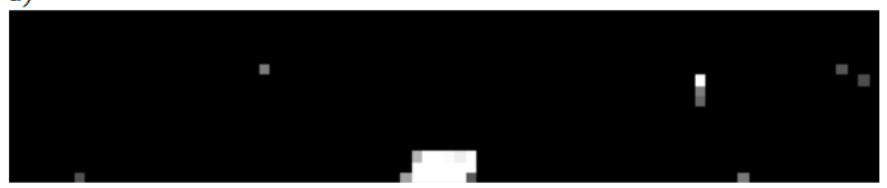

e)

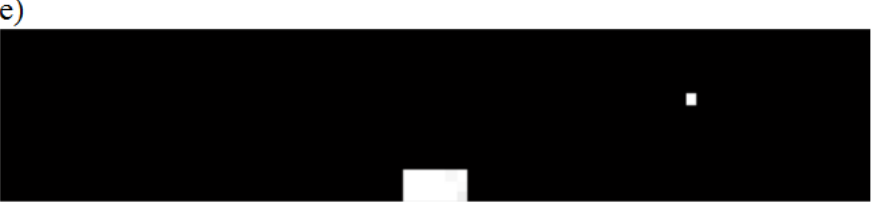

Figura 47 - Resultado da otimização. Número de iterações: a) 200; b) 400; c) 600 ; d) 800 e e) 1000 .

\begin{tabular}{cc|cc}
\hline \multicolumn{2}{c|}{ Ruído 1\% } & \multicolumn{2}{c}{ Ruído 2\% } \\
$\omega_{r}$ & $\omega_{a}$ & $\omega_{r}$ & $\omega_{a}$ \\
\hline 10,478 & 40,124 & 10,471 & 40,135 \\
57,959 & 85,977 & 57,915 & 85,922 \\
98,476 & 107,522 & 98,518 & 107,497 \\
127,186 & 139,422 & 127,138 & 139,219 \\
186,555 & 199,121 & 186,523 & 199,194 \\
246,049 & 246,975 & 246,113 & 246,921 \\
272,520 & & 272,623 & \\
\hline
\end{tabular}

Tabela 14 - Frequências da estrutura com dano e perturbadas com ruído $(\mathrm{Hz})$. 
a)

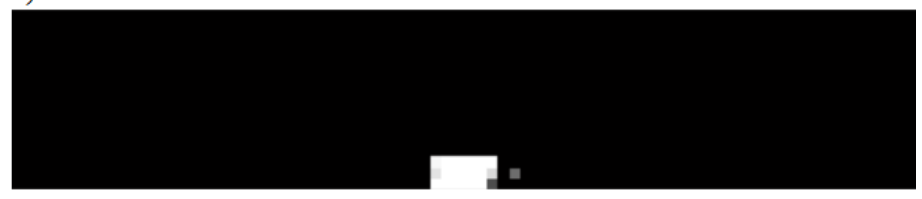

b)

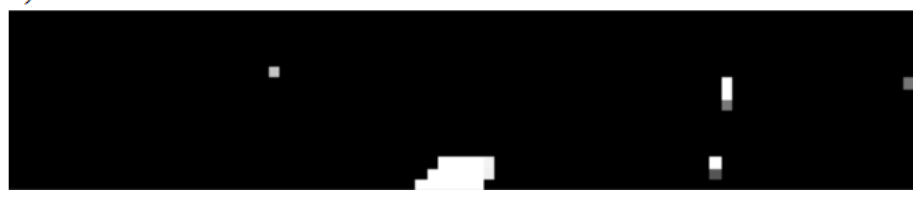

Figura 48 - Exemplo 3 com a adição de ruído de: a) $1 \%$; b) $2 \%$.

\subsection{Exemplo 4}

Este exemplo trata de uma viga com dimensões de $5 \mathrm{~m}$ de comprimento e $1 \mathrm{~m}$ de altura. As vinculações são caracterizadas por possuir simetria, sendo compostas de apoios de segundo gênero na extremidade inferior esquerda e extremidade inferior direita, como mostra a Figura 49.a. A Figura 49.b mostra a viga com um dano na parte inferior central da viga, o qual possui as mesmas dimensões de dano dos exemplos 2 e 3 (item 6.2).

A malha de elementos finitos é mostrada na Figura 50.

A Tabela 15 mostra os valores das frequências ressonantes $\left(\omega_{r}\right)$ e anti-ressonantes $\left(\omega_{a}\right)$ da estrutura sem dano e da estrutura com dano teórico, assim como a diferença percentual entre os mesmos. A frequência ressonante que teve a maior variação foi a quarta $(-6,54 \%)$, já a frequência anti-ressonante que teve a maior variação foi a sexta (-2,69\%). As médias das variações foram de 2,02\% para as frequências ressonantes e 0,98\% para as frequências anti-ressonantes.

Os valores atribuídos aos diversos parâmetros para a otimização deste exemplo estão demonstrados na Tabela 16.

A Tabela 17 mostra a comparação dos resultados das frequências ressonantes e anti-ressonantes da estrutura danificada de modo teórico e os resultados obtidos após a otimização, assim como a diferença entre os valores.

A variação dos resultados para diferentes iterações está mostrada na Figura 51. Como se observa (Figura 51.e), com 1000 iterações obtevese um resultado satisfatório quando do objetivo de detectar a posição e geometria do dano. Porém, com 600 iterações (Figura 51.c) já é possível 


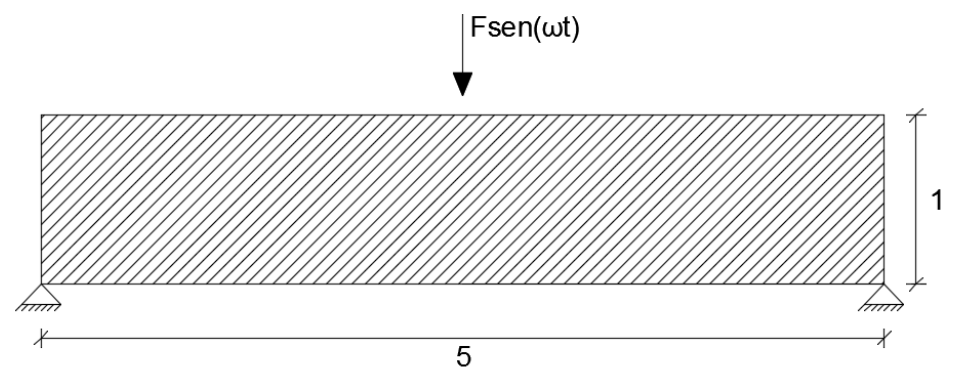

a)

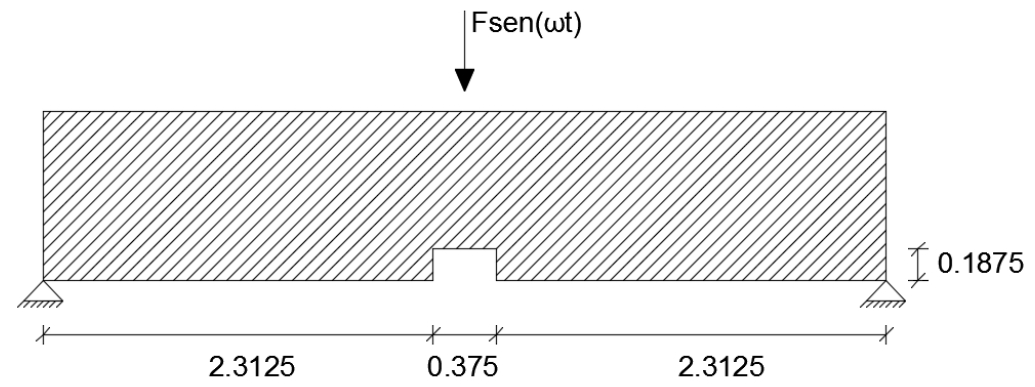

b)

Figura 49 - Exemplo 4: a) estrutura sem dano; b) estrutura com dano.

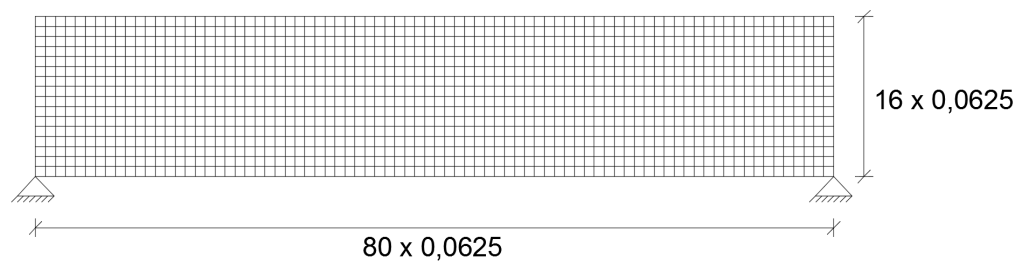

Figura 50 - Malha de elementos finitos do exemplo 4. 


\begin{tabular}{cc|cc|cc}
\hline \multicolumn{2}{c|}{ Sem dano } & \multicolumn{2}{c|}{ Com dano } & \multicolumn{2}{c}{ Dif. (\%) } \\
$\omega_{r}$ & $\omega_{a}$ & $\omega_{r}$ & $\omega_{a}$ & $\omega_{r}$ & $\omega_{a}$ \\
\hline 36,491 & 54,760 & 35,753 & 55,149 & $-2,02$ & 0,71 \\
54,760 & 91,335 & 55,149 & 89,203 & 0,71 & $-2,33$ \\
101,832 & 101,832 & 101,663 & 101,663 & $-0,17$ & $-0,17$ \\
135,301 & 156,285 & 126,459 & 154,632 & $-6,54$ & $-1,06$ \\
188,289 & 188,289 & 186,910 & 186,910 & $-0,73$ & $-0,73$ \\
194,144 & 194,727 & 188,849 & 189,483 & $-2,73$ & $-2,69$ \\
263,262 & 281,897 & 259,672 & 280,368 & $-1,36$ & $-0,54$ \\
334,624 & 334,624 & 337,244 & 337,244 & 0,78 & 0,78 \\
357,464 & 357,464 & 354,620 & 354,620 & $-0,80$ & $-0,80$ \\
443,334 & & 423,805 & & $-4,41$ & \\
& & & Média & 2,02 & 1,09 \\
\hline
\end{tabular}

Tabela 15 - Frequências ressonantes e anti-ressonantes da estrutura com e sem dano $(\mathrm{Hz})$.

\begin{tabular}{cc}
\hline Parâmetro & Valor utilizado \\
\hline raio(item 3.3.4) & 0,28 \\
$\mathrm{n}^{\mathrm{o}}$ ressonâncias(item 5.2) & 10 \\
$\mathrm{n}^{\mathrm{o}}$ anti-ressonâncias(item 5.2) & 9 \\
coeficiente $p$ (item 3.2.2) & 1 \\
coeficiente $q$ (item 3.2.2) & 1 \\
$\eta($ item 3.3.5) & 0,7 \\
fator de ponderação $w_{r, i}$ (item 5.2) & 1 \\
fator de ponderação $w_{a, i}$ (item 5.2) & 1 \\
lim (item 5.5.1) & 0,0001 \\
$m \_a$ (item 5.5.1) & 1,01 \\
$m_{-} d$ (item 5.5.1) & 0,9 \\
\hline
\end{tabular}

Tabela 16 - Valores dos parâmetros utilizados na otimização. 


\begin{tabular}{cccccc}
\hline \multicolumn{2}{c}{ Com dano teórico } & \multicolumn{2}{c}{ Dano otimizado } & \multicolumn{2}{c}{ Dif. (\%) } \\
$\omega_{r}$ & $\omega_{a}$ & $\omega_{r}$ & $\omega_{a}$ & $\omega_{r}$ & $\omega_{a}$ \\
\hline 35,753 & 55,149 & 35,753 & 55,149 & 0,00 & 0,00 \\
55,149 & 89,203 & 55,149 & 89,203 & 0,00 & 0,00 \\
101,663 & 101,663 & 101,663 & 101,663 & 0,00 & 0,00 \\
126,459 & 154,632 & 126,459 & 154,632 & 0,00 & 0,00 \\
186,910 & 186,910 & 186,910 & 186,910 & 0,00 & 0,00 \\
188,849 & 189,483 & 188,849 & 189,483 & 0,00 & 0,00 \\
259,672 & 280,368 & 259,672 & 280,368 & 0,00 & 0,00 \\
337,244 & 337,244 & 337,244 & 337,244 & 0,00 & 0,00 \\
354,620 & 354,620 & 354,620 & 354,620 & 0,00 & 0,00 \\
423,805 & & 423,805 & & 0,00 & \\
\hline
\end{tabular}

Tabela 17 - Resultado da otimização.

\begin{tabular}{cc|cc}
\hline \multicolumn{2}{c|}{ Ruído de 1\% } & \multicolumn{2}{c}{ Ruído de 2\% } \\
$\omega_{r}$ & $\omega_{a}$ & $\omega_{r}$ & $\omega_{a}$ \\
\hline 35,732 & 55,172 & 35,766 & 55,098 \\
55,142 & 89,172 & 55,131 & 89,163 \\
101,518 & 101,641 & 101,600 & 101,804 \\
126,500 & 154,689 & 126,336 & 154,622 \\
186,884 & 186,979 & 186,919 & 186,643 \\
188,791 & 189,508 & 189,151 & 189,040 \\
259,582 & 280,466 & 259,640 & 280,740 \\
337,264 & 337,239 & 337,404 & 337,665 \\
354,466 & 354,702 & 354,633 & 354,052 \\
423,468 & & 424,551 & \\
\hline
\end{tabular}

Tabela 18 - Frequências da estrutura com dano e perturbadas com ruído $(\mathrm{Hz})$.

ter uma ideia da localização do dano.

A Figura 52 mostra a variação dos resultados para diferentes números de informações disponíveis da estrutura danificada. Todos esses resultados foram obtidos utilizando-se 1000 iterações. É possível observar que com 6 informações das frequências ressonantes e 5 anti-ressonantes já é possível ter uma ideia da localização da posição do dano.

A Tabela 18 demonstra os valores das frequências ressonantes e anti-ressonantes da estrutura com dano teórico com a adição de ruído.

A Figura 53 mostra o resultado obtido quando considerado o ruído mostrado na Tabela 18. Pode-se observar que o resultado foi afetado pela 
a)

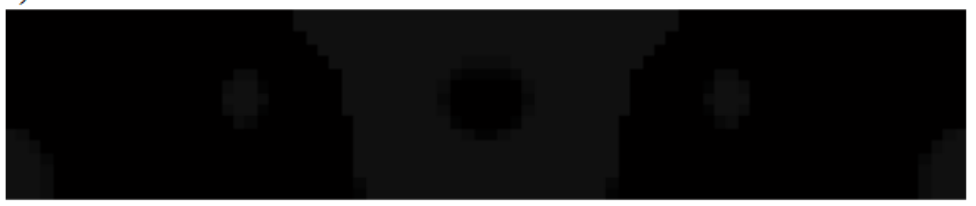

b)

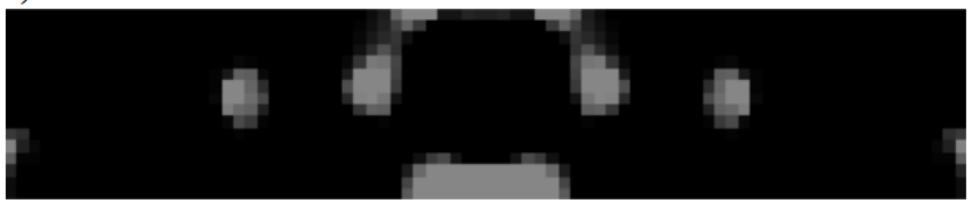

c)

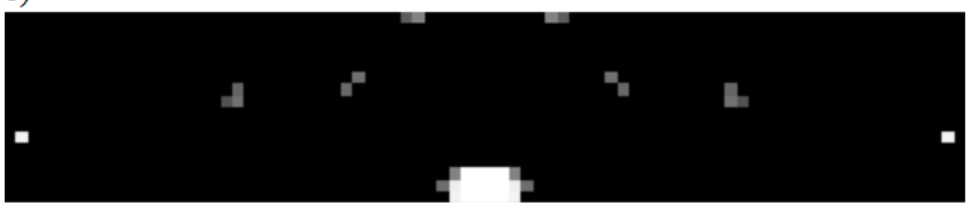

d)

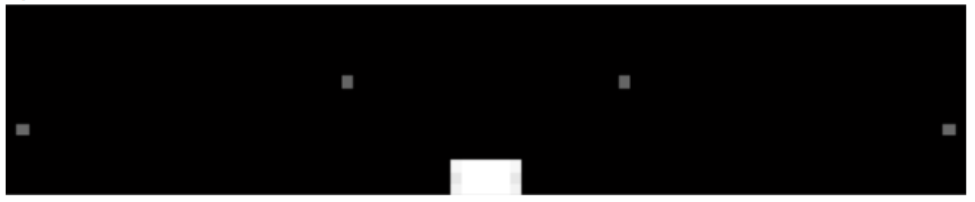

e)

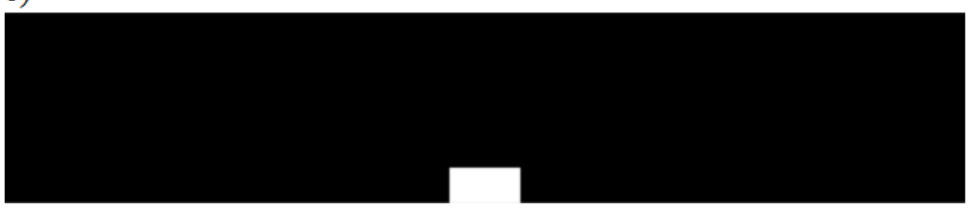

Figura 51 - Resultado da otimização. Número de iterações: a) 200; b) 400; c) 600 ; d) 800 e e) 1000 . 
a)

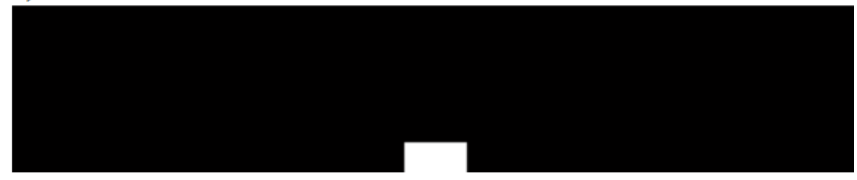

b)

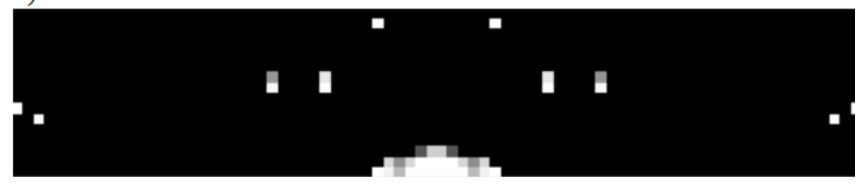

c)

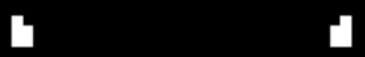

-

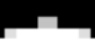

d)

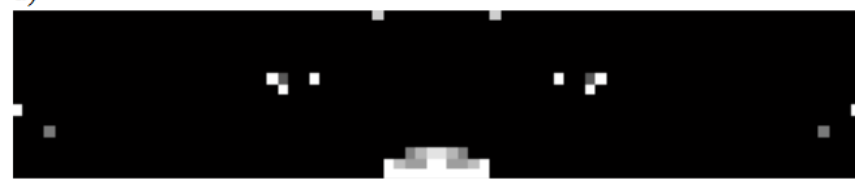

e)

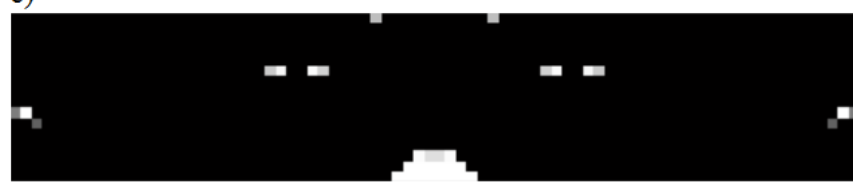

f)

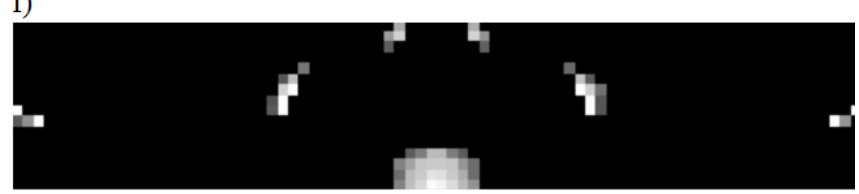

Figura 52 - Resultado da otimização. Número de frequências ressonantes/anti-ressonantes: a) $10 / 9$; b) $9 / 8$; c) $8 / 7$; d) $7 / 6$; e) $6 / 5$ e f) $5 / 4$. 
a)

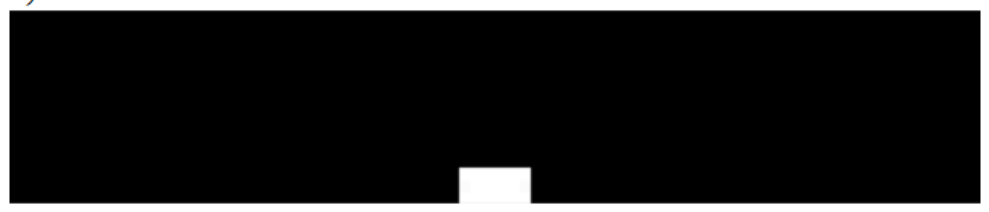

b)

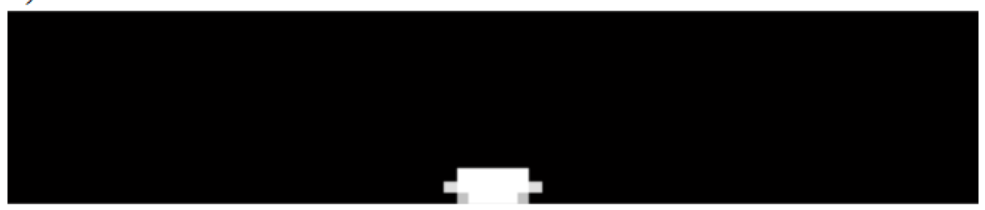

Figura 53 - Exemplo 4 com a adição de ruído de: a) $1 \%$; b) $2 \%$.

presença de ruído nos dados, porém, ainda sendo possível uma identificação da posição do dano. 



\section{Considerações finais}

\subsection{Aspectos conclusivos}

Neste capítulo são apresentados as considerações finais do trabalho desenvolvido. São apresentadas considerações com relações as metodologias utilizadas para a realização de tal, e também comentarios referentes aos exemplos testados.

\subsubsection{Metodologias utilizadas}

Um aspecto que chama atenção nos resultados obtidos para os exemplos testados, é o número de iterações necessárias para a obtenção dos resultados satisfatórios, como por exemplo, 1200 iterações para o exemplo 2. Tal situação ocorre pelo fato da utilização dos limites móveis muito pequenos, utilizados na programação linear sequencial. Isso já foi obsevado em outros trabalhos onde utiliza-se essa ferramenta, como por exemplo o trabalho de Meneghelli[32], em que verificou-se a necessidade em 2000 iterações.

Pode-se observar, também, que a utilização do filtro de sensilidades mostrou-se importante para um bom resultado da estrutura otimizada. Para o exemplo 2, ao desabilitar a aplicação do filtro, pode-se observar que o código não foi capaz de desenhar a geometria do dano em questão (Figura 40).

Outra técnica utilizada neste trabalho é a de redução do número de variáveis de projeto. Aqui, foi utilizada a técnica proposta por Lee, Kim e Kim[11], que é a estratégia PR (item 3.3.5). Pode-se observar que a utilização da mesma foi importante para a correta detecção do dano (posição e geometria). No exemplo 2, através da Figura 41, é possível verificar que a não utilização dessa estratégia leva a um resultado não tão interessantes no que diz respeito a tipologia final da estrutura otimizada.

Outra simulação feita é a adição de perturbações nos dados de referência utilizados para a otimização. Os níveis de ruído utilizados foram da ordem de $1 \%$ e $2 \%$. O código mostrou-se capaz de localizar o dano e sua geometria com a perturbação menor, e perdeu precisão a medida que o nível de perturbação aumentou. Tal conclusão é parecida com a que Palacz e Krawczuk[33] chegaram, na qual os pesquisadores concluiram que a qualidade dos resultados dominuí conforme dimínuia também a qualidade das medições. 
Os exemplos 2, 3 e 4, os quais são estruturas caracterizadas por possuirem as duas dimensões com ordens de grandezas parecidas $(5 \mathrm{~m}$ de comprimento e $1 \mathrm{~m}$ de largura), a utilização apenas das informação de frequências ressonantes, para os formulações e metodologias utilizadas, não foram suficientes para a deteção do dano (posição e geometria), como demonstra, por exemplo, a Figura 42.

Em todos os exemplos, para as variáveis $p$ e $q$ foram atribuídos valores unitários, desprezando o método das penalizações. No contexto da otimização topológica, inúmeros autores recomendam o uso de valores para estas variáveis, porém, neste trabalho, no contexto da deteção de dano, os exemplos mostrados atingiram o objetivo de detectar o dano sem a utilização desse método.

Para os fatores de ponderação utilizados na formulação da função objetivo (item 5.2) foram atribuídos valores unitários, em todos os exemplos. A formulação utilizada nesta pesquisa foi baseada no trabalho de Nishizu, Takezawa e Kitamura[13]. Neste, os autores também utilizaram fatores de ponderação unitários.

\subsubsection{Exemplos testados}

No exemplo 1 (item 6.1), em que se testou uma estrutura com comprimento muito maior que sua altura (na ordem de 20 vezes). A finalidade deste exemplo é de testar a capacidade do código em detectar o dano utilizando apenas informações das frequências ressonantes. A tabela 5 mostra que o código foi capaz de encontrar a presença de dano no elemento $5 \mathrm{com}$ uma boa precisão. Tal fato também pode ser verificado na Figura 33.

Já no exemplo 2 (item 6.2), pode-se verificar através da Figura 42 que a utilização apenas das frequências ressonantes não foi suficiente para obter a informação da localização do dano na estrutura. Já a utilização em conjunto de informações das frequências ressonantes e anti-ressonantes (6 e 5, respectivamente) mostrou-se suficiente para a detecção do dano na estrutura, sendo possível a localização do dano assim como sua geometria, sendo necessárias para tal resultado 1200 iterações, como mostra a Figura 39.d. Porém, observa-se (Figura 39.a) que com 300 iterações já é possível ter uma ideia da localização do dano.

No exemplo 3 (item 6.3), a utilização em conjunto de informações das frequências ressonantes e anti-ressonantes ( 7 e 6 , respectivamente) mostrou-se suficiente para a detecção do dano na estrutura, sendo possível sua localização e geometria, sendo necessárias 1000 iterações, como mostra a Figura 47.e. Porém, observa-se (Figura 47.c) que com 600 iterações já é possível se ter uma ideia da localização da posição do dano. 
No exemplo 4 (item 6.4). A utilização em conjunto de informações das frequências ressonantes e anti-ressonantes mostrou-se suficiente para a detecção do dano na estrutura, possibilitando a localização do dano, assim como sua geometria, sendo necessárias 1000 iterações, como mostra a Figura 51.e. Porém, observa-se (Figura 51.c) que com 600 iterações já é possível ter uma ideia da localização do dano. A Figura 52 mostra a variação dos resultados de acordo com o número de informações disponíveis. Nota-se que com 6 frequências ressonantes e 5 anti-ressonantes é possível ter uma ideia da localização do dano, porém, não é possível identificar sua geometria, sendo para isso necessárias 10 informações de frequências ressonantes e 9 anti-ressonantes. Este exemplo, que trata de uma estrutura simétrica, foi aquele que precisou de um maior número de informações para fazer a detecção do dano. No mesmo sentido dessa afirmação, Miguel, Lopez e Miguel[34] comentam que é difícil distinguir o dano em locais simétricos de uma estrutura simétrica.

\subsection{Sujestões para trabalhos futuros}

Algumas sujestões para trabalhos futuros podem ser feitas:

- testar diferentes formulações para a função objetivo e restrições;

- utilizar outros métodos de otimização que não a SLP, como por exemplo o MMA;

- considerar outras informações da estrutura danificada para tentar localizar o dano, sejam características estáticas ou dinâmicas do sistema;

- utilizar outras técnicas de redução do número de variáveis de projeto diferentes da estratégia PR, utilizada neste trabalho.

- testar outras formas de representar o dano, diferentes da metodologia utilizada neste trabalho, que é baseada na metodologia SIMP, onde uma variável densidade multiplica as matrizes de rigidez e massa da estrutura. 



\section{Referências}

1 DESSI, D.; CAMERLENGO, G. Damage identification techniques via modal curvature analysis: overview and comparison. Mechanical Systems and Signal Processing, v. 52, p. 181-205, 2015. Citado na página 23.

2 RYTTER, A. Vibrations based inspection of civil enginnering structures. Tese (Doutorado) - Aalborg University, Aalborg, Denmark, 1993. Citado na página 24.

3 LEET, K. M.; UANG, C. M.; GILBERT, A. M. Fundamentos da análise estrutural. São Paulo: AMGH, 2009. Citado na página 25.

4 SALAWU, O. S. Detection of structural damage through changes in frequency: a review. Engineering Structures, v. 19, p. 57-67, 2003. Citado na página 24.

5 KIM, J. T. et al. Damage identification in beam-type structures: frequency-based method vs mode-shape based method. Engineering Structures, v. 25, p. 57-67, 2003. Citado na página 24.

6 NHAMAGE, I. A. Aperfeiçoamento do algoritmo de otimização híbrido Pincus-Nelder e mead para a detecção de dano em estruturas a partir de dados vibracionais. Dissertação (Mestrado) - Universidade Federal de Santa Catarina, Florianópolis, 2014. Citado 2 vezes nas páginas 25 e 76.

7 DILENA, M.; MORASI, A. The use of antiresonances for crack detection in beams. Journal of Sound and Vibrations, v. 276, p. 195-214, 2004. Citado na página 25.

8 LEE, U.; SHIN, J. A frequency response function-based structural damage identification method. Computers and Structures, v. 80, p. 117-132, 2002. Citado na página 25.

9 STUBBS, N.; KIM, J. T.; TOPOLE, K. An efficient and robust algorithm for damage localization in offshore platforms. In: Proceedings of the ASCE tenth structures congress. [S.1.: s.n.], 1992. p. 543-546. Citado na página 25.

10 CURADELLI, R. O. et al. Damage detection by means of structural damping identification. Engineering Structures, v. 30, p. 3497-3504, 2008. Citado na página 25. 
11 LEE, J. S.; KIM, J. E.; KIM, Y. Y. Damage detection by the topology design formulation using modal parameters. International Journal for Numerical Methods in Engineering, v. 69, p. 1480-1498, 2006. Citado 8 vezes nas páginas 25, 26, 27, 45, 46, 47, 65 e 103.

12 NIEMANN, H. et al. Damage localization using experimental modal parameters and topology optimization. Mechanical Systems and Signal Processing, v. 24, p. 636-652, 2010. Citado 2 vezes nas páginas 26 e 65.

13 NISHIZU, T.; TAKEZAWA, A.; KITAMURA, M. Damage detection method by topology optimization based on eigenvalue analysis. International Ocean and Polar Engineering Conference, p. 883-889, 2014. Citado 4 vezes nas páginas 26, 68, 69 e 104.

14 SILVA, D. C. C. M. Determinação de termos rotacionais da resposta dinâmica por técnicas de análise modal. Dissertação (Mestrado) Universidade Técnica de Lisboa, Lisboa, 2003. Citado 2 vezes nas páginas 29 e 31 .

15 LOFRANO, M. Técnicas para estimativa de FRFs angulares em análise modal experimental com aplicações a estruturas do tipo viga. Tese (Doutorado) - Universidade de São Paulo, São Carlos, 2003. Citado na página 29.

16 MAIA, N. M. M.; SILVA, M. M. J. Theorical and experimental modal analysis. [S.1.]: Research Studies Press Ltda, 1997. Citado na página 30.

17 CARRILLO, O. J. B. Algoritmo híbrido para avaliação da integridade estrutural: uma abordagem heurística. Tese (Doutorado) Universidade de São Paulo, São Carlos, 2007. Citado 3 vezes nas páginas 31,32 e 33 .

18 MIGUEL, L. F. F. Identificação de sistemas e avaliação da integridade de estruturas treliçadas. Tese (Doutorado) - Universidade Federal do Rio Grande do Sul, Porto Alegre, 2007. Citado 3 vezes nas páginas 33, 35 e 36.

19 SOEIRO, N. S. Análise modal experimental. Universidade Federal do Pará, Belém, 2001. Citado 3 vezes nas páginas 33, 35 e 36.

20 BENDSOE, M. P.; SIGMUND, O. Topology Optimization: Theory, Methods and Applications. Berlin: Springer-Verlag, 2003. Citado 5 vezes nas páginas 37, 39, 42, 43 e 44 .

21 KIYONO, C. Y. Método de otimização topológica aplicado ao projeto de sonodros para transdutores piezelétricos. Dissertação (Mestrado) Universidade de São Paulo, São Paulo, 2008. Citado 4 vezes nas páginas $39,40,42$ e 75. 
22 SIGMUND, O. On the design of compliant mechanisms using topology optimization. Mechanics of Structures and Machines, v. 24, p. 493-524, 1997. Citado na página 43.

23 RAO, S. Vibrações mecânicas. São Paulo: Pearson Prentice Hall, 2008. Citado na página 52.

24 AFOLABI, D. An anti-resonance technique for detecting structural damage. In: Proceedings of the Fifth International Modal Analysis Conference. [S.1.: s.n.], 1987. p. 491-5. Citado na página 58.

25 MENDROK, K.; UHL, T. Overview of modal model based damage detection methods. In: Proceedings of. [S.1.: s.n.], 2004. Citado na página 65.

26 MORALES, J. D. V. Detecção de dano em estruturas via inteligência computacional e análise dinâmica. Tese (Doutorado) - Universidade de São Paulo, São Carlos, 2012. Citado 2 vezes nas páginas 65 e 74.

27 ANDREASSEN, E. et al. Efficient topology optimization in matlab using 88 lines of code. Structural Multidisciplinary Optimization, v. 43, p. 1-16, 2010. Citado na página 66.

28 ARORA, J. S. Introduction to optimum design. Amsterdam: Elsevier, 2004. Citado 5 vezes nas páginas 70, 71, 72, 74 e 76.

29 CHEN, T. Calculation of the move limits for the sequential linear programming method. International Journal of Numerical Methods in Engineering, v. 36, p. 2661-2679, 1993. Citado na página 73.

30 LAMBERTI, L.; PAPPALETTERE, C. Comparison of the numerical efficiency of diferente sequential linear programming based algorithms for structural optimisation problems. Computers and Structures, v. 76, p. 713-728, 2000. Citado na página 73.

31 WUJEK, B.; RENAULD, J. New adaptative move-limit management strategy for aproximate optimization, part i. AIAA Journal, v. 36, p. 1911-1921, 1998. Citado na página 73.

32 MENEGHELLI, L. R. Projeto de mecanismos flexíveis com restrição de tensões utilizando o método da otimização topológica. Dissertação (Mestrado) — Universidade do Estado de Santa Catarina, Joinville, 2013. Citado na página 103.

33 PALACZ, M.; KRAWCZUK, M. Vibration parameters for damage detection in structures. Journal of Sound and Vibration, Academic Press, v. 249, n. 5, p. 999-1010, 2002. Citado na página 103. 
34 MIGUEL, L. F. F.; LOPEZ, R. H.; MIGUEL, L. F. F. A hybrid approach for damage detection of structures under operational conditions. Journal of Sound and Vibration, Elsevier, v. 332, n. 18, p. 4241-4260, 2013. Citado na página 105. 